
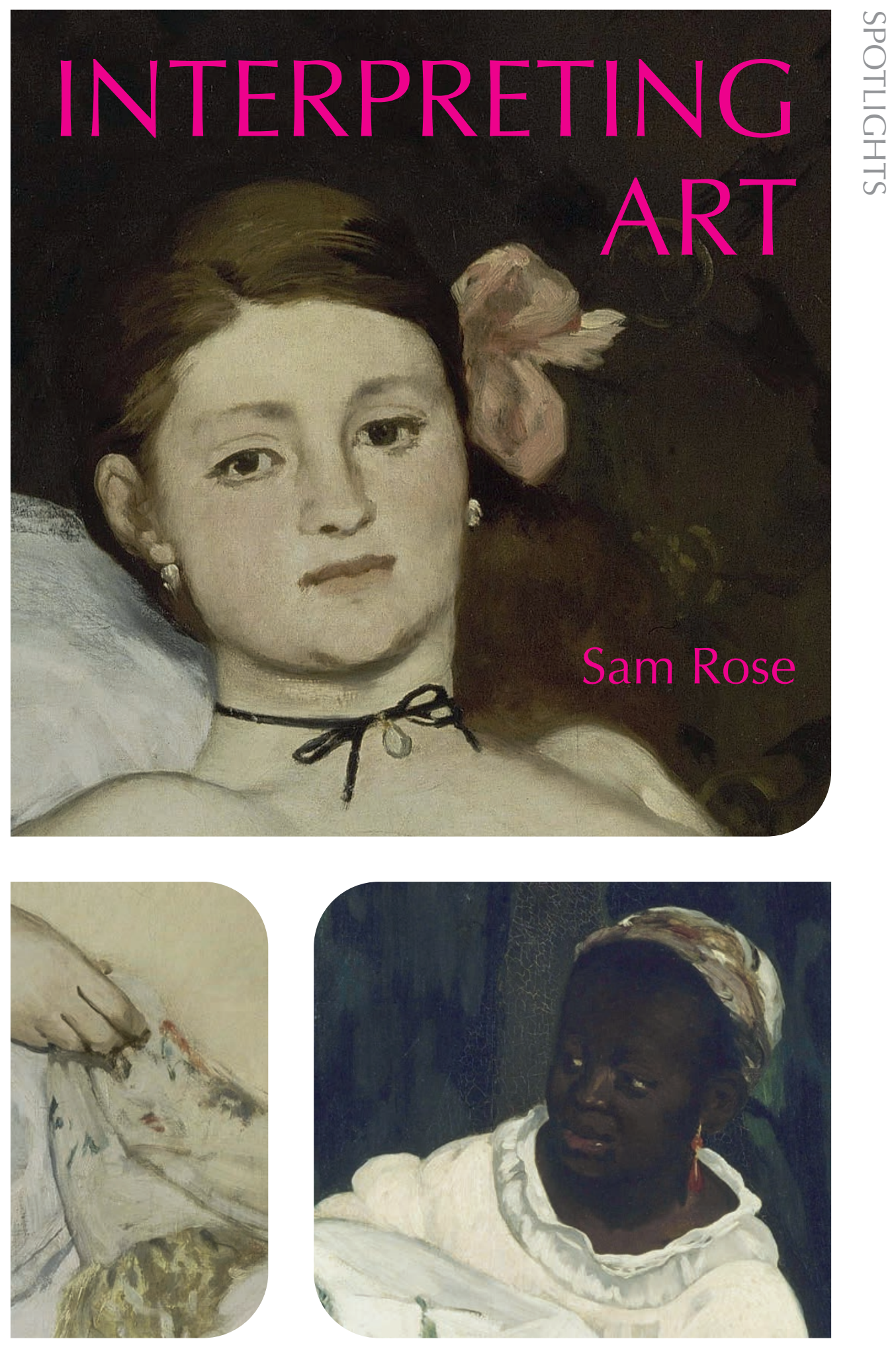

${ }^{\star}$ UCLPRESS 
Interpreting Art 


\title{
SPOTLIGHTS
}

\author{
Series editors \\ Emily Baker, Alena Ledeneva, Timothy Mathews \\ and Uta Staiger, UCL
}

SPOTLIGHTS is an open-access, short monograph series for authors wishing to make defining or experimental aspects of their work available to a wider audience. The series offers a forum for novel developments both within and across disciplines, and welcomes diversity of topic, approach and presentation. Projects that foreground the interrelation of form and content in any intellectual endeavour are especially welcome.

Emily Baker is Lecturer in Comparative Literature and Latin American Studies, UCL.

Alena Ledeneva is Professor of Politics and Society at the School of Slavonic and East European Studies, UCL.

Timothy Mathews is Emeritus Professor of French and Comparative Criticism, UCL.

Uta Staiger is Associate Professor of European Studies, Executive Director of the UCL European Institute, and Pro-Vice-Provost (Europe), UCL. 


\section{Interpreting Art}

Sam Rose

UCLPRESS 
First published in 2022 by

UCL Press

University College London

Gower Street

London WC1E 6BT

Available to download free: www.uclpress.co.uk

Text (C) Author, 2022

Images (C) Author and copyright holders named in captions, 2022

The author has asserted their rights under the Copyright, Designs and Patents Act 1988 to be identified as the author of this work.

A CIP catalogue record for this book is available from The British Library.

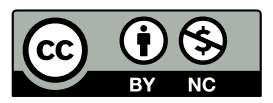

Any third-party material in this book is not covered by the book's Creative Commons licence. Details of the copyright ownership and permitted use of third-party material is given in the image (or extract) credit lines. If you would like to reuse any third-party material not covered by the book's Creative Commons licence, you will need to obtain permission directly from the copyright owner.

This book is published under a Creative Commons Attribution-Non-Commercial 4.0 International licence (CC BY-NC 4.0), https://creativecommons.org/licenses/ by-nc/4.0/. This licence allows you to share and adapt the work for non-commercial use providing attribution is made to the author and publisher (but not in any way that suggests that they endorse you or your use of the work) and any changes are indicated. Attribution should include the following information:

Rose, S. 2022. Interpreting Art. London: UCL Press. https://doi.org/10.14324/111.9781800081772

Further details about Creative Commons licences are available at https://creativecommons.org/licenses/

ISBN: 978-1-80008-179-6 (Hbk)

ISBN: 978-1-80008-178-9 (Pbk)

ISBN: 978-1-80008-177-2 (PDF)

ISBN: 978-1-80008-180-2 (epub)

ISBN: 978-1-80008-181-9 (mobi)

DOI: https://doi.org/10.14324/111.9781800081772 


\section{Contents}

List of figures vii

Acknowledgements $\quad$ xi

1. Introduction 1

2. Artists 9

3. Contexts 32

4. Reception 53

5. Complexity 71

6. Depths 88

References 111

$\begin{array}{ll}\text { Index } & 121\end{array}$ 



\section{List of figures}

Fig. 1.1 J.J. Winckelmann, Geschichte der Kunst des Alterthums, 2nd edition, Vienna, 1776.

Fig. 1.2 Alice Feaver, Deana Lawson: An Aperture monograph, 2021. Digital Painting. CC BY-NC 4.0.

Fig. 2.1 Ed Clark, Untitled, 1957, Oil on canvas and paper, on wood, $116.84 \times 139.7 \mathrm{~cm}$, The Art Institute of Chicago. (C) Estate of Ed Clark / Hauser \& Wirth.

Fig. 2.2 Michelangelo Buonarotti, Moses, marble, $235 \times 210$ $\mathrm{cm}$, San Pietro in Vincoli, Rome. Photograph: Jörg Bittner Unna. CC BY 3.0.

Fig. 2.3 Illustrations to Sigmund Freud, 'Der Moses Des Michelangelo', Imago 3 (1914).

Fig. 2.4 Tomb of Andrea Vendramin, c. 1480-95, marble, Santi Giovanni e Paolo, Venice. Photograph: Didier Descouens. CC BY-SA 4.0.

Fig. 2.5 Tullio Lombardo, effigy of Andrea Vendramin. Photograph courtesy of Mauro Magliani/Artchive.

Fig. 2.6 Johannes Vermeer, Woman in Blue Reading a Letter, c. $1663-4$. Oil on canvas, $49.6 \times 40.3 \mathrm{~cm}$.

Rijksmuseum, Amsterdam.

Fig. 2.7 Michelangelo Merisi da Caravaggio, Basket of Fruit. Oil on canvas, $46 \times 64.5 \mathrm{~cm}$, Biblioteca Ambrosiana, Milan.

Fig. 3.1 Frontispiece to La Font de Saint-Yenne, L'Ombre du Grande Colbert, 1752.

Fig. 3.2 Charles-Nicolas Cochin, Les Misotechnites aux Enfers, 1763.

Fig. 3.3 Masaccio, The Virgin and Child. Egg tempera on wood, c. $1426,134.8 \times 73.5 \mathrm{~cm}$. National Gallery, London. 
Fig. 3.4 Folio from a Divan by Sultan Ahmad Jalayir (Angels Amidst Clouds), c. 1400. Ink, colour and gold on paper, $29.5 \times 20.4 \mathrm{~cm}$. Freer Gallery of Art.

Fig. 3.5 Marta Minujín, Kidnappening, 1973. Performed at the Museum of Modern Art, as part of the Summergarden programme, August 3 and 4, 1973. Courtesy of the Marta Minujín Archive, Buenos Aires.

Fig. 3.6 Context as Plausible Limit: Michael Baxandall's 'triangle of re-enactment'. Illustration: Alice Feaver. CC BY-NC 4.0.

Fig. 3.7 Jean-Baptiste Siméon Chardin, A Lady Taking Tea, 1735. Oil on canvas, $81 \times 99 \mathrm{~cm}$. Hunterian Art Gallery, Glasgow.

Fig. 3.8 Context as Limit without Limits: 'Hegel's wheel' according to E. H. Gombrich. Illustration: Alice Feaver. CC BY-NC 4.0.

Fig. 3.9 Pieter Bruegel (attributed), Landscape with the Fall of Icarus, c. 1560 . Oil on canvas, $73.5 \times 112 \mathrm{~cm}$. Royal Museums of Fine Arts of Belgium, Brussels.

Fig. 3.10 Rembrandt van Rijn, Syndics of the Draper's Guild, 1662. Oil on canvas, $191.5 \times 279 \mathrm{~cm}$. Rijksmuseum, Amsterdam.

Fig. 4.1 View of the Ambulatory at the Basilica of St-Denis, Paris, c. 1140-4. Photograph: Wiki Commons. CC BY 3.0.

Fig. 4.2 Nicolas Poussin, Et in Arcadio Ego, 1637-8. Oil on canvas, $85 \times 121 \mathrm{~cm}$, Musée du Louvre.

Fig. 4.3 Nicolas Poussin, Et in Arcadia Ego, 1627-8. Oil on canvas, $101 \times 82 \mathrm{~cm}$. Devonshire Collection, Chatsworth.

Fig. 4.4 Sandro Botticelli, Calumny of Apelles, 1494-5. Tempera on panel, $62 \times 91 \mathrm{~cm}$. Uffizi, Florence.

Fig. 4.5 David Bailly, Self-Portrait with Vanitas Symbols, or Still Life Self-Portrait, 1651 . Oil on canvas, $65 \times 97.5 \mathrm{~cm}$. Leiden, Museum de Lakenhal.

Fig. 4.6 Édouard Manet, Olympia, 1863, oil on canvas, $130 \times$ $191 \mathrm{~cm}$. Musée d'Orsay.

Fig. 4.7 Hispano-Philippine, St Michael the Archangel, seventeenth century. Ivory with polychromy and gilding. San Esteban, Salamanca. Photograph: Stephanie Porras. 
Fig. 5.1 Piero della Francesca, Madonna del Parto, c. 1460.

Fresco (now detached), $260 \times 203 \mathrm{~cm}$. Musei Civici Madonna del Parto, Monterchi. Photograph: Stefano Guerrini. CC BY-SA 3.0.

Fig. 5.2 Alleged portrait of Michelangelo, an attribution also said to be 'a modern invention first proposed in 1941'. Detail from Raphael, The School of Athens, 1509-11. Fresco, $500 \times 770 \mathrm{~cm}$. Apostolic Palace, Vatican City.

Fig. 5.3 Uche Okeke, Owls, from the Oja Suite, 1962. Ink on paper, $19 \times 14 \mathrm{~cm}$. Newark Museum of Art, New Jersey. (C) Uche Okeke / Asele Institute.

Fig. 5.4 Diego Velázquez, Las Meninas, 1656. Oil on canvas, $318 \times 276 \mathrm{~cm}$. Museo del Prado, Madrid.

Fig. 5.5 J. A. D. Ingres, Antiochus and Stratonice (detail), 1840. Oil on canvas, $77 \times 61 \mathrm{~cm}$, Musée Condé, Chantilly.

Fig. 5.6 Amrita Sher-Gil, Self-Portrait as a Tahitian, 1934. Oil on canvas, $90 \times 56 \mathrm{~cm}$. (C) Estate of Amrita Sher-Gil / Courtesy of Vivan and Navina Sundaram.

Fig. 6.1 Laure (detail of Édouard Manet, Olympia, 1863), oil on canvas, $130 \times 191 \mathrm{~cm}$. Musée d'Orsay.

Fig. 6.2 Jean-Léon Gérôme, The Snake Charmer, c. 1879. Oil on canvas, $82.2 \times 121 \mathrm{~cm}$. Sterling and Francine Clark Art Institute, Williamstown.

Fig. 6.3 Thomas Gainsborough, Cornard Wood, near Sudbury, Suffolk, 1748 . Oil on canvas, $122 \times 155 \mathrm{~cm}$. National Gallery, London.

Fig. 6.4 Jean-Antoine Watteau, Pierrot, c. 1718-19. Oil on canvas, $184.5 \times 149.5 \mathrm{~cm}$. Musée du Louvre, Paris.

Fig. 6.5 N. C. Wyeth, The Wreck of the 'Covenant', 1913. Oil on canvas, $102.6 \times 81.9 \mathrm{~cm}$. Brandywine River Museum of Art. (C) Brandywine River Museum of Art / Bequest of Mrs. Russell G. Colt, 1986 / Bridgeman Images.

Fig. 6.6 Carrie Mae Weems, Not Manet's Type, 1997. Gelatin silver print with text on mat (second in series of five), $62.9 \times 52.7 \mathrm{~cm}$. San Francisco Museum of Modern Art. (C) Carrie Mae Weems. Courtesy of the artist and Jack Shainman Gallery, New York. 



\section{Acknowledgements}

This book has been at least ten years in the making, but writing much of it over the course of 2020 and 2021 was one of the hardest things I have ever had to do. My main debt is to those friends and family who kept me going. Many are named in what follows and the rest know who they are, but thanks above all have to go to Stephanie O'Rourke, who has variously guided, encouraged, and just put up with me over that time. Without her this book could not have been written. It would be traditional at this point to also thank Henry, but he was no help at all.

Given the length of this project and the many false starts along the way it's hard to name all the people who have commented on texts that fed into the book in one way or another. In the very final stages I was lucky to have three close readers of the manuscript from three different disciplines: Tom Geue, C. Oliver O'Donnell, and Justin Snedegar. (Who knew my funniest feedback would come from an analytic philosopher?) With apologies for many inevitable omissions here, others who have commented on earlier texts in decisive ways include David Peters Corbett, Todd Cronan, Whitney Davis, Linda Goddard, Julian Luxford, Lizzie Mitchell, Polly Mitchell, Bence Nanay, Sophie Oliver, Gavin Parkinson, Alistair Rider, Kathryn R. Rudy, and Vid Simoniti. Others have advised on particular points, shared drafts of relevant texts, or have otherwise offered thoughts that fed in to the book in one way or another: Natalie Adamson, Euan Bell (for extensive thoughts about the relevance of Bob Ross), Adrian Blau, Kate Cowcher, Gregory Currie, James Day, Frankie Dytor, Emilie Oléron Evans, Lily Foster, Luke Gartlan, Jonas Grethlein (who in the gentlest and most charming way possible prodded me to think about why I was more than just a second-rate Scottish Gadamer), Jack Hartnell, Sophie Hatchwell, Hans Christian Hönes, Thomas Hughes, Shona Kallestrup, Elsje van Kessel, Lorenz Korn, Marika Knowles, Donald MacEwan, Lambros Malafouris, José Marcaida (approaching Euan in his love of Bob Ross), Alex Marr, Andrei Pop, Rey Conquer, James Rae, Ünver Rüstem, Catherine Spencer, Jakub Stejskal, Ilse Sturkenboom, Justin 
Underhill, Kamini Vellodi, Francesco Ventrella, Jeff Wallace, Karolina Watras, and Christopher S. Wood. Thanks also to those in my section of a world art history project whose recent discussions have been - as well as fascinating and a lot of fun - enormously helpful in thinking about where this book stands in relation to art history as it currently exists: Clemena Antonova, Parul Dave-Mukherji, James Elkins, Jaś Elsner, Walter Benn Michaels, Pippa Skotnes, Jakub Stejskal, and Kenneth Warren.

Camilla Røstvik made the importance of open access publication clear to me and I'm extremely grateful for that, as well as for her broader help with understanding the past and present wrongs and possible futures of academic publication. Open access does have its challenges, though, and given this I'm also extremely grateful to those who have kindly responded to me and have allowed works to be used, as well as the people who helped me track down suitable images in the first place: Adrienne Chau (and the Ed Clark Estate), Didier Descouens, Mauro Magliani (and his project Artchive), Saloni Mathur, Rebecca Mecklenborg (and the Jack Shainman Gallery), Marta Minujín (and the Marta Minujín Archive), Sophie Nurse (and Hauser and Wirth), Stephanie Porras, Catherine Spencer, Vivan Sundaram, Ijeoma Loren Uche-Okeke (and the Asele Institute), Jörg Bittner Unna, Tiffany Wang, Carrie Mae Weems, and (for the wonderful illustrations) Alice Feaver. 


\section{Introduction}

\section{The minds of the artists}

Can we see into the minds of artists? Interpretations are often written as if the answer is a definite 'yes'. This kind of mindreading goes back at least to the origins of modern art criticism in the early modern academies of art. It's hardly surprising to find the vivid presentation of an artist's thoughts in the inveterate storyteller Giorgio Vasari's 1550 Lives of the Most Excellent Painters, Sculptors, and Architects. ${ }^{1}$ But it also came naturally to the artist-academicians of the following centuries, reconstructing and debating parts of particular works of art that they assumed could be attributed to the actions of a fully conscious creator. ${ }^{2}$ By the later 1700s art writers had started to adapt this feature to grander ends, using the language of conscious intent for abstract notions far beyond the artistic choices directly observed in artworks by the academicians. 'The Greek artists were convinced that, as Thucydides says, greatness of mind is usually associated with a noble simplicity', claimed a sentence added to the posthumous 1776 edition of J.J. Winckelmann's History of the Art of Antiquity (Geschichte der Kunst des Alterthums, see Fig. 1.1). In varying degrees of ambition, the claim to know what the artist really thought has become a familiar part of art history right through to the present day, even where we might least expect it. It's a commonplace that artists are not in conscious control of meanings. Yet everywhere the language of the fully conscious artist creeps back in.

Perhaps talking of artists as if we've read their minds is just a case of people not meaning what they say, no more than an accidental writerly habit. It hasn't seemed problematic, for example, for the same art historian who famously called for an 'art history without names' to analyse artworks 


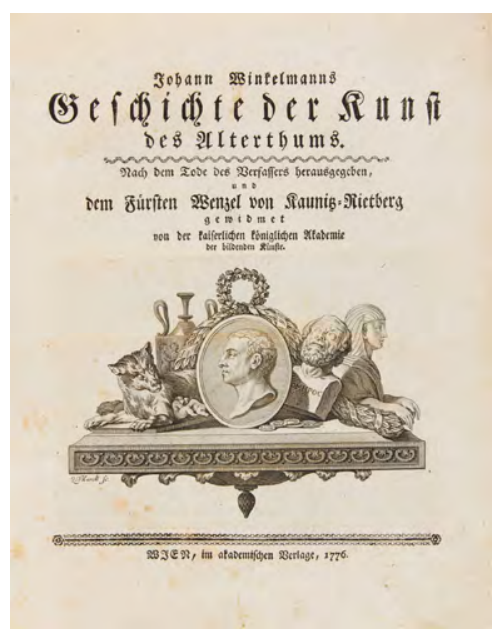

Fig. 1.1. J.J. Winckelmann, Geschichte der Kunst des Alterthums, 2nd edition, Vienna, 1776.

by seeming to mindread in telling us what an individual artist like Raphael 'saw', 'wanted', 'reserved his right to', and 'decided'. ${ }^{4}$ Likewise no one bats an eyelid now when an art historian cautions us that 'among the many methods art historians have at their disposal, reading minds is not one of them', but nonetheless through a close analysis of Jan van Huysum's flower paintings does exactly that, telling us what the artist was 'less interested in' as opposed to 'more', and what 'For van Huysum' is just a 'nice and playful detail' as opposed to what 'really matters'. ${ }^{5}$

But if apparent mindreading is just an accident of writerly habits, the true strangeness is seen nowhere better than when we argue over who has the right to say what a still-living artist has done. In 2018 an Aperture monograph on the artist-photographer Deana Lawson was published with a moving essay by Zadie Smith on Lawson's vision of the subjects of the African diaspora in a 'kingdom of restored glory' (Fig. 1.2). ${ }^{6}$ These were celebratory artworks, Smith wrote, in which '[b]lack people are not conceived as victims, social problems, or exotics but, rather, as what Lawson calls "creative, godlike beings" who do not "know how miraculous we are".' The same year Steven Nelson published a two-part article in which he included his own essay originally intended for the Aperture monograph.? Nelson interpreted Lawson's work as powerful less for direct affirmation than for its critical questioning of a medium so often bound up with the production of stereotypes and caricatures: showing 'selves [that] are complex and complicated bodies that refuse boundaries that would restrict what is possible in the representation of black women'. In doing so he 


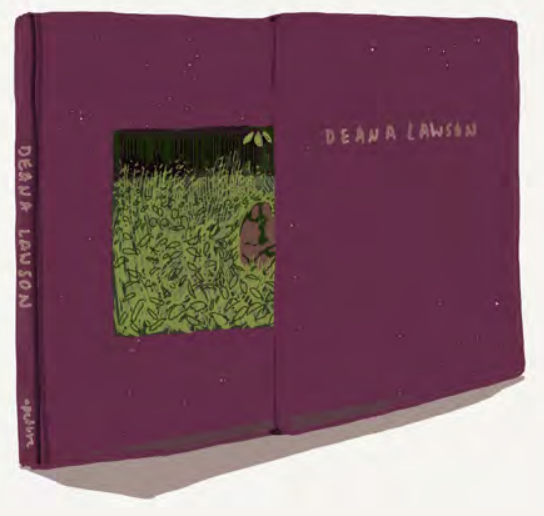

Fig. 1.2. Alice Feaver, Deana Lawson: An Aperture monograph, 2021. Digital Painting. CC BY-NC 4.0.

contextualized her artwork, against the artist's wishes, in terms of her commissioned photojournalism as well as her fine art photography. Nelson's essay was rejected, and replaced with the one by Smith.

Nelson's response to the artist's apparent role in refusing publication of the essay reverberated with critics and historians: surely his task was to put forward 'a rigorous examination of the artist's work', rather than 'to regurgitate the artist and her editor's views'? Whatever the rights and wrongs of this position, one small but revealing detail went unrecognized in the controversy that ensued, no doubt because it's such a habitual part of writing on art that no one thought it significant. ${ }^{8}$ Namely, that Nelson's interpretation concluded by setting out its views - the particular understanding of the body that was central to it - as the artist's own. 'Lawson, like Adrian Piper, Lorna Simpson, Weems and others, understands the body not only as a site that insists on the construction of identity, but also as one where the artist can question the implication of black women in the long histories of representation that define a racialized present characterized by their demonization.' In this moment we see the interpreting writer speak over and to the artist about herself. With the article now a source of information for further interpreters to draw upon, even, the strange possibility arises that future histories will 
be written in which the critic's interpretation offered by Nelson but denied by the artist, is nonetheless widely accepted as a true account of the artist's own thought.

This is a book about things people say about works of art. But it is unusual insofar as most scholarship of this kind tends to search for difference and division. Histories and analyses of art criticism and art history usually focus on particular individuals, periods and schools of thought, or connections to particular artistic movements, or particular 'theories' and 'methods', or the most exceptional of interpreters and novel possibilities for interpretation. As the examples I have briefly set out suggest, though, there are features shared across a great deal of art interpretation, regardless of whether the author is a 'critic' or 'historian', regardless of artistic period discussed, regardless of the dates or location of the writer, and regardless of any self-proclaimed allegiance to a particular 'theory' or 'method'. These are features that writers do not necessarily acknowledge in their own accounts of what they do, but are nonetheless present in the very way that interpretation is practiced and written down. The major premise of this book is that we might study and set out shared features and premises of interpretation of this kind. What if we attended to similarity as much as difference? What if we examined what interpreters of art actually do as much as what they claim that they are doing? Rather than insignificant details or accidents, such features may supply fascinating insights into the aims and underlying claims of interpretation, including how it is practised and how it achieves its effects.

\section{Organization and use of this book}

Most of this book is devoted to mapping out interpretation as it is often found in the Western tradition of art history, along the way drawing attention to a series of rhetorical and persuasive features and techniques that are involved. In doing so I attempt a clear and constructive analysis of art historical interpretation, accounting for the kinds of oddity seen in my opening examples even while accepting that some art writing remains unanalysable because it is grounded in 'light reverie, meandering, the gentle deliquescence of ideas, and the allure of half-conscious structures'.

The book proceeds by setting out features of the way we tend to make sense of an art object. What are the assumptions, premises, and patterns that work to guide interpretation along the way? My account is intended to be relatively uncontroversial. I keep to clear cases and real-life examples taken from art and art history as much as possible. Theoretical 
assumptions are necessary, of course, but in that regard I try to build a coherent analysis that follows widely agreed points in recent philosophies of art, art history, and history. One of the interesting things that emerges is that art history could be realist, just as other recent theoretical work has explored. ${ }^{10}$ Perhaps critics and historians really could show us the reality of artworks and their pasts, might 'carve' an artwork and its history 'at its joints', to adapt Plato's famous formulation. And yet in showing how art history could be understood as realist, we will also see all the problems that ideal meets in practice. The importance of observing not just the ideal and the eccentric, but how things work in the process of everyday interpretation, is a key premise of this whole book. What are some of the features that we might need to examine more closely if we were to be confident that we really were recovering the past? And in what ways do we see how this is not exactly what happens in practice? In this sense the book is also about the expansion of interpretation as much as any sense of correctness: it shows how the norms of interpretation - and the kinds of practices that we usually carry out - even when the account is aiming at accurate recovery of the past, tend to expand the meaning of the artworks over time.

'Interpretation' will strike some as a strange choice as an overarching term for the many kinds of things people do with works of art. Susan Sontag famously attacked interpretation as a practice that replaced the sensuous immediacy of art with a kind of tamed and intellectualized textual translation. ${ }^{11}$ Worries about the secondary nature of interpretation continue in similar form through to the present in the humanities. We should not 'interpret' in search of 'meaning', so the underlying argument goes, but instead prioritize a more direct engagement with artworks (an engagement put forward under slogans such as 'description', 'understanding', 'presence', 'affect', 'form', 'the signifier', and so forth). Useful as the time-honoured calls to attend more closely to works of art are, for a book of this kind I've found it more helpful not to prejudge the issue. Following the traditions of hermeneutics and pragmatism, I take inspiration from their insight that the standpoint or 'horizon' from which one interprets can play a role in determining even the most basic details of what we take things to be in the first place. ${ }^{12}$ To talk of interpretation in the history of art can thus be to talk of the sense-making process from encountering an unfamiliar object through to the most abstract and elaborate forms of meaning-making. Interpretation is therefore not just the activity involved when we ask what an artwork 'means', but is present in everything from that highest-level activity down to the basic moment when we are faced with an unfamiliar object and try to 'understand' or 
'describe' what is before us. ${ }^{13}$ This range of possible activities and levels of complexity has inspired the way the book was researched, which was to work upwards and outwards, mapping out a particular set of what might be called interpretative 'logics', 'features' or 'moves' as they proceed from the most basic sense-making to the highest-level attributions of extremely complex 'meaning'. This method is part of my claim for an analysis both sensitive to practice and clear and constructive. I follow through the various steps and premises with a range of actual examples of interpretation in practice, but in following things through step by step I build up an overall account that is far more than the sum of its parts. In other words, it is not just a set of case studies that each reveal the irreducibly unique nature of both art and analyses of it, or that reveal the entirely incommensurable natures of interpretations that appeal to different theories or methods or modes of narration.

Given this method and its limitations I also need to make two appeals to the reader here. First of all, this is only one way of analysing interpretation, not the logic of all interpretation in the whole history of art (let alone of art per se). But if the reader is charitable, they will see that what I cover does in fact apply to an extraordinary amount of art interpretation, not just that seen in the academic 'art history' of recent years from which (writing as an academic art historian) my examples tend to be drawn. It can likewise reveal various choices or crossroads where interpretative practice could be otherwise. All the same, there is much that is not covered here, and one merit of this is to make all the clearer what is involved in the legacies of the Western Enlightenment tradition that global and post-colonial histories are currently attempting to break away from. I would be very happy if laying this out inspires readers to pursue genuinely new practices that diverge from what is shown here, but I wager that much of what they instinctively think of as 'novel' or 'alternative' does not. Second, I ask that the reader respects the stress on interpretation in practice, and remains broad-minded in applying what they know. That 'theory' does not actually change practice in straightforwardly direct ways is a well-trodden theme, whether because theory is entirely inconsequential for practice, accidentally consequential, or simply deeply removed in ways that mean one does not neatly impact the other. ${ }^{14}$ Very often I'm sure the reader will find that a theory new or old they are aware of suggests that things would look very different from what is mapped out here. But again I wager that more often than not they will find that actual interpretations of art that in some way appeal to or claim to be driven by that theory really are not. 
A final point about my own interest in all of this. It's a commonplace now that as much as we construct the objects we encounter, they also push back, surprise us, reveal their non-human otherness in the anarchic action that ensues. In art history the implications continue to be explored under banners such as presence, agency, temporality, ecology, mobility, and materiality. But lessons for the study of art writing can also be drawn from ways this thinking has fed into literary studies via what is sometimes called French pragmatic sociology. ${ }^{15}$ Artworks do not have to be revealed as the 'causes' (historical, social, political) that might stand behind them, so this goes, and those who use and enjoy those artworks do not have to be denounced as the fabricators and dupes that Pierre Bourdieu's early 'critical sociology' would have labelled them. ${ }^{16}$ 'How do we speak of the love of art, or of wine, or of any object or practice', asks Antoine Hennion,

without being satisfied by showing that it is really a matter of something else than what it thinks it is? No one reading Bourdieu's 1966 The Love of Art would have thought for a moment that the book would actually speak about the love of art: come on, you are not going to take the artwork 'itself' seriously, are you? That would mean falling back into aesthetics, or letting actors seduce you with their talk, getting sucked into belief rather than showing its mechanism. Well, as it happens, taking the love of art seriously is exactly what I'm working on. ${ }^{17}$

In literary studies the 'postcritical' is one term for the suggestion that we might work with texts in ways that value sympathetic description over suspicious denunciation. ${ }^{18}$ Though I prefer not to embrace the favoured postcritical word 'description' as a universal term for what art writers do, the key lesson remains that we can be analytic and sympathetic, can explain practices without undermining their value. I am interested in interpretation in art history in the most inclusive sense, not the narrow sense of interpretation 'as critique' as it is now commonly understood. ${ }^{19}$ I aim to use that same inclusivity to interpret the texts I discuss in this book. My own enjoyment of art and art history has been deepened immeasurably by my pleasure in reading art writing over the years. And in this book I want to take not just artworks but 'the love of art' - as it actually manifests itself - seriously, which is to say taking seriously the constructions discovered in art writing, and sometimes being open to 'letting actors seduce you with their talk'. 


\section{Notes}

1 As brilliantly discussed in Barolsky, Why Mona Lisa Smiles and Other Tales by Vasari; and Barolsky, Giotto's Father and the Family of Vasari's Lives.

2 That is to say, the artwork revealed an artist who was not only the active origin of its various pictorial features - 'Mr Poussin has clothed his figures...' - but also the maker of apparently conscious higher-level pictorial decisions: '...Mr Poussin, intending to shew how the Manna was sent to the Israelites, did not believe it would be sufficient to represent it fallen on the Ground....' Félibien, Seven Conferences Held in the King of France's Cabinet of Paintings; Félibien, Conferences de l'Academie royale de peinture et de sculpture, 97, 101-2.

3 Winckelmann and Lodge, The History of Ancient Art, 120-1. Lodge most likely drew on Winckelmann, Geschichte der Kunst des Alterthums, 2nd ed., Vol. 1, 325, with the sentence absent from the first edition, Vol. 1, 169.

4 Wölfflin, Classic Art: An introduction to the Italian Renaissance, 89-91. In his later reflections on the book in which he had made the claim, Wölfflin explicitly stated that the kind of 'vision' aimed at in his art history was after all 'the artist's way of seeing'. Wölfflin, 'Kunstgeschichtliche Grundbegriffe: Eine Revision', 215.

5 Grootenboer, 'Rembrandt'; Grootenboer, 'The Pensive Imge', 29, 24.

6 All Smith quotations from Zadie Smith, 'Through the Portal'.

7 All Nelson quotations from Nelson, 'Issues of Intimacy, Distance, and Disavowal in Writing about Deana Lawson's Work'.

8 The controversy was explored in particular in the interview cluster Petrovich, 'Intimacy, Distance, and Disavowal in Art Publishing: Conversations with Dushko Petrovich'.

9 Elkins, Our Beautiful, Dry, and Distant Texts, xvii.

10 As explored for instance in Gilmore, The Life of a Style; Verstegen, A Realist Theory of Art History.

11 Susan Sontag, 'Against Interpretation', 3-14; Preziosi, Rethinking Art History, 111-12 (for critiques of Panofsky along these lines).

12 In addition to the works of Hans Georg Gadamer and Richard Rorty I have found particularly useful (though concluding not as I do that we should after all use 'understanding' for more immediate areas) Shusterman, 'Beneath Interpretation', as expanded in Shusterman, Surface and Depth. Over the last half century the analytic philosophy of art has worked through the actual functions and limits of the often-overstated claims about horizon, in writings ranging, for instance, from Walton's 'Categories of Art' to Lamarque's Work and Object. Also helpful in thinking about the functions and limits has been recent work in the philosophy and psychology of perception, in particular: Noë, Action in Perception; Siegel, The Contents of Visual Experience; and Nanay, Between Perception and Action. Equally helpful in thinking about the limits of interpretation have been two of the most influential scholarly critiques of interpretation's alleged dominance in the humanities, Gumbrecht's Production of Presence and Felski's The Limits of Critique.

13 John Frow usefully speaks of (and models) such an 'inclusive sense of interpretation, extending it beyond exegesis to the complex of knowing, interpreting, judging, valuing, feeling, and consequentially acting which works as an inseparable whole in every act of making sense of things' (Frow, On Interpretive Conflict, 3).

14 Fish, Doing What Comes Naturally, 315-41; Elkins, Our Beautiful, Dry, and Distant Texts, 33-60, 112-45.

15 Carreira da Silva and Baert, Social Theory in the Twentieth Century and Beyond, 42-3.

16 As in Hennion and Latour, 'Objet d'art, objet de science: Note sur les limites de l'anti-fétichisme'; Hennion, 'Those Things That Hold Us Together'; and Hennion, The Passion for Music.

17 Hennion, 'From ANT to Pragmatism', 299. I have discussed the relevant recovery of aesthetics and 'the aesthetic' in Rose, 'The Fear of Aesthetics in Art and Literary Theory'.

18 Eve Kosofsky Sedgwick and Bruno Latour's early 2000s comments on 'reparative reading' and moving beyond 'critique' laid much of the ground, later developed into ideas that include 'surface reading' (Sharon Best and Stephen Marcus), the 'descriptive turn' (Heather Love), and most broadly the 'postcritical' (Rita Felski).

19 Frow, On Interpretive Conflict, 7-11. 


\section{2}

\section{Artists}

Like all cultural objects, artworks are strange things. We treat artworks neither as purely imaginary entities that exist only in the mind, nor as purely physical objects that exist independently in the world. ${ }^{1}$ For this reason it's hard to say much about an artwork before a maker enters the scene (Ed Clark's painting Untitled, 1957, serves as an example in Fig. 2.1). We can attempt to enumerate physical properties ('oil and acrylic...'). ${ }^{2}$ But as soon as we try to account for what an artwork represents or what it is like to experience, we quickly find ourselves describing how that artwork is for someone. (Its true scale originates not in these measurements but in the felt immensity and vigor of the closed and crossed shapes they encompass.') And once we start to speculate about the traces of action that made the work look the way it does, we move to how the artwork was caused by someone. ('Although Clark has covered almost all the canvas with oil and acrylic to work up a picture, he also opens that picture out by varying the paint density from opaque to translucent and the paint surface from matte to glossy.') It is hardly surprising that in interpretation across the history of art the someone has tended to be the artist. The artist is the figure whose thought and action caused the work to look the way it does, who experienced the work as it was being created and in its finished state, and who was as well placed as anyone to consider and anticipate its use by others.

In the history of art the centrality of the artist was set from the start. It may only have been in the eighteenth century that the attempt to accurately label pictures in galleries with correct maker and date took hold, the nineteenth century when the norm of monographic life-andworks histories of single artists was established, and even then not until late nineteenth and early twentieth-century developments in professional art dealing, connoisseurship and curation that the labelling of works by definite artist or 'artistic personality' (or group thereof) was standardized. ${ }^{3}$ 


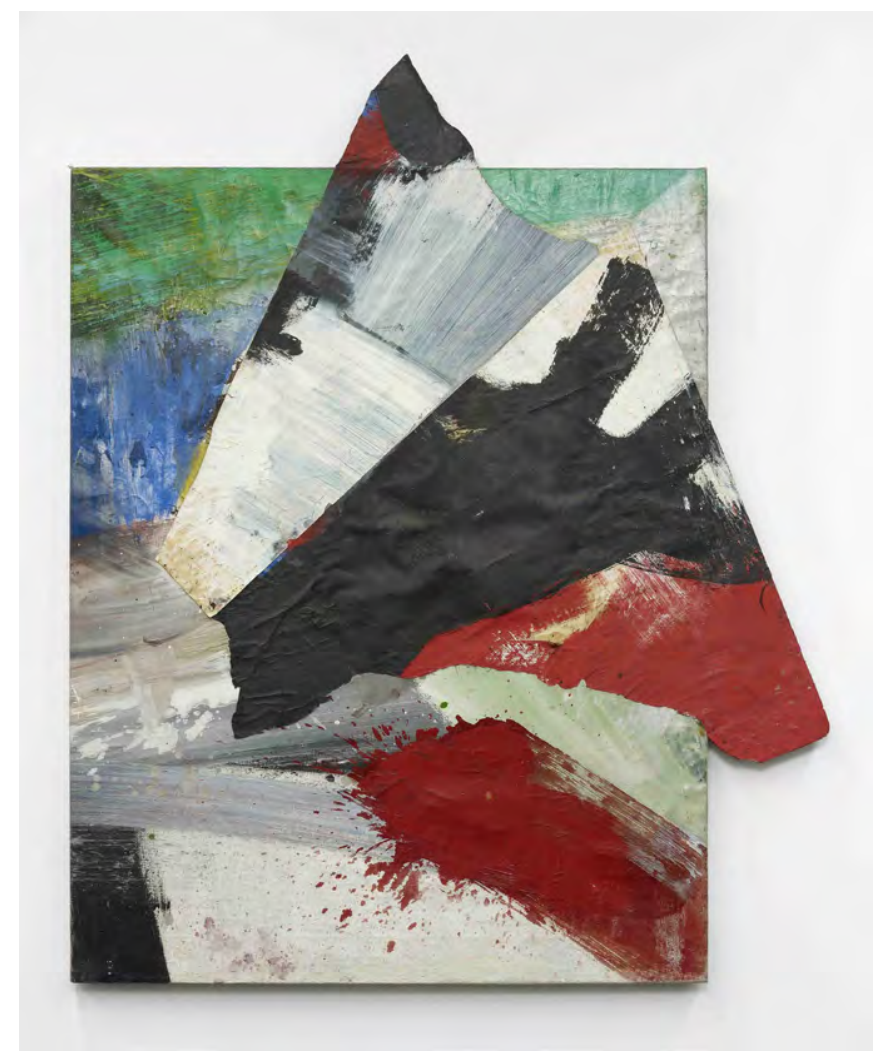

Fig. 2.1. Ed Clark, Untitled, 1957, Oil on canvas and paper, on wood, $116.84 \times 139.7 \mathrm{~cm}$, The Art Institute of Chicago. (C) Estate of Ed Clark.

But in the foundational written models for modern art history - Pliny, then Vasari and writers in numerous early modern academies of art who followed his lead - artworks were firmly linked to their origins in the creative acts of artists and their relevant life, thoughts or career, while also discussing subsequent 'uses' of artworks largely through their reception and impact on other, later artists.

When grand contextualist art histories arose over the course of the nineteenth century, the artist was a handy figure through which the spirit of the times could act.

This citizenship, this love of enterprise, in small things as in great, in their own land as on the high seas, this painstaking as well as cleanly and neat well-being, this joy and exuberance in their own 
sense that for all this they have their own activity to thank, all this is what constitutes the general content of their pictures.

So noted Hegel of Dutch art, before adding that it was 'Fired by a sense of such vigorous nationality' that 'Rembrandt painted his famous Night Watch', 'Van Dyck so many of his portraits', and 'Wouwerman his cavalry scenes'. ${ }^{4}$ (Where it was inconvenient or unpractical to focus on individual artists, alternatively, collective styles were often called upon to do the work of generalizing about the intentions and actions of large groups of individuals: 'classical', 'baroque', 'romantic', and so on, calling to mind a group of characteristics that would apply to any one maker subsumed within.) When the needs of the art market and a professionalizing and newly empirical discipline demanded more rigorous classification as that century went on, the artist once again provided the basis: dealers, critics, connoisseurs, and scholars could now focus on the oeuvres of individual artists as a means of classifying, understanding, and interpreting previously disparate or mysterious works..$^{5}$ Despite now-canonical pronouncements about the death of the author and injunctions against reading artists' biographies directly into their works, not only do monographic exhibitions and books remain standard in the present day, but, as we will see, artists have maintained their authoritative place through the very way that artworks are talked about. Despite the bombastic rhetoric of some, that is, interpretation in the history of art has never found a way to circumvent the artist entirely.

Certain foundational writers in the academic discipline of art history as seemingly opposed as Heinrich Wölfflin and Erwin Panofsky have opted to openly acknowledge the indispensability of the artist in making sense of the work before us. ${ }^{6}$ Contemporary philosophy of art has its own terms for this, with Sherri Irvin and Amie Thomasson writing of the 'artist's sanction' as determining 'the ontological status of the work': the artist's actions and intentions ultimately fix the 'boundaries' and 'features' (not the full and final meaning) of otherwise deeply ambiguous works. ${ }^{7}$ Yet artists remain controversial figures on which to base arthistorical interpretation. For every claim that they form the basis of what art historians do, there are counters that the idea of the artist is irredeemably problematic: that the very idea of the singular 'artist' is deeply misleading about the often multiple forms of authorship that artworks have, that artists are just one viewer of artworks among many, and no more interesting than others, even that the recovery of what the artist did in making the work is an impossible task we'd be best not to even try to pretend to carry out. 
This chapter examines the appeal of the artist that remains in spite of all these problems: how it is that such a controversial figure can remain at the heart of what so many interpreters do. To this end I ask four key questions, the answers to which will show how the appeal to the artist manages to avoid so many of the accusations levelled against it. How can we be so interested in what the artist has done, and nonetheless refuse to take the artist at their word (an approach to which we might give the shorthand description 'Cruel Intentions')? If we can't rely on the artist's word, how might our own looking in the present be a better tool for reconstruction of the artwork as it was originally seen and used? ('The Deliberate Artwork'.) What can we claim to have recovered of the artist, if the artwork is our primary source? ('The Artwork's Artist'.) And how, finally, does all of this get set down convincingly as written historical interpretation, avoiding dubious claims that we have read the minds of artists while still putting forward our interpretation as if it might have recovered the way that the artist themselves once engaged with the work? ('Makerly Narration and Mindreading Narration'.)

\section{Cruel intentions}

'I am always surprised at all the things people read into my photos, but it also amuse[s] me. That may be because I have nothing specific in mind when I'm working.'

Cindy Sherman

Could we just rely on the artist to tell us about their work? 'He who dedicates himself to painting must start by cutting out his tongue', Henri Matisse famously wrote in his artist-book Jazz. ${ }^{8}$ The artist has their own way of communicating what they have done - the works of art they produce. So, Matisse asked in the explanatory note, 'Why do I need to employ a medium other than my own?' ${ }^{9}$ The words of an artist, writing about their own work, that disavow the words of artists writing on their own work, beautifully captures something of the subtle cruelty of the intentions of artists. Artworks are brought into being by their makers. And, as such, in searching for the 'original context' with which to make sense of the work, there is no more obvious basis than how the work was for that maker or group of makers. Discovery of the 'artist's artwork', the true intention of the artist in creating their work, might thus seem to promise an end to interpretation, a final point at which the original artwork is fully and clearly revealed. In search of this possibility of 
knowing the work as it originally was, artists are questioned and their words recorded and often reverently reproduced. Yet artworks are not entirely verbal things. Nor are they necessarily made in entirely conscious ways. Because of the nature of artworks and artistic creation there is, ultimately, no chance that the words of an artist could fully and finally capture how the work was for them. In other words intentions are a hope, even a promise, that can never quite be made good on.

The simultaneous desire for and distrust of the artist's words is a perennial feature of the history of art. The expectation that 'the artist speaks' has struck some as a twentieth-century phenomenon: the rise of the group manifesto explaining the basis of a new 'movement' in the early twentieth century, through the post-1960 moment when, rather than leaving it to the critics, artists increasingly attempted to intervene in and manage interpretation of their work, to the present situation today where the individual artist's statement has become a standard expectation in the presentation of work. But the practice of both hearing the artist's words and treating them with caution was standard already by the time of the early modern academies of art. There, though artists' views were widely distributed in the form of letters and treatises, even the words of the most revered of theorists, Nicolas Poussin, could not have the final say. In pictorial matters right down to somewhat arcane debates over subjects - in painting Eliezer and Rebecca at the Well should Poussin not have depicted all ten of the camels? - the evidence of the artworks themselves was set alongside recorded words to be debated again and again among academicians. ${ }^{10}$ It is the same basic stance that has continued right through to the 'crit' favoured in present-day academies, the central event in graduate art instruction in which staff and students gather to view, discuss, and generally make sense of a student-artist's recent work. Usually the student will talk briefly to introduce their work, though in some cases they are expected to offer full written statements and in others no more than a title. Even when faculty are asked for a 'cold read' - a response without any introduction to the work - the student will eventually be called upon to answer questions and elucidate, to 'own your position whatever it is. ${ }^{11}$ Nonetheless, students are aware that they are not expected to neatly sum up, let alone control, the meaning of their work, to give all the 'information' or overly 'clear references'. The artist's words are acknowledged, questioned, and used critically as just one part of an unfolding process during which nothing is more important than the experience of the actual work of art. 'I think of it as being in a dark room', notes one instructor of the process; 'After twenty minutes, you can see everything'. 
Could there be a less cruel form of intention? What if the artist could conceptualize the work before or after creation, then say or write this down, leaving us with no harder a task than finding out what they stated about the work in question? Could we ever just 'reprint their cognition', as one art historian has put it? ${ }^{12}$ Unfortunately this would require a model of the creative process that no working art historian seems to have ever actually believed. Either the artist would have to envision the work entirely in their mind before seamlessly transfering that vision into an identical artwork, or once complete the artist would look back on the work and again envision clearly and entirely the meaning in their mind. Artists would have to be able to know and verbalize exactly what they are doing: with no non-conscious and nonverbalized moments of training, habit, or background entering into their practice during creation. ${ }^{13}$ And artists would have to be able to know and verbalize exactly what their work was going to do: with no unexpected effects for present-day and future audiences beyond what they were able to definitely envision.

According to this mythic conception of meaning - sometimes variously and polemically implied to have been held by pre-modernist artists, by Benedetto Croce, and by unreflective art historian iconographers - the meaning of artworks could and maybe even should equate to definite things thought by the artist and their close associates. ${ }^{14}$ Meaning would in this case be a consciously known and stateable intention, as if a recoverable proposition stood 'behind' the work and could be revealed through 'peeling back the literal surface'. ${ }^{15}$ In the terms of analytic philosophy this position is a 'realist absolute intentionalism' or 'extreme actual intentionalism', more elegantly described (and supported) by Arthur Danto as 'surface interpretation', wherein the meaning of the artwork is simply the artist's own interpretation of that artwork. ${ }^{16}$ (It is also this conception that has been famously attacked in writings by Roland Barthes and Michel Foucault on the 'death of the author' or overcoming of the 'author function'. ${ }^{17}$ ) But whatever it is called, the position would leave the historian bound to repeat the words of the artists they study and unable to make claims that fall outside the artist's stated aims. Imagine an art-history textbook or lecture series that consisted of nothing but artists' statements, with all images, history, and analysis left aside. Despite the abstract theorizing of some, it is hard to conceive of, let alone actually find, anyone who writes about art this way. 


\section{The deliberate artwork}

'I myself don't know exactly what I want from a picture, so it's hard to articulate that to somebody else - anybody else. When I'm doing it myself, I'm really [trying] to summon something I don't even know until I see it.'

Cindy Sherman

A writer, relaxing in the warmth of the day, lies down among sheep and listens to the conversation between a shepherd and peasant woman. The writer recounts a long dialogue with a girl who seems to cry over a dead bird but maybe is really in mourning for the loss of her virginity. The writer tells of a long dream in which a series of episodes lead up to the suicide of a priest. These are the kinds of passage found in the Salons of Diderot, who in texts produced from 1759 to 1781 (though only published years after his death) is often said to have elevated art criticism into the widely known and celebrated genre that it became over the next few hundred years. ${ }^{18}$ Yet these passages taken in isolation also fundamentally subvert a primary basis of the historical interpretation of art, including interpretation as practised in the discipline of art history over the same period. For in these passages Diderot treats the artwork as a mere found thing or natural object for the beholder to interact with as they please: occasions on which 'art and artist are forgotten' to the extent that the artwork is 'no longer a canvas, it is nature, it is a portion of the universe that one has before one'. ${ }^{19}$ The responses to the artworks here involve the forgetting that the artwork is a made thing, and instead the treatment of it as a real scene in which the viewer might imaginatively wander, or else as an occasion for creative fiction. In these moments - and it is important to note that in Diderot's writing these are only moments - we see what art writing looks like in which artworks are not made by particular people but are natural or accidental things. With the maker removed, criticism is set free, as writers as different as Oscar Wilde and Roland Barthes have noted. With no maker to fix meaning, the act of viewing becomes one of creating anew, making the viewer's own artwork out of what they encounter - a process that, in Wilde's words, 'is in its way more creative than creation, as it has least reference to any standard external to itself'. ${ }^{20}$

Diderot also reminds us that historical interpretation of art depends on the opposite move: assuming that one is dealing with a 'deliberate artwork'. From Greek ekphrasis onwards, writers who evoke works of art in fiction and poetry have often abandoned the deliberate artwork entirely. But Diderot himself in the end always assumed deliberate artworks, a 
point partly obscured by the sheer length of his often cut-down or extracted Salons. Diderot celebrated artworks that could so effectively make the viewer forget that they had been authored that they allowed a particularly all-encompassing form of engagement, but he was also deeply concerned with 'the variety of brushes', that is, individual artists and their characteristics. ${ }^{21}$ It was the artist who, with their immense skill and imagination, enabled the critic to interact with the painting as an immersive scene rather than a made object, and in this sense Diderot's absorption was itself crafted by the artist. Diderot's combination of intensely creative personal response with attention to what the artist has done has inspired much of the most creative (and outlandish) criticism of subsequent centuries, where the writer is able to rely on personal response and yet also anchor this in the artist themselves. We might term this the 'implicitly deliberate' artwork: allowing flights of fancy, but with these flights backed by the knowledge that they are after all guided by the authority of a maker who controls the work and its effects.

The stricter adherence to 'explicitly' deliberate artworks that became more common in the history of art can be seen in Goethe's writing later that century on the Laocoön. ${ }^{22}$ In this mode the artwork is not only assumed to be a 'network of artistic decisions', as Neil Flax puts it, but the writer constantly reminds their readers that it is the traces of these decisions that they are looking at. In the Diderotian model the made-ness is largely implicit, present for example in titles or surrounding passages. In this second model the writing foregrounds the work as deliberate by tying visible features of the artwork back to the actions of the maker, with comments such as 'the three figures are chosen extremely judiciously', or 'one loses oneself in astonishment at the wisdom of the artists'. Over subsequent centuries interpretation in the history of art has sometimes adhered to the Diderotian model of the implicitly deliberate, and sometimes the Goethian of the explicitly deliberate. But no art history has found a way to fully deny the deliberate artwork and embrace open fictionalizing while retaining the claim to, in some sense, be more than art criticism.

It was in large part the connoisseurs and art historical formalists of the late-nineteenth and early-twentieth centuries that formalized the deliberate artwork, both theorizing and more importantly practising modes of art historical interpretation that treated the artwork as the ultimate form of documentary evidence. ${ }^{23}$ The deliberate artwork provided a solution, here, to the historical discipline's twin problems that many artworks had little or no documentation associated with them, and that many were loosely or entirely misattributed. If the work was itself a 
kind of primary or 'internal' evidence, then close inspection of artworks might be enough to date and attribute them, place them in historical sequence, and explain their most significant features. Whether in the hands of connoisseurs hoping to attribute artworks or formalists aiming to analyse the structures and effects of artworks and to place them in proper historical sequence, interpretation prioritized what the presentday interpreter most vividly saw, or experienced, in their direct encounter with the work. The evidence of this encounter was historically valid because it closed in on the artwork as it had originally been. (Not the artwork 'in itself', but the artwork 'as originally created'.) The premise and its practice were distilled into a single text as succinctly as anywhere by Sigmund Freud, who in writing on Michelangelo's Moses pointed - in contrast to the vast array of commentaries he first noted - to the strange position of the stone tablets clutched in the crook of one arm, and suggested that Moses was shown in the act of recovering and controlling himself, having a moment earlier almost dropped the tablets in anger after witnessing his people worshipping the golden calf (Figs. 2.2-2.3). ${ }^{24}$

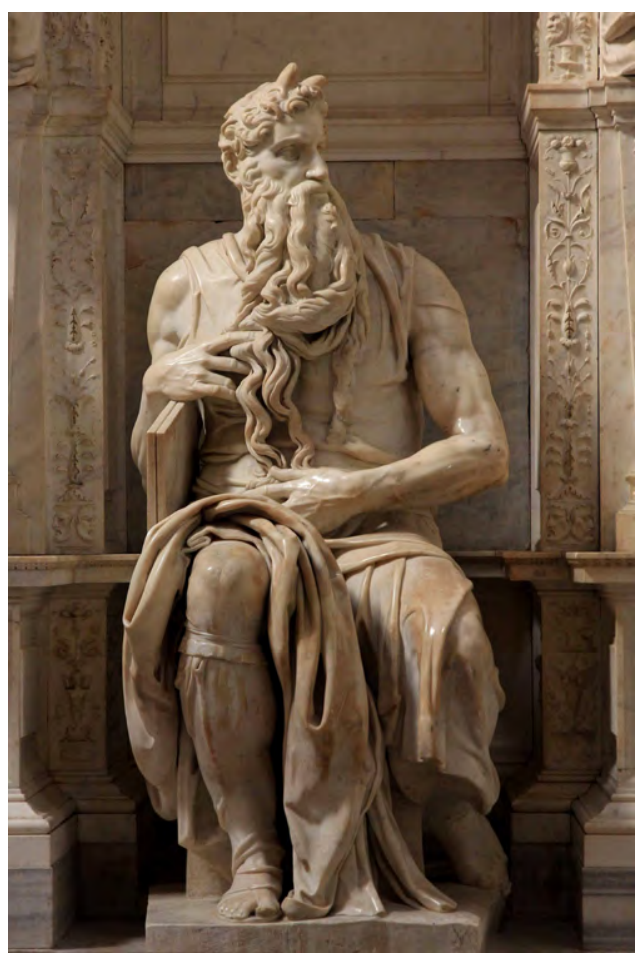

Fig. 2.2. Michelangelo Buonarotti, Moses, marble, $235 \times 210 \mathrm{~cm}$, San Pietro in Vincoli, Rome. Photograph: Jörg Bittner Unna. CC BY 3.0. 


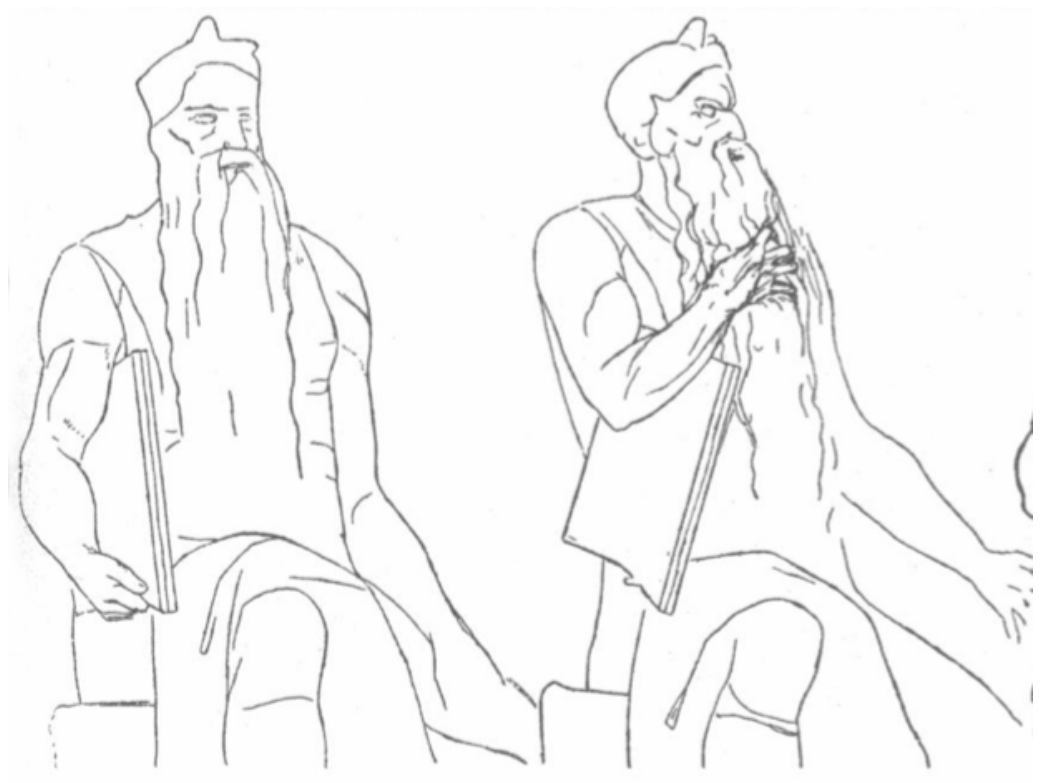

Fig. 2.3. Illustrations to Sigmund Freud, 'Der Moses Des Michelangelo', Imago 3 (1914).

A careful reader of Morelli, Freud as so many of the connoisseurs started with the 'powerful effect on me of the work', assuming that one could reason from 'effect on me' to effect on the artist to what the artist had thought and done in making the work 'in so far as he has succeeded in expressing it in his work and in getting us to understand it'. Freud's interpretation thus recovered 'the artist's intention', his ultimate goal, even though as far as the artist was concerned that intention could never be 'communicated and comprehended in words'.

Drawing on all of these figures along with later ones who helped spell things out, it is possible to extract three underlying principles that tend to operate whenever interpretation proceeds on the basis of assuming a deliberate artwork. First: The artist relinquishes their work..$^{25}$ The creation of artworks involves often-lengthy forms of serial action, as they are conceptualized, modelled, reworked, and so on repeatedly over time. But there is also a point when the artist stops, deciding that their work is finished enough to go out into the world, or else they are simply unable to continue work. We are left with a concrete thing that is at once the end point of purposeful action, and a survival of that end point from past into the present. Second: Though artworks may not be the product of consciously known action, they are at least the product of deliberate 
action. ${ }^{26}$ The artwork that the viewer sees is a record of the artist's deliberate action, so that features of the artwork noticed by the viewer can be assumed to be ones that the maker deliberately caused to be that way. Even when 'chance operations' are employed, they are either done so knowingly or at least accepted by the artist as forming part of the work. Third: The artist works not just with the eyes, but for the eyes. ${ }^{27}$ Artworks are not only products of deliberate action, experienced by artists as they are made, but are perhaps also made by artists to be experienced in particular ways. Artists, that is, may act as spectators of their own work while imaginatively playing the role of future viewers.

\section{The artwork's artist}

'...Or I'm just very, very smart.'

Cindy Sherman

The deliberate artwork has allowed interpreters in the history of art to skirt arguments about intention, almost universally attempting reasoned historical reconstructions of how original artists and viewers engaged with artworks - without ever, that is, being constrained by the narrow model of 'intentions' dismantled by critiques of the author. (As I've pointed out elsewhere, even where rival factions argue over high-level theoretical and methodological differences, they end up working in much the same way. ${ }^{28}$ ) This laissez-faire approach has strange implications of its own, however: troubling for much literary history's claims to be actual 'history', and potentially just as worrying for art-historical interpretation if practised without care.

When writers assume a deliberate artwork, their account of the work reveals what the artist has done in creating that work. In turn this account can subtly shade into describing the artist as revealed by the work: the kind of person who acted in creating this particular work. 'I don't analyze what I'm doing', states Cindy Sherman, 'I've read convincing interpretations of my work, and sometimes I've noticed something that I wasn't aware of, but I think, at this point, people read into my work out of habit. Or I'm just very, very smart.' ${ }^{29}$ In this joke Sherman wonderfully indicates how even the most complex forms of interpretation can, strangely, come to seem like they were, after all, thoughts and aims that the artist themselves had in making the work - a process whereby the cleverness of interpreters elevates the artists to a similar level of cleverness. ${ }^{30}$ 
The connoisseurs and art historical formalists were well aware that in revealing the artwork as originally created, their interpretations couldn't help but reveal that original creator, often in ways that seemed to go beyond or even contradict documentary evidence about any real-life person who had made the work. In a neat loop, close attention to the artwork revealed how its maker had made it to be, and how the artwork's maker had made it to be revealed the personality of that maker. But because of this loop, these writers did not take close engagement with an artwork to discover the maker as 'person', precisely, but instead the 'artistic personality' (Berenson and Fry), or the 'aesthetic personality' (Croce), or 'creative personalities' (Julius von Schlosser). The 'determination of purely artistic personalities' through the experience of the work came first, Berenson wrote, 'and only then, and chiefly for mere convenience of naming, might one turn to documents ... and attempt to connect with this abstract some actual personality in the past'. ${ }^{31}$ So is the artistic personality thought to be real, or is it just a creative fiction of the interpreter's own?

A long convention in criticism has stressed the latter answer. According to this convention critics engage in a kind of fictionalizing talk when they speak of the artwork in relation to its maker. ${ }^{32}$ The name of the artist invokes no more than an imaginary character consistent with a set of public productions and statements, a useful way to talk about what was realized in the artwork but which makes no claim about real-life persons and goings-on. So it is fine to confidently say things like 'Cindy Sherman sees the world as ...', going far beyond or directly contradicting Sherman's own words, because one is talking not of a real person but just a character consistent primarily with a set of artworks. Griselda Pollock has put the point especially clearly: "The usual formulation is this: Edouard Manet is the historical person, but "Manet" is the author whose artistic identity is derived from a study of the texts and practices which constitute an artistic project. ${ }^{33}$ But Pollock's essay and work more broadly are constant reminders that art historians should not allow what Pollock calls 'painted fictions' to occlude actual 'historical persons'.

Whereas criticism may assume a deliberate artwork but just reveal an imaginary character as the source of the work, historical interpretation necessarily makes a real-life claim about an actual person or people, a hypothesis about lives and events that has consequences and implications beyond what imaginative whimsy might. The critic and the historian may be working in exactly the same way: gathering all available evidence then engaging with the work as closely as possible and testing how it seems to be. The critic may instead, however, push to maximize the interest or 
value of artwork for them and their moment over the reconstruction of how things were. The critic may even - in a move favoured in much 'depth interpretation' in art and literary history - maximize value for the present, then 'resurface' and claim that they were speaking not of an imaginary character but the real-life maker all along. With art interpretation's tendency to look from our own perspective and end up speaking for others, these are possibilities that any form of interpretation that wants to claim historical and ethical responsibility for itself needs to bear carefully in mind. The issue is all the more forceful, as we see next, when the very mode of writing seems to speak not just for, but even having briefly become, those others.

\title{
Makerly narration and mindreading narration
}

\author{
'I don't think I can see the world through other people's eyes, but I can \\ capture an attitude or a look that makes others think I can. I have an \\ appreciation for why people choose to look the way they do. But I \\ can't know what they experience.'
}

Cindy Sherman

We have seen that once an interpreter goes looking for the artist's artwork by assuming a 'deliberate' artwork, they often find the artwork's artist: the work revealed is taken to be that of the 'artistic personality' involved in the work's creation. What we see now is how the powers and possibilities of the work come to be attributed to, because they are narrated as, the actions and thoughts of the artist.

To make sense of mindreading narration it's helpful to first note its forerunner, makerly narration. Makerly narration is a practical and perhaps unavoidable corollary to the assumption that artworks are deliberate. Because artworks are products of deliberate action, 'networks of artistic choices', the form of the finished work seems to reveal something of the actions that went into its creation. In describing the finished work, then, it is natural to talk of the artist's action such as it is revealed in that finished work. Even more than this, descriptions of artworks may in part take the form of the imagined story of their making. We have seen this already in the opening example of this chapter, where Darby English describes Ed Clark's painting by listing not only the facts of the physical object, and how the work affects a particular viewer, but the actions of the artist that caused the work to look the way it does. The feature can be found in some of the earliest writings on art in the Western tradition 
- Pliny, Homer, and so forth - where what sometimes appear to be makerless descriptions of the scenes that artworks present, on closer inspection turn out to be stories about the artist making the work. Classical ekphrases are often said to deny the made-ness of works altogether, but look closer, and in many we see instead that writers in fact narrate the series of events and actions involved in the work coming to assume its finished form.

In perhaps the single most famous example of early ekphrasis, Homer's passages on the shield of Achilles in Book XVIII of the Iliad, scene after scene on the shield is recounted as if the very thing stood before the narrator's eyes. Nonetheless, the careful charting of the scenes on the shield is preceded by an account of its maker Hephaestus readying self and tools, then language that reminds us that the shield's features are specifically made by him. First Hephaestus retires to the forge, sets bellows and furnace in action, adds silver, brass, tin and gold, and takes up hammer and tongs. The opening description of the shield is then punctuated by phrases that remind us the scene is unfolding before our eyes because we are hearing it described in the act of making: the shield is first 'formed', then features one after another 'wrought' or 'designed'. Soon this sense of the makerliness of the narration is so natural that the description slips largely into pure enumeration of the scenes, only occasionally punctuated by reminders of the makerly narration unfolding such as 'A field deep furrow'd next the god design'd', or (in Alexander Pope's free translation) 'Next this, the eye the art of Vulcan leads' ${ }^{34}$ The technique is so powerful because of the subtlety with which the maker's presence is felt, perfectly intertwined as it is with seemingly neutral description. We feel when the scenes are described that they could be no other way, but we are also left in no doubt that this is also how the maker and his first audience would have seen the work. The conceit is brilliantly exploited in W. H. Auden's reworking in which, highlighting how different things might be from Homer's makerly narration that collapses making and viewing, a viewer looks upon the shield unfolding and sees something entirely different and unexpected, their horror at the scenes of war and suffering all the more powerful because they are mere spectator to that which the silent artist unfolds before them: ${ }^{35}$

She looked over his shoulder

For vines and olive trees,

Marble well-governed cities

And ships upon untamed seas,

But there on the shining metal

His hands had put instead 
An artificial wilderness

And a sky like lead.

The narration involved in the Iliad's passages on the shield of Achilles, like the narration involved in the majority of early modern writing around the academies from Vasari through to Georges Guillet de Saint-Georges, concerns itself with what are very obviously actions and choices about the making of the work - that is, choices that concern what is most obviously and straightforwardly an artistic matter. Remarks about thoughts and character are often made, but only of the kind that have or could have been observed by others. ${ }^{36}$ Almost always we are firmly in the realm of what the artist did rather than what they thought. These writings, as such, are for the most part very coy about the artist's subjectivity.

It was not until the nineteenth century that art writing habitually attributed grand forms of thought to artists that strayed well beyond the bounds of makerly narration. John Ruskin's disdain for later-fifteenthcentury Venice had already given him the basic context of decadence and decline, but climbing the ladder to confirm that the sculptor of the tomb effigy of Andrea Vendramin (Fig. 2.4) really had only bothered to carve the half of the head visible from the ground, Ruskin placed all of this back into the agency and psychology of the artist themselves (Fig. 2.5). Where we might expect to read of disdain for the artist's times and working conditions, instead we are told of that 'utter coldness of feeling, as could only consist with an extreme of intellectual and moral degradation: Who, with a heart in his breast, could have stayed his hand as he drew the dim lines of the old man's countenance - unmajestic once, indeed, but at least sanctified by the solemnities of death - could have stayed his hand, as he reached the bend of the grey forehead and measured out the last veins of it at so much the zecchin?'37 The attribution of grand forms of thought to artists was found in more strictly academic writers just as much as those renowned for poetic licence. In a particularly astonishing passage in which the slippage from patron and wider context back to artist is laid bare, Jacob Burckhardt wrote of Brunelleschi (as the architect of the Palazzo Pitti façade) that 'one wonders who was this man of power who scorned the world and who, thanks to the means at his disposal, tried to keep himself distant from anything pleasing or delicate'. ${ }^{38}$ 'It was in the works of Florentine artists', Francis Haskell comments, that Burckhardt 'discovered many of the attributes that he would later describe as characteristic of the Renaissance despot'. ${ }^{39}$ Attentive as he was to the works of the artists, it should also be said, Burckhardt seemed to discover these attributes in the artists' very minds. 
Mindreading artists alone is hardly likely to convince. But nineteenthcentury art writing, as the passage from Ruskin suggests, also combined such mindreading with makerly narration, leading to a new form of 'mindreading narration'. Makerly narration, to repeat, was already extraordinarily powerful because the sense that the account is backed by the maker allows all other elements around it to appear to have the same authority. Words and phrases directly linked to traces of the action of the maker are used as reminders that makerly narration is unfolding. ${ }^{40}$ ('Formed', 'wrought', 'designed', 'the art of Vulcan leads'.) But art writing tends to trade largely in description of the features, likenesses, and effects of the artwork that are either attributed to the artwork itself or phrased in the passive voice. ('Here sacred pomp and genial feast delight'.) Taken out of context, these artwork-centred and passive-voice descriptions are entirely ambiguous about who perceives the likeness or is being affected. So without having to state that these things are this way for the artist, the reminders of the artist's action give the impression that we are reading of the artist's own sense of their work.

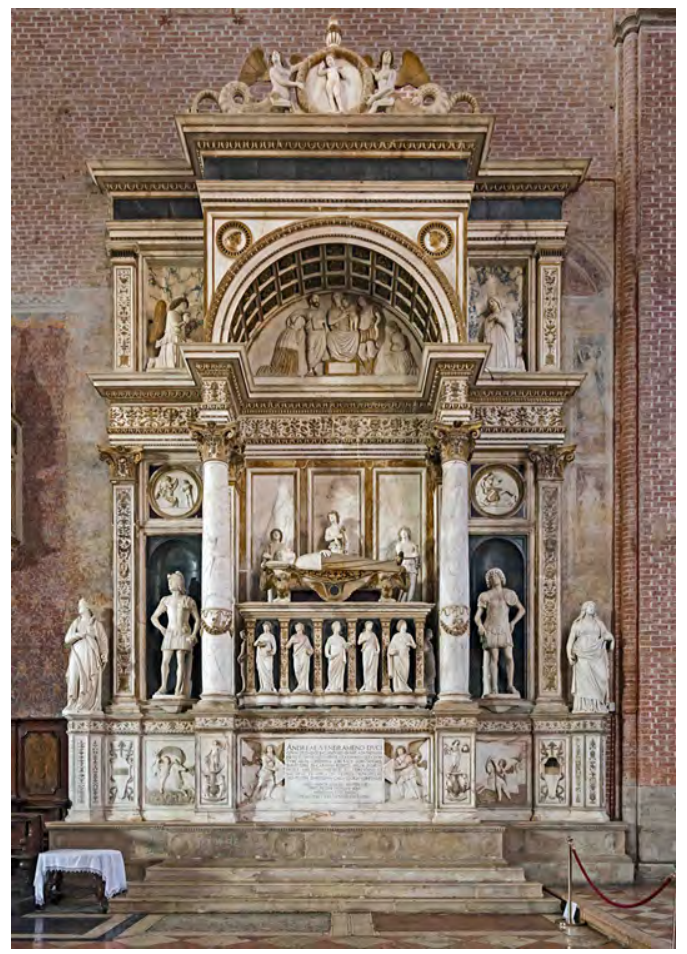

Fig. 2.4. Tomb of Andrea Vendramin, c. 1480-95, marble, Santi Giovanni e Paolo, Venice. Photograph: Didier Descouens. CC BY-SA 4.0. 


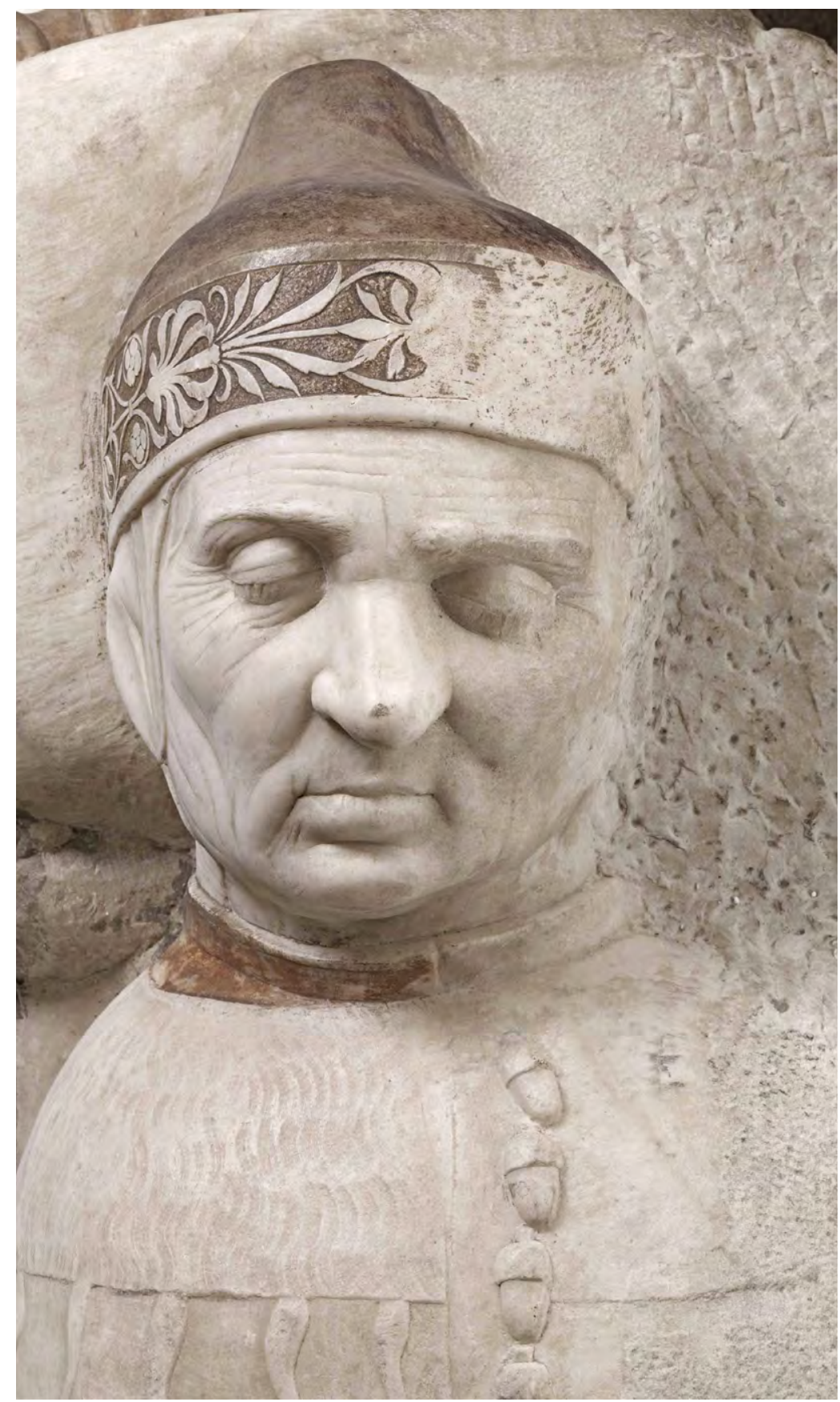

Fig. 2.5. Tullio Lombardo, effigy of Andrea Vendramin. Photograph courtesy of Mauro Magliani/Artchive. 
Mindreading narration takes things a step further. In makerly narration it is never certain that the vision or thought are that of the artist except in relation to the observable actions of the artist. Mindreading narration adds accounts of seeing and thinking that go far beyond the observable, effectively telling us about the minds of artists while seeming to be justified in doing so because the interpreter anchors their speculations in an apparently objective story of the work's making. It is most obvious when explicit, something that is familiar and often remarked upon in the older forms of art criticism and history that revelled in (and were sharply criticized for) their heavy psychologizing (Fig. 2.6). 'Vermeer seems almost not to care, or not even to know, what it is that he is painting. What do men call this wedge of light? A nose? A finger? What do we know of its shape? To Vermeer none of this matters, the conceptual world of names and knowledge is forgotten, nothing concerns him but what is visible, the tone, the wedge of light. ${ }^{31}$ But explicit mindreading narration can also be found in 'new' art history of the later twentieth century through to the present, as in moments when a hard-earned reading is affirmed or secured with a rhetorical flourish; "Vermeer recognizes the world present in these women as something other than himself and with a kind of passionate detachment he lets it, through them, be.' ${ }^{42}$

Crucially though, instead of grand and entirely open feats of mindreading of these kinds, the writer can use the mode with incredible subtlety. In this case they almost entirely use makerly narration to describe the work through constant reference to the artist's action as visible in features of the artwork. In addition however, and sometimes even just once or twice in the narrative, the writer will subtly switch to a deeper register and tell us something more, securing their account as 'of' the artist in a deep sense while avoiding the feeling that they are involved in unwarranted psychologizing. Thus Norman Bryson writes of Caravaggio's 'aggrandising' approach to still life (Fig. 2.7), a project of using the insignificant to demonstrate the power of art by showing its ability to turn even the ordinary from 'dross' to 'gold', in pages almost entirely precise in containing only makerly narration and powers attributed to the work rather than the artist. ${ }^{43}$ Phrasing that tells us of the artist's agency is given only for what we can observe in the work: 'Caravaggio chooses fruits with complex markings on their skin'; 'Caravaggio deliberately abstracts his still life from any mundane location we can recognise'. More abstract thoughts are phrased actively as belonging to artworks or passively as judgements about artworks: 'the Caravaggio deliberately cuts still life's ties to the earth'; 'in the Caravaggio 


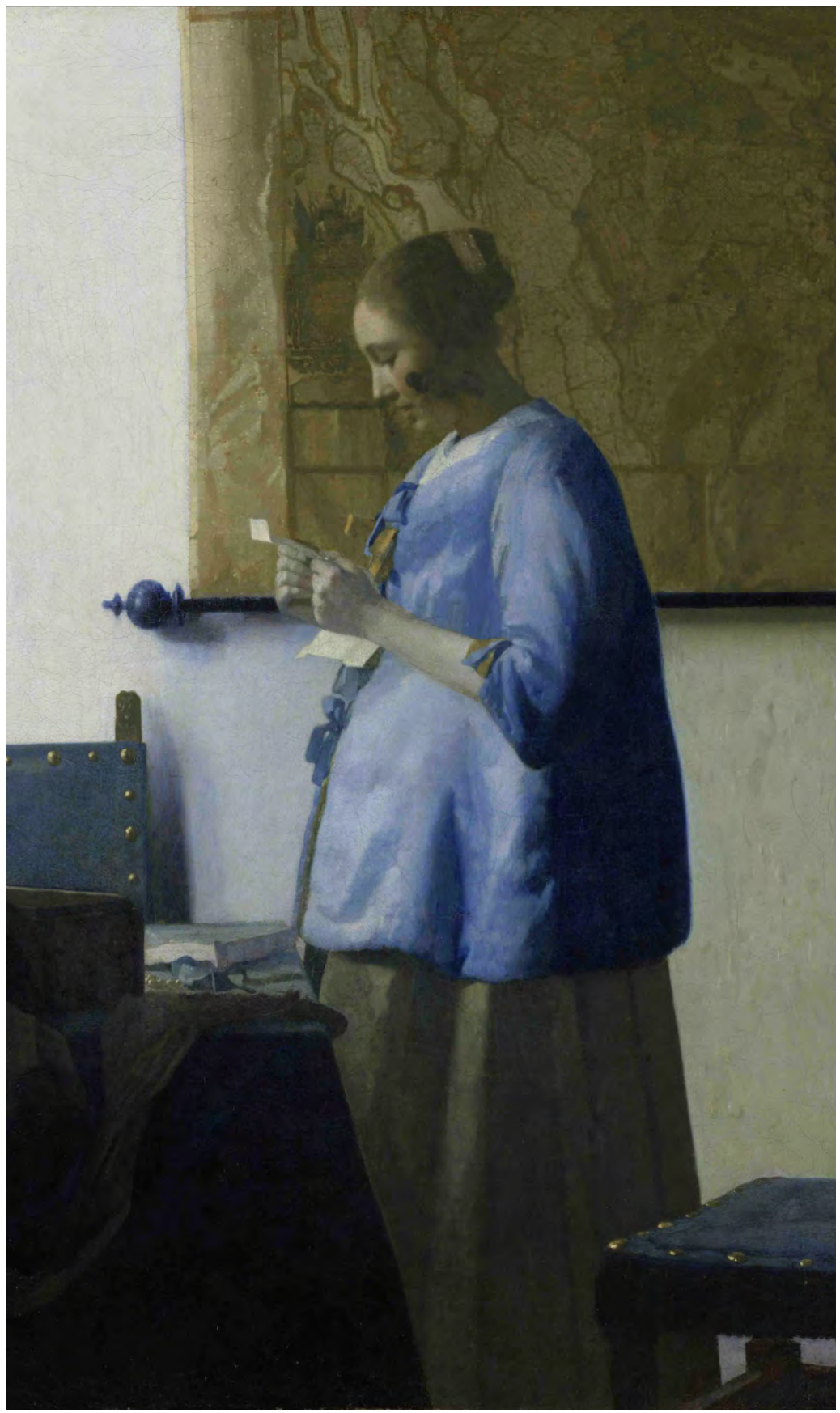

Fig. 2.6. Johannes Vermeer, Woman in Blue Reading a Letter, c. 1663-4. Oil on canvas, $49.6 \times 40.3 \mathrm{~cm}$. Rijksmuseum, Amsterdam. 


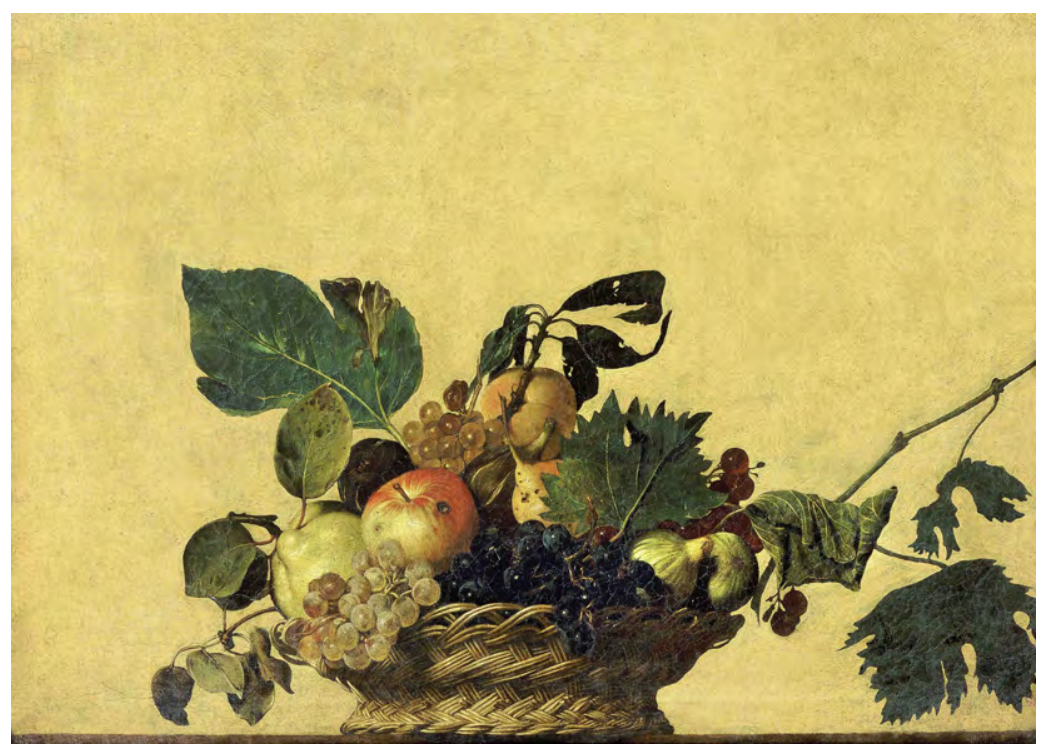

Fig. 2.7. Michelangelo Merisi da Caravaggio, Basket of Fruit. Oil on canvas, $46 \times 64.5 \mathrm{~cm}$, Biblioteca Ambrosiana, Milan.

still life the interest lies exactly in the power of art - and of this artist - to raise an intrinsically humble branch of painting to the level of the heroic'. Even at one point speaking of the actual aims of Caravaggio's art, Bryson avoids a definite appeal to the artist by subtly asking what 'is the aim of his painting?' Then, finally, Bryson offers us just one line that reminds us that what the interpretation has told us is Caravaggio's perspective for sure: 'Caravaggio wants hyperbole, not bathos'. It is in exactly this way, to return to this book's opening example, that Steven Nelson can write persuasively and poignantly of Deana Lawson's work in a way that does not precisely conform with her own view, rigorous throughout in attributing agency to the work and himself, before finally suggesting that 'Lawson ... understands the body' a particular way. ${ }^{44}$

It is ironic, in retrospect, that the late-nineteenth and earlytwentieth centuries were the period of great scholarly enterprises of sorting out the reality of various documentary texts on artists and their lives, yet in the hands of the connoisseurs and formalists it was also the period when academic art history fully embraced this form of writing, which lent a powerful literariness and fiction-like quality to the accounts of artists being produced. ${ }^{45}$ It has remained a standard mode in art history ever since, though with the mode, let alone its strange consequences, rarely brought into the open. One of these strange consequences, for 
instance, is the historian's ability to speak for and as the artist, while denying that they have any interest in what the artist themselves actually claims about their work. ${ }^{46}$ Whatever the rhetoric of interpreters, however, mindreading narration does make claims about the people whose stories it tells, and in this sense has an equally strange consequence for the way that art history seems to straddle the borderlines between fact and fiction, truthful recounting and fanciful storytelling. According to a broad consensus in narratological theory of the last half century, non-fiction writing demands a knowing narrator, able to coolly survey histories that stretch across times, places, and characters. ${ }^{47}$ The non-fiction narrator is in this sense very nearly the 'omniscient narrator' of the realist novel, the God-like figure who can move not only across time and space but inside minds to communicate the thoughts and feelings of characters. ${ }^{48}$ In nonfiction writing, however, because the narrator is the real-life author and knows only what that author knows, the ability to look inside a character's head is characteristically earned, always suitably qualified in the text with footnotes and a cautious 'perhaps', or 'maybe', or 'he/she/they must have thought'. ${ }^{49}$ Art historians, as narrators, love to dispense with the telling warning tags. Unqualified as they are, statements like 'To Vermeer none of this matters ...' or 'Lawson ... understands the body ... as' present themselves as definite reports of an artist's thought. With makerly narration the interpreter seems to have travelled back in time to have watched the artist making the work, and then reports this back to the reader. With mindreading narration it is as if artworks allow interpreters to be something more than day-to-day critics and historians. It is as if they travel back in time to briefly become the artist themselves, seeing and experiencing the work and world as the artist did, before resuming their own perspective and telling others what they have learned.

\section{Notes}

1 Lamarque, Work and Object, 56-77, 143-86; Thomasson, 'Ingarden and the Ontology of Cultural Objects', 115-36; Thomasson, 'The Ontology of Art', 78-92.

2 Quotations in this paragraph from the extraordinarily careful and thorough description of Clark's untitled work in English, 1971, Chap. 1.

3 Yeazell, Picture Titles, 19-77; Pullens, 'The Individual's Triumph', 1-26; Guercio, Art as Existence, 34-224.

4 Hegel, Aesthetics, 169 (Vol. 1).

5 White, Canvases and Careers, 76-110; Green, 'Dealing in Temperaments', 57-76; Green, 'Stories of Self-Expression', 527-32; Soussloff, The Absolute Artist, 79-93; Rose, Art and Form, 18-70. Though focused on Van Gogh, Nathalie Heinich has given a particularly revealing analysis of the general interpretative procedures that could follow, in Heinich, The Glory of Van Gogh, 3-34.

6 Wölfflin, 'Kunstgeschichtliche Grundbegriffe: Eine Revision', 210-18; Panofsky, 'The History of Art as a Humanistic Discipline', in Panofsky, Meaning in the Visual Arts, 35-8, 43-5. 
7 Irvin, 'The Artist's Sanction in Contemporary Art', 320, as discussed in Thomasson, 'Ontological Innovation in Art'.

8 The phrase, as Jack Flam notes, was one Matisse used a number of times; Matisse, Matisse on Art, 2.

9 Matisse, Jazz, 34.

10 Montagu, The Expression of the Passions, 16.

11 The account and quotations are drawn from Fine, Talking Art, xiii, 58, 73, 110-13.

12 Whitney Davis, The Canonical Tradition in Ancient Egyptian Art, xvii.

13 The practical impossibility of this ideal is nicely brought out in Herbert, Brushstroke and Emergence.

14 Respectively Nochlin, 'Seurat's Grande Jatte', 134; Wollheim, Art and Its Objects: An introduction to aesthetics, 68, 99-100; Preziosi, Rethinking Art History, 111-12.

15 Krauss, The Originality of the Avant-Garde and Other Modernist Myths, 293.

16 Livingston, Art and Intention, 139-40; Carroll, 'Interpretation and Intention', 75-6; Danto, The Philosophical Disenfranchisement of Art, Chapters 2 and 3. Danto's 'surface interpretation' was refined to a more 'modest' intentionalism in response to the elaboration by Peg Brand and Myles Brand, 'Surface and Deep Interpretation' (with response by Danto) in Rollins (ed.), Danto and His Critics, 69-83.

17 Barthes, 'The Death of the Author', in Barthes, Image, Music, Text, 142-8; Foucault, 'What is an Author?', in Foucault, Aesthetics, Method, and Epistemology, 205-22.

18 I have taken these examples from the Salons of, respectively 1765,1763 , and 1765 . Théophile Gautier and Lawrence Alloway are among the prominent writers who have made the claim that Diderot was responsible for establishing the genre of art criticism in its modern form, as mentioned in Houston, An Introduction to Art Criticism: Histories, strategies, voices.

19 Diderot, CEuvres esthétiques, 686-7.

20 Wilde, Oscar Wilde: The major works, 261.

21 Diderot, Essais sur la peinture, 181.

22 Goethe, 'Über Laokoon', in Goethe, Gedenkausgabe der Werke, Briefe und Gespräche, 165 (Vol. 13), as discussed in Flax, 'Fiction Wars of Art', 7-10.

23 Whitney Davis, A General Theory of Visual Culture, 45-119; Rose, Art and Form, 1-70.

24 'The Moses of Michelangelo', in Freud, Collected Papers, 257-87 (Vol. 4). First published as Freud, 'Der Moses Des Michelangelo'.

25 Baxandall, Patterns of Intention, 13-15; Lamarque, Work and Object, 33-41.

26 Lamarque, Work and Object, 41, 66-8, 154-60.

27 Wollheim, Painting as an Art, Chap. 1; Whitney Davis, Masking the Blow, 30-3.

28 Rose, 'Close Looking and Conviction'.

29 Interview Magazine, 'Cindy Sherman'.

30 Alexander Nemerov has drawn attention to this in recent art-historical writing, in Nemerov, 'Paper Stars'.

31 Berenson, The Study and Criticism of Italian Art, vii-viii (Vol. 1).

32 Especially clear articulations are given in Nehamas, 'The Postulated Author' and Levinson, 'Defending Hypothetical Intentionalism'. The fuller range of possibilities for this position are usefully spelled out in Livingston, Art and Intention, Chapter 6.

33 Pollock, Differencing the Canon, 255. The point is explored in detail in Orton and Pollock, AvantGardes and Partisans Reviewed, 315-42.

34 I have used the particularly well-known Pope translation (Homer, 1761), which somewhat dramatizes the effect, though the basic point I make here is a widely accepted one going back at least to Lessing's observation that 'Homer does not paint the shield as finished and complete, but as a shield that is being made'. This sense of the shield in the process of being made is explored in particular detail by James A. W. Heffernan, who points among other things to the narrative force provided by the heavy use of past tense action verbs; Heffernan, Museum of Words, 10-22.

35 Auden, The Shield of Achilles.

36 A key exception are certain epigrams, in which fictionalizing or poetic licence allowed the writer to inhabit the imagined maker's person quite fully. Thanks to Elizabeth Mitchell for discussions on this point.

37 Ruskin, The Works of John Ruskin, 49-52 (Vol. 11). I owe this point to Haskell, History and Its Images, 323.

38 Burckhardt, Der Cicerone, 177. 
39 Haskell, History and Its Images, 341, 343.

40 This analysis draws on Baxandall, 'The Language of Art History' and Rose, 'The Significance of Form'.

41 Gowing, Vermeer, 19.

42 Alpers, The Art of Describing, 223.

43 Bryson, Looking at the Overlooked, 77-81 (my italics for the quotation about 'his painting').

44 Nelson, 'Issues of Intimacy, Distance, and Disavowal in Writing about Deana Lawson's Work'.

45 Enterprises that have been brilliantly discussed in Platt, 'The Artist as Anecdote'.

46 Rose, 'Close Looking and Conviction', 161-2, 166-7.

47 Pihlainen, 'The Moral of the Historical Story'; Genette, 'Fictional Narrative, Factual Narrative'; Cohn, 'Signposts of Fictionality'.

48 Though still in quite specific ways and to complex ends, as in Warhol, 'A Feminist Approach to Narrative', 96.

49 Löschnigg, 'Narratological Categories and the (Non)-Distinction between Factual and Fictional Narratives'. 


\section{Contexts}

It's rarely mentioned how much time is spent not discussing artworks in the founding work of modern art criticism - a pamphlet review of the 1746 Salon of the Académie Royale by the French courtier La Font de Saint-Yenne. The pamphlet began with a lengthy discussion of the glories of history painting and its decline in contemporary France, including such choice elements as a digression on the deleterious effects of mirrors in interior decoration. In doing so the pamphlet set up a context for the art about to be discussed, a frame according to which sense could be made that highlighted the perspective from which the critic was (and by extension their audience should be) looking. Turning finally to the works of art on display, the analysis of detail, which also involved the unprecedented inclusion of harsh comments about the paintings that outraged the academicians, has a kind of naturalness or felt inevitability due to this advance contextualization.

So why devote three pages to mirrors and a total of thirteen to general matters (in the modern French edition) before the mention of any actual works of art on display in the exhibition? ${ }^{1}$ In a general sense, the preamble is a reminder of something already indicated in the previous chapter: we rely on information outside the artwork itself to help establish what it is that we are actually encountering. Many others around La Font's time had noticed how radically words connected with an artwork might affect the way it was understood. Art-writer-theorists like the Abbé du Bos and Jonathan Richardson warned artists that the depiction of unfamiliar stories would lead to unintelligibility, while artists from Gerard de Lairesse to William Hogarth experimented with textual additions in order to avoid the ambiguities that resulted from contextless depictions of bodily actions, facial expressions, and events. ${ }^{2}$ La Font's great achievement was to demonstrate that for an extended piece of art writing to say more than just the obvious, it too should use words to set up a context or 
contexts through which to shape the artworks discussed. La Font himself soon showed how broad the possibilities were in writing arguably his greatest piece of art criticism, just a few years later, as a dialogue between the Louvre, the city of Paris, and the ghost of the seventeenth-century minister and architect of the Académie Royale, Jean-Baptiste Colbert (Fig. 3.1). The device was later turned back on the critic by the defender of the academy Charles-Nicolas Cochin, who in Les Misotechnites aux Enfers showed La Font cast into the River Styx for his art-critical sins (and forced to read the art criticism his example had encouraged), in dialogue with another critic just arrived in the underworld (Fig. 3.2). ${ }^{3}$ Though many followed La Font in contextualizing with their own analysis of the state of contemporary art, devices for the construction of a context soon ranged all the way to satirical pamphlets that narrated an imagined encounter with the exhibition in a deliberately comic or bizarre situation: 'Merlin at the Salon' (1787), 'Judgement of a Fourteen Year Old Girl' (1777), 'The Living Dead at the Salon' (1779), 'A Glimpse of the Salon by a Blind Man' (1775), and even 'Ah! Ah! Or Veritable, Interesting, Curious,

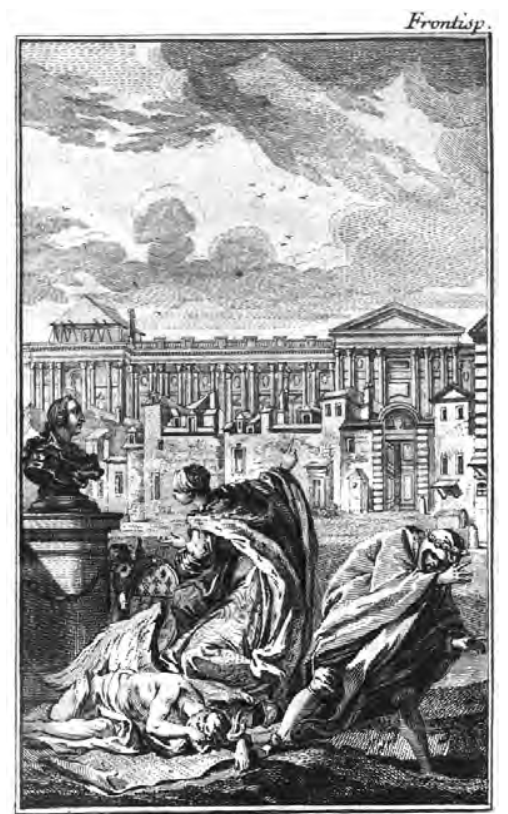

D.L.F. inten, Eüren Woram axpred. Le Bas are caliev

L'OMBRE DU GRAND COLBERT.

Fig. 3.1. Frontispiece to La Font de Saint-Yenne, L'Ombre du Grande Colbert, 1752.

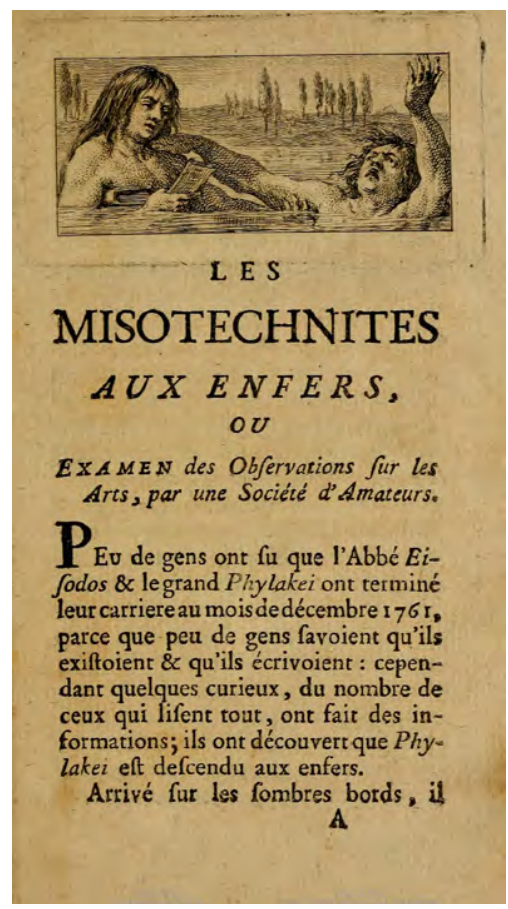

Fig. 3.2. Charles-Nicolas Cochin, Les Misotechnites aux Enfers, 1763. 
And Remarkable Account of the Conversation between Marie Jeanne the Flowergirl and Jérôme the Ferryman at the Louvre Salon, While Examining the Pictures There on Display, Gathered and Presented by Mr. A.B.C.D.E.F.G.H.I.J.K.L.M.N.O.P.Q.R.S.T.U.V.W.X.Y.Z. etc., Optician to the Quinze-Vingts, Nowhere and Everywhere' (1787). ${ }^{4}$ Though not always obvious, and certainly not as flamboyant as in these cases, it is hard to imagine interesting art writing without interesting contextualization of some such kind.

For such a widely used term, 'context' is surprisingly resistant to being defined or employed with any kind of precision. Contexts in the broadest sense might simply be a concrete situation in which people have certain beliefs, interests, and purposes, according to the philosopher Robert Stalnaker's characterization of the standard 'informal' and 'intuitive' use of the term. ${ }^{5}$ In related artistic terms a context may simply be a 'reception situation' with its own 'prearranged interpretative spheres' for artwork and beholder, as the art historian Wolfgang Kemp puts it. ${ }^{6}$ In various academic disciplines that interpret cultural objects, however, 'context' has come to be more narrowly associated with original historical context, that is, with placing things back into the time and place in which they were created and first used. This historicist use of context developed from an earlier linguistic one also common in art writing, in which a word or passage is said to be made sense of through the 'context' of those around it. By the 1930s, art writers regularly referred to 'context' in terms of the original historical setting of artworks to be 'restored' by the art historian, the work of art itself now 'a fragment torn from the context of time'. ${ }^{7}$ Nonetheless, it was not until 1970s polemics around a new social history of art that the demand to place art 'in context' became a 'catchphrase' or basis of a 'new orthodoxy in the discipline'. ${ }^{8}$ By the early 1980s figures as different as the art historian Werner Hoffman, the historian of West Africa Marion Johnson, and the artist Rita Donagh could write of putting anything from one artist to an entire continent's art 'in context', safely assuming their readers would both know and accept the premise without question. ${ }^{9}$ According to the historicist-contextualist sense at work in all of these writings, contexts can be used to solve problems of ambiguity and intelligibility: in a minimal sense to delimit some parameters to the ways within which artworks can plausibly be said to have functioned when they were first made, and more ambitiously to ensure that our present-day encounters with those works can be accurately brought into line with the way they originally functioned.

That, at least, is the dream of historical context. Just as often, though, it has been attacked. One prominent instance in art history came 
from the poststructuralists of the 1980s and '90s, who pointed out that supposedly safe and stable 'historical contexts' were as much a product of interpretation as that which they were supposed to anchor. '[I]t cannot be taken for granted', Mieke Bal and Norman Bryson caution, 'that the evidence that makes up "context" is going to be any simpler or more legible than the visual text upon which such evidence is to operate. ${ }^{10}$ The elements that make up an 'original context' are open to interpretation, as are their connections to features of works of art. And even having decided on a secure context, we inevitably also 'retrofit', to borrow a term from Bruno Latour. ${ }^{11}$ Our best present-day accounts of the phenomena that make up a particular context (from the materiality of paint through to dynamics of economic structures and personal identities) will be used to make sense of it, leading to an account of an 'original context' updated with terms and concepts that would not have been explicitly recognized or used during the historical moment to which they refer. The most basic art-historical example of this is the retrospective use of stylistic labels literati, baroque, minimalist - that claim to label something real even though not described as such by actual artists of the time. But the process really pervades even the most historicist forms of contextualization, for we can never fully dispense with present-day accounts of phenomena when trying to make sense of the historical past.

Controversies around context should not make us abandon the term, let alone (as some have concluded) abandon all hope of historical understanding, but instead to be well aware of how contexts cut both ways. ${ }^{12}$ For the historicist-contextualist, contexts can be used to disambiguate, to make sure that artworks are not limitless and unruly, to make sure that we are not seeing in an entirely presentist way. But because contexts are used to make sense of works, it is equally true that their use requires creativity and is productive of new ways of seeing. In practice art writers of all stripes (however avowedly 'contextualist' or 'noncontextualist', 'historicist' or 'presentist') use contexts to say things about works of art.

\section{Contextualization from pre-set to saw-toothed}

It is a truism that the translation of visual artwork into words is a potentially endless activity. ${ }^{13}$ In Michel Foucault's famous terms there is an 'infinite relationship' between language and painting. ${ }^{14}$ Donald Davidson is drier, but no less telling: 
How many facts or propositions are conveyed by a photograph? None, an infinity, or one great unstatable fact? Bad question. A picture is not worth a thousand words, or any other number. Words are the wrong currency to exchange for a picture. ${ }^{15}$

Because of this, as writers on description in art history have long recognized, even the lengthiest and most seemingly thorough description of a work will only ever have picked out a certain number of features of that work, with interpretation inevitably focusing on that limited set of features. Other disciplines have acknowledged the point in their own ways. In relation to films David Bordwell has spoken of these features that form the basis of interpretation as 'cues', 'textual features', or 'units'. ${ }^{16}$ Analytic philosophy of art prefers to speak in terms of what can be done with the 'properties' of artworks. ${ }^{17}$ The important point here is that even a focus on a defined set of features of the work ultimately doesn't narrow down or delimit interpretation, as contexts can be used in interpretations to transform these apparently stable features in all manner of creative and unexpected ways.

A standard use of contexts in art writing, then, is in what might be called redescription. In this practice a feature of an artwork is described in relation to a context, in the process turning it into a more elaborate feature than it might otherwise have seemed. ${ }^{18}$ At its most obvious, redescription might pick out and describe a feature of an artwork, then introduce the context and subsequently redescribe that feature, a process I call saw-toothed contextualization. But at the other end of the spectrum the context may have been already introduced - sometimes so carefully that the reader will barely notice - so that what seems like an initial description is already a contextualized redescription. In this case we might say that contextualization is 'pre-set'.

In La Font we have already seen the use of pre-set contextualization. In this mode at its most obvious the writer will open with an extensive contextualizing discussion. The writer can then give the impression that they are simply describing the artworks they deal with in an entirely natural way. The fact that they are really being interpreted in light of the context remains only implicit. The mode is extremely powerful in that it gives a sense of offering mere description, of seeing the works as they simply are, while all the same quietly shaping the works in the service of that writer's particular goals. The technique is one employed by writers who are often thought to disavow contexts just as much as those who openly embrace contexts. Reading avowedly contextualist writings like the early Marxist art histories of Friedrich Antal and Arnold Hauser, we 
might be well aware that every artwork will be interpreted as a clear outcome or 'reflection' of the foregiven context of economic structure and class struggle: the 'monumental naturalism of Massaccio' with its 'emphasis on the clarification of spatial relationships and proportions' shows the reaction of the emergent 'plain and industrious' bourgeoisie against the late-Gothic decorative exuberance favoured in contemporary aristocratic taste (Fig. 3.3). ${ }^{19}$ Such precontextualization can be equally obvious in the case of the philosophizing art critics of the same moment, as when the philosophical position of Herbert Read or Jean-Paul Sartre just so happens to translate perfectly into the work. ${ }^{20}$ But exactly the same moulding of artworks to fit personal views can be true of the 'formalist' writers allegedly focused on strictly artistic and visual concerns. Alois Riegl, or Roger Fry, or Clement Greenberg, are as likely to rely on a general contextualizing discussion of forms of viewing, or a particular kind of attention to pictorial space, or the artistic challenges raised by earlier artworks, which then animates everything they have to say about the works of art they go on to deal with. ${ }^{21}$

The use of context is even more obvious in the inverse of precontextualization, 'saw-toothed' contextualization. This technique is a parallel to the form of history writing Roland Barthes termed 'zig-zag or saw-toothed history', in which the historian jumps back in time from new elements in the narrative to give their prehistory, before continuing where they had left off. ${ }^{22}$ In the case of art-historical interpretation writers will present a feature of the work, then go back to offer a contextualization of the feature. Redescribed in light of the context the initially confusing feature turns out to solve an apparent interpretative problem. Pointing out that figures and scenes around the edges of texts in the Freer Divan of Sultan Ahmad Jalayir have no clear connection with the text, an interpretation moves back to discuss manuscripts on 'so-called Chinese painted paper' with tinted and gold-painted leaves, suggesting the influence of China on a new and purely decorative relationship between text and image seen in subsequent years in Timurid, Safavid, Ottoman, and Mughal manuscripts (Fig. 3.4). ${ }^{23}$ Noting that 'the black man is dressed more fashionably than the others' and his gesture 'contrasts sharply' with the actions of the crew, an interpretation of John Singleton Copley's Watson and the Shark turns to a ten-page history of American connections to the slave trade and the abolitionist movement that 'gave particular meaning to Copley's picture'. ${ }^{24}$ The sparse wooden chair in Édouard Manet's illustration of Edgar Allen Poe's Le Corbeau, which seems to contradict the stuffed velvet seat of the verse, leads another interpretation into an intricate discussion of the very possibility 


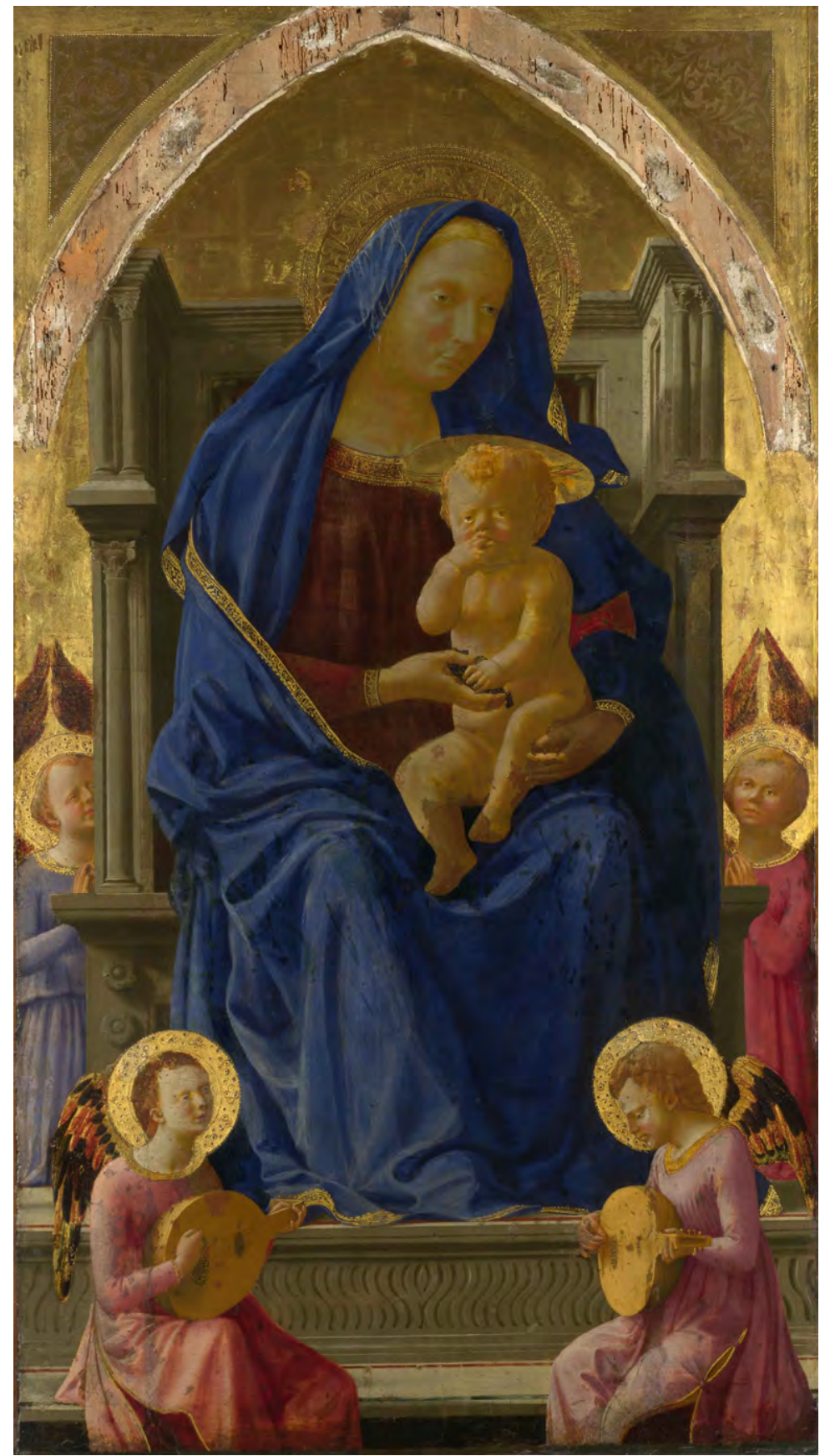

Fig. 3.3. Masaccio, The Virgin and Child. Egg tempera on wood, c. 1426, $134.8 \times 73.5 \mathrm{~cm}$. National Gallery, London. 


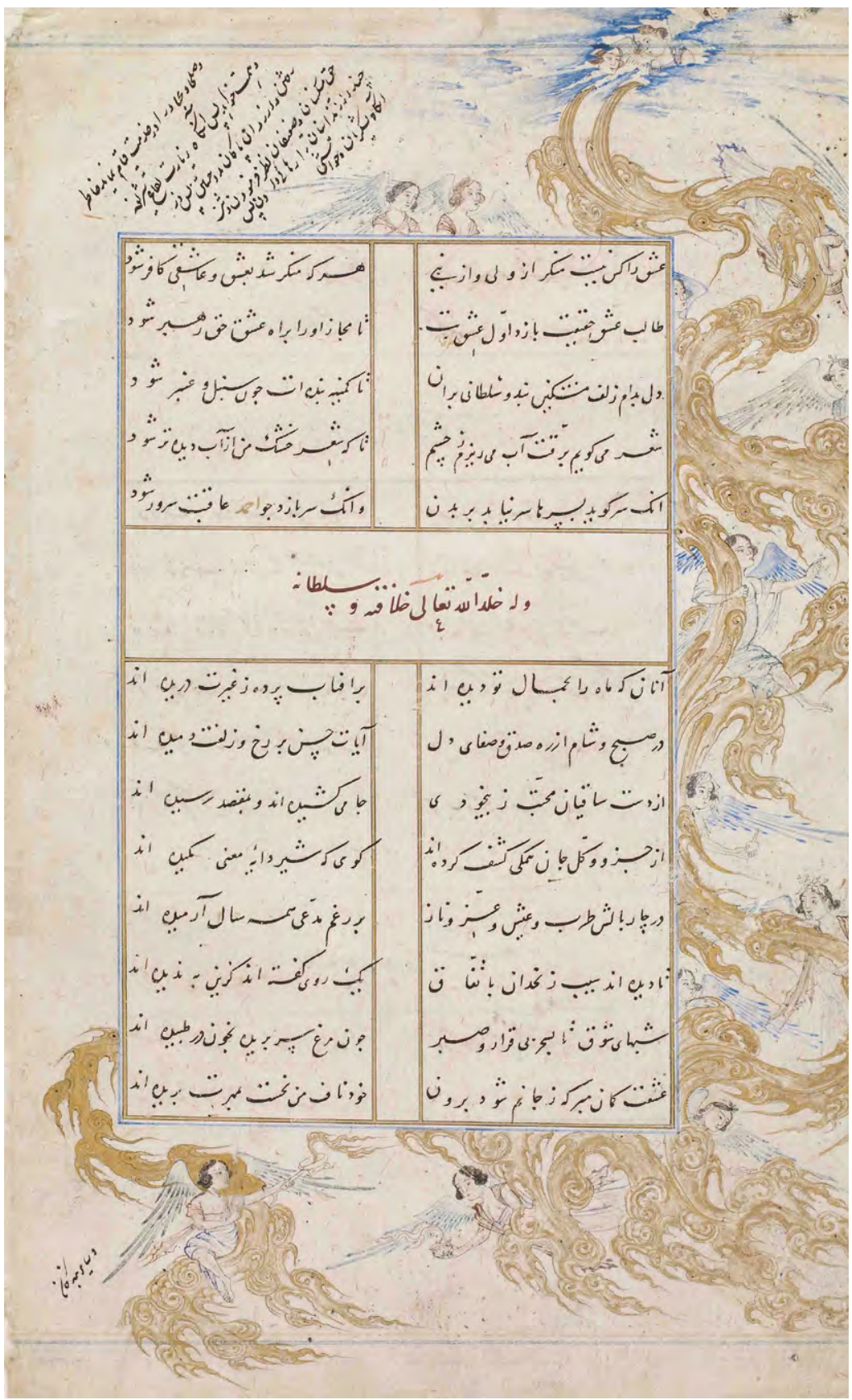

Fig. 3.4. Folio from a Divan by Sultan Ahmad Jalayir (Angels Amidst Clouds), c. 1400 . Ink, colour and gold on paper, $29.5 \times 20.4 \mathrm{~cm}$. Freer Gallery of Art. 
of private language and meaning as raised not just by philosophers later in the century but also by Poe and by Manet in this artwork. ${ }^{25}$ The 'actual kidnappings' that unexpectedly resulted from Marta Minujín's staged but chaotic Kidnappening performance leads an interpretation back to Argentina's 'worsening political situation' in the early 1970s that included the deadly clashes at Ezeiza airport upon Juan Peron's return from exile in June 1973, just one month before Kidnappening took place, the artwork's contemporary 'connotations' depending on its reproduction of the threat of violence within what was ultimately the safe space of institutional structures (Fig. 3.5). ${ }^{26}$

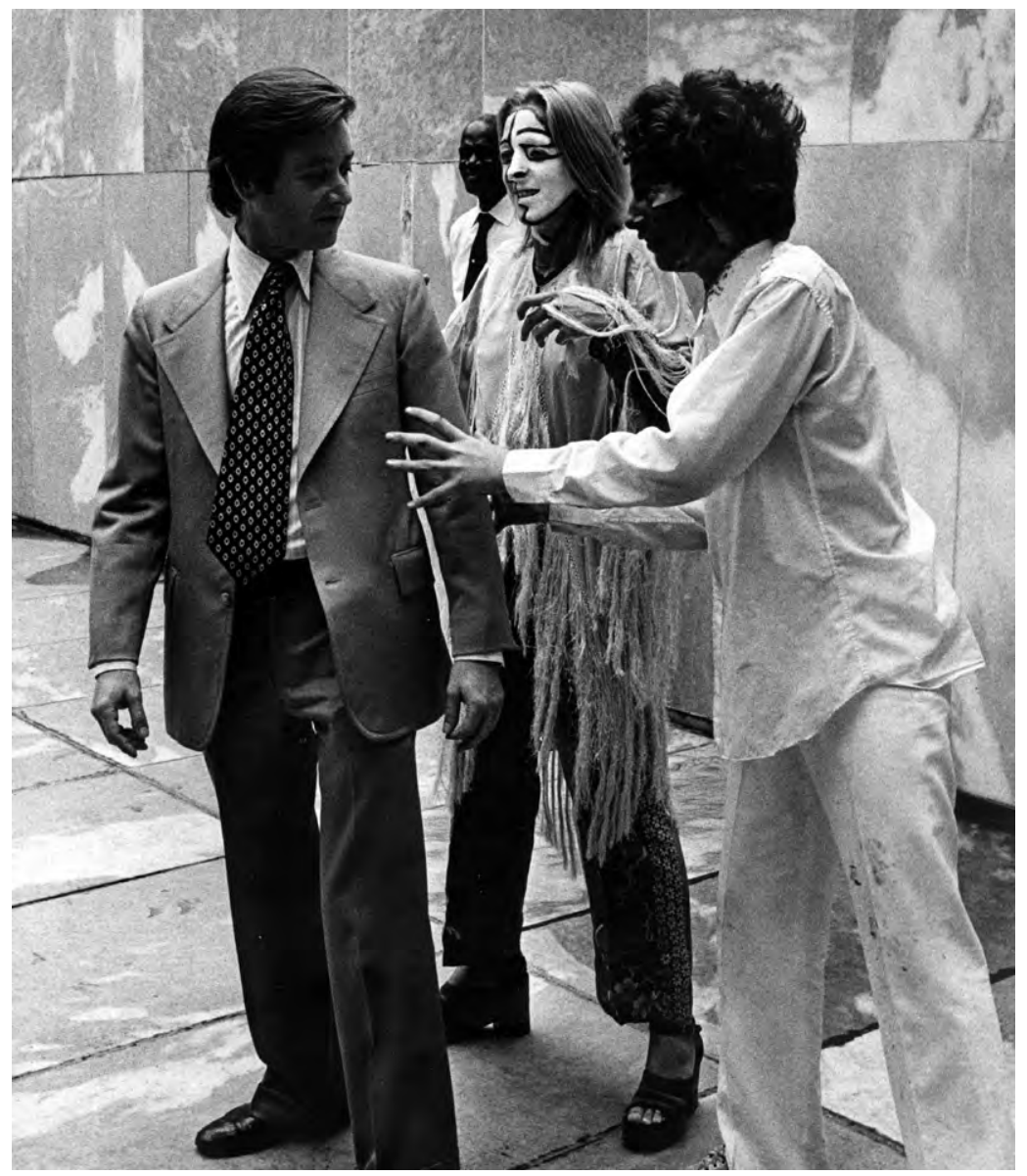

Fig. 3.5. Marta Minujín, Kidnappening, 1973. Performed at the Museum of Modern Art, as part of the Summergarden programme, August 3 and 4, 1973. Courtesy of the Marta Minujín Archive, Buenos Aires. 
Saw-toothed history is a venerable technique that Barthes noted as far back as Herodotus, but saw-toothed contextualization has found especial popularity in the writing of later-twentieth-century academic art history (regardless of subject matter or place of publication). ${ }^{27}$ Thomas Crow could write in 2006 that every single article published in the Art Bulletin, then the major art history journal in the US and arguably the world, ultimately was an example of the social history of art whether it acknowledged it or not. ${ }^{28}$ But such a generalization really depends on the equation of contextualization with social history. It would be more accurate to say that the majority were dependent on saw-toothed contextualization, as an increasingly standardized mode for how academic art history deals with its images. It should all the same be stressed that 'pre-set' and 'saw-toothed' are abstractions at two notional poles of a spectrum. The two strategies alternatively lean towards contextfirst or feature-first forms of redescription, but they are alternated between and combined over the course of most interpretations rather than found in strictly isolated or 'pure' form. Friedrich Antal's Florentine Painting and its Social Background, for instance, practises pre-set contextualization in spending four chapters on matters of economic, social, cultural, and intellectual history before finally turning to chapters on art. ${ }^{29}$ But it also practises saw-toothed contextualization in immediately opening with a comparison between paintings by Masaccio and Gentile da Fabriano that leads from the works to a contextualization that will make sense of them. Both strategies, ultimately, are variations of the same basic operation of using context to do things with works of art.

\section{Reconstruction and context as plausible limit}

Things remain relatively under control when art historical interpretation aims at reconstruction of how artworks might once have been for makers and users in the past. Here, interpreters have to reason both for themselves and in dialogue with others. The key test of a context is simply whether, assessing the artwork in the present together with knowledge of the resources available for making and using artworks within its particular culture, the context seems like it would have significantly impacted how the artwork was experienced and understood by its past makers and users. Vague as it is, this way of describing the test nonetheless raises two very specific issues. First, in reconstructing artworks in particular contexts we are always dealing with plausibility rather than proof. Because we are inevitably inferring based on only partial evidence there is no possibility 
that 'proof' could be found for any one context, however convinced we might be, and no hope of assembling a complete set of contexts that would fully and finally place the work of art 'back' into its original surroundings. And second, our sense of what is plausible will depend on our own general theories (even if intuitive and never actually articulated) of how broadly contexts might come to affect how people engaged with works in the past - essentially our own view of what it is or was to make and to experience a work of art. We see this as clearly as anywhere in the model of art-historical 'reconstruction' or 're-enactment' offered by Michael Baxandall, held up in recent times as 'a kind of ideal of art history as it has fashioned itself in the past 40 years', his reflections - as one prominent art historian has recently written - 'map[ping] out what many art historians (certainly in my acquaintance) think about their practice, and would likely say themselves if they had his "extraordinary rhetorical alertness", 30

In this model, artworks are to be treated as concrete responses to particular problems in particular circumstances. The art historian works by reconstructing the problem faced by the artist, the resources available within the 'culture' of the time, and a verbal description of the work of art itself. ${ }^{31}$ Our developing sense of artist, culture, and described artwork are continually set against one another, allowing the interpreter to reason about what in the past was 'conceptualizable' in conformation with all three (Fig 3.6). Baxandall gave as his primary example the work carried out by Benjamin Baker on the Forth Bridge. For this Baxandall drew up a group of contexts or 'ranges of resources offered the agent' that divided roughly into issues around medium, available models, and aesthetics: such as the need for the bridge to resist side winds, the new availability of steel, and Baker's statement of his own 'expressive functionalism'.

Yet in laying out the model Baxandall elsewhere pushed at the limits of plausible reconstruction, as when he connected the empiricist philosophy of John Locke and the painting of J. S. Chardin, in a case used to 'discuss how far we can think ... about relations between the visual interest of pictures and (taking the extreme case) the systematic thought, science or philosophy, of the culture they come from' (Fig. 3.7). In discussing Chardin's Lady Taking Tea, Baxandall took certain visual oddities in the painting as a spur to look closer into the puzzle of 'Distinctness', as 'one corner of an eighteenth-century web of preoccupation with Lockeanism'. Baxandall had no relevant statements from Chardin to draw on, and rejected art criticism as an entirely unhelpful guide to how the works were seen at the time. ${ }^{32}$ Perceptual issues of focus and visual attention, Baxandall nonetheless concluded, were ordinary enough in Chardin's general culture and in the concerns of 


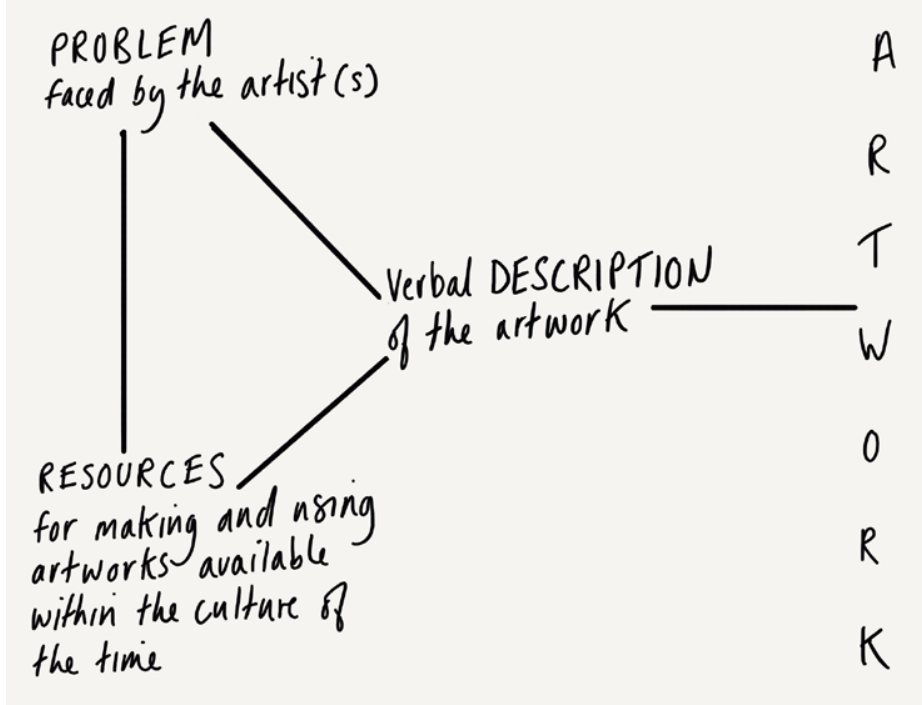

Fig. 3.6. Context as Plausible Limit: Michael Baxandall's 'triangle of re-enactment'. Illustration: Alice Feaver. CC BY-NC 4.0.

artists that they could reasonably be supposed to be resources that a painter might draw on. Importantly the pictorial traditions and contemporary artistic discourses of interest to Chardin also provided specific artistic means to engage with these perceptual issues, so that they might genuinely claim to have affected the look of the work.

In the case of the Forth Bridge we see a fairly obvious and secure sense of the resources available within the given culture, 'artistic' and 'technical' as they mostly were. In Chardin we are dealing with concepts that, according to Baxandall, had widespread cultural currency in the eighteenth century and which we can therefore read into paintings, even if we can only link them indirectly to the artist's frame of reference. The controversial nature of the Chardin demonstration reminds us why art history has often stuck to more obviously 'artistic' contexts as closely as possible. As one sceptical writer expertly summed up the problem: 'The fact is that theories about the visual world, even new ones energetically debated, need not have any great impact on how we see, or how we usually feel about that world', and furthermore that perhaps this desire for an exciting context had led the art historian to ignore the 'qualities ... central to the art he is writing about'. ${ }^{33}$ If we're after ways that the artwork was taken by makers and users in the past, would we not prioritize things 


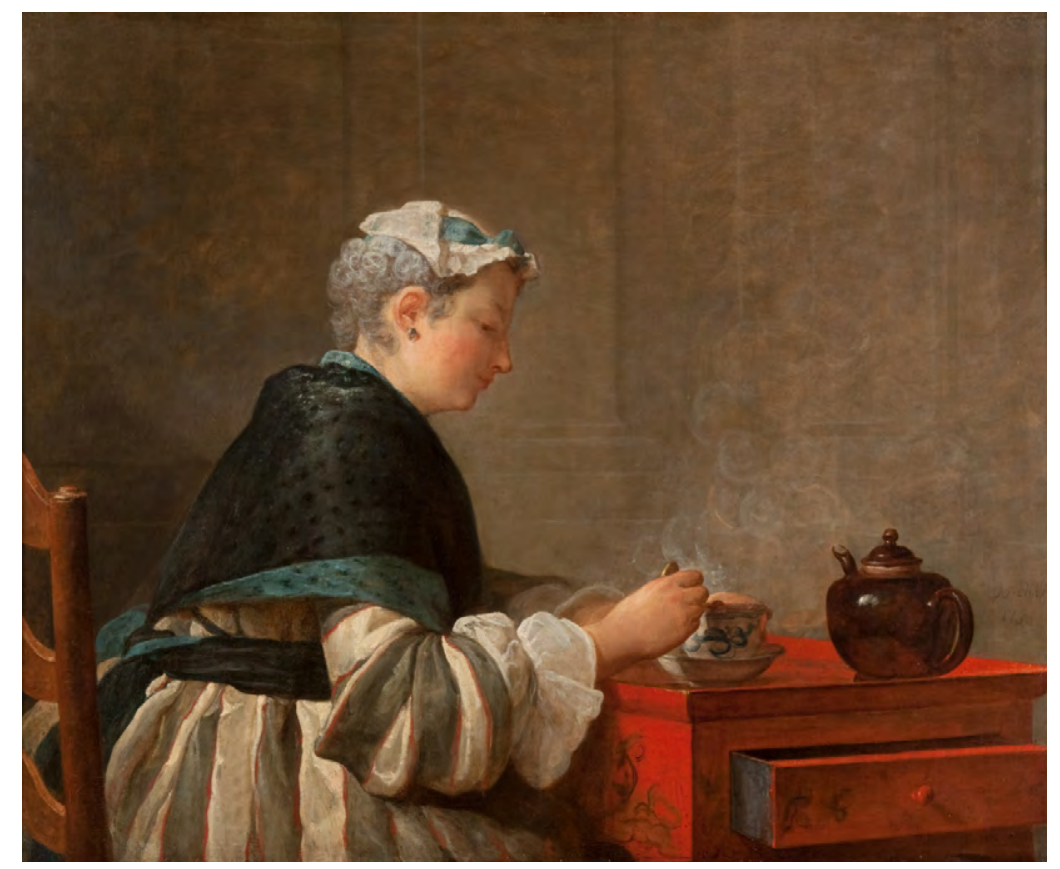

Fig. 3.7. Jean-Baptiste Siméon Chardin, A Lady Taking Tea, 1735. Oil on canvas, $81 \times 99 \mathrm{~cm}$. Hunterian Art Gallery, Glasgow.

obviously central to the taking of the work, and would that not be the visual, artistic, and technical contexts that unarguably connect to how the work was made and seen?

As we see throughout the present book, the move beyond the most obvious 'art' context or contexts is a perennial feature of interesting arthistorical interpretation. Nonetheless, ways of cutting this cake are one of the major historical dividing lines between schools of art history. Different art historians have often drawn attention to different features of works of art depending on their preferences: style for one, subject matter for another. But even more important is the way that different thinkers have come down on the question of what cultural resources could have been used by the artist to make the work look and be experienced a particular way. What contexts, that is, meaningfully show up in the way that the artwork was for makers and users in the past? ${ }^{34}$ This is the ground contested by 'theories and methods', even if we might not always acknowledge it: differing claims about which historical and conceptual information should be prioritized as determinant of an artwork's proper 'context'. 
All of this provides at once the basic starting point for, and challenge to, novel art histories: how to show that contexts (race, ecology, materiality) not only did show up for makers and users at the time, but could conceivably have been powerfully important for how the works in question were taken. It also poses an ethical quandary for those who desire to push an overarching context in the name of committed or interesting interpretation, for the same creativity that can use a 'theory and method' to see something new in a work can just as well serve as a homogenizing tool that screens out so much else that might be there to be seen and said. Trading in examples such as the prevalence of Lockeanism in the eighteenth-century perception of interior scenes can distract from the seriousness of the point, as can be seen by briefly shifting focus entirely to a case in more recent artistic production. Talking of 'what we call "black art" in the United States', Darby English has drawn attention to how interpreters of the work of African-American artists have again and again assumed that so-called 'black art' must be addressed solely through the lens of race. Ignoring actual intentions and informing contexts, even well-meaning interpreters thus end up engaging in a kind of 'tactical segregation': filtering the work through what they take to be a 'foreknown certainty such as "the black artist" or a "black experience", and in doing so reducing unique work after unique work to 'another homogenizing reflection of African-American culture'. ${ }^{35}$ This is a dramatic reminder that new - and even apparently or at one point politically progressive contextualization can soon become a troubling habit, controlling what is said about artworks in ways that long passes without notice.

\section{Depth reconstruction and context as limit without limits}

Contexts are necessary to fix the identity and key features of works of art at particular moments. ${ }^{36}$ But can there be a limit to which contexts are brought to bear in interpretation? The writers and artists of the earlyeighteenth century who worried about the shifting nature of pictorial meaning were dealing with what they took to be at least resolvable cases of ambiguity: with a change of title the artwork presented one definite facial expression or person or story rather than another. Yet as the doctrine of art as a reflection of its time took hold over the course of the first half of the nineteenth century, such clear cases of ambiguity seemed to shift into almost limitless plurality. ${ }^{37}$ Of the many figures linked to this change - from Winckelmann through to Goethe and on to Ruskin and 
Michelet - none was at once as direct and as potentially expansive as Hegel, in whose famous formulation,

World history represents ... the evolution of the awareness of spirit of its own freedom ... Every step, being different from every other one, has its own determined and peculiar principle. In history such a principle becomes the determination of the spirit - a peculiar national spirit. It is here that it expresses concretely all the aspects of its consciousness and will, its total reality; it is this that imparts a common stamp to its religion, its political constitution, its social ethics, its legal system, its customs but also to its science, its art and its technical skills. These particular individual qualities must be understood as deriving from that general peculiarity, the particular principle of a nation. Conversely it is from the factual details present in history that the general character of this peculiarity has to be derived. ${ }^{38}$

In Ernst Gombrich's admittedly tendentious analysis, Hegel's influence authorized a programme for interpretation in the history of art that could be visualized by a wheel with 'spirit' at the centre ringed by concrete manifestations in art, religion, science, laws, technology, and so on (Fig. 3.8). ${ }^{39}$ Because everything found on the periphery were ultimate realizations of the same central spirit, any one part of the wheel might be traced in to the centre and back out again. All art, that is to say, might be seen to inevitably reflect the 'spirit' at the heart of the society or the age. But as all other parts were also reflective of that spirit, perhaps

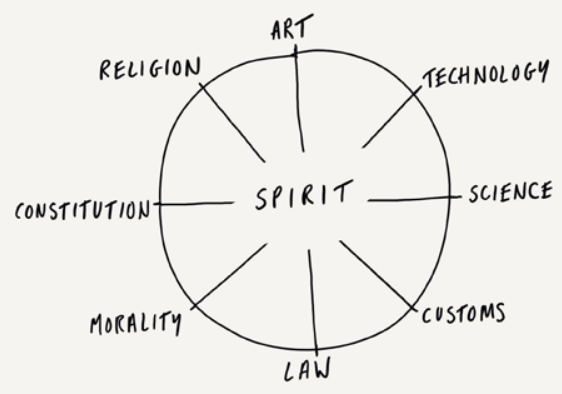

Fig. 3.8. Context as Limit without Limits: 'Hegel's wheel' according to E. H. Gombrich. Illustration: Alice Feaver. CC BY-NC 4.0. 
interpretation could, even without explicit evidence, draw on all things on the periphery - religion, science, laws, technology, and so on - as part of the expanded 'context' through which works of art should be understood. As such contexts worked at a level far beyond the individual, there was also no need for any one person in the past to have consciously experienced or acknowledged works as such, in order for interpretation to proceed.

This is art history's game of contexts in an expanded sense, a step beyond reconstruction that might be termed 'depth reconstruction'. With depth reconstruction it is asserted that things really were experienced or understood or simply were a certain way for people in the past even though no one was able to know or acknowledge them as such at the time. We see it in the more offhand speculative moments of interpreters across the history of art, as when Vasari links the revival of Italian art to the climate, or Berenson the quality of Venetian painting to the city-state's oppressive system of government. But it is equally seen in more scholarly form in much art history, foregrounded in early-twentieth-century histories written in Germany, Hungary, and Austria in particular, but continuing right through to the present day. In all such cases the interpretative method is to analogize and allegorize, searching for structural likenesses between artwork and its effects on the one hand, and the time and place of its creation on the other. In practice this means drawing connections between features and broader contexts that are aesthetically and rhetorically satisfying to the interpreter and their readers. Gombrich himself called this the 'exegetic' mode, referencing general likeness of the type that would see a connection between the Israelites passing through the Red Sea and the Baptism of Christ. David Summers later spoke of interpreters making 'physiognomic inferences from presumably expressive form', so that they might move smoothly from artwork to historical minds and worldviews: from the 'elongated linear forms and nondescriptive colours of mannerist painting' to the 'psychological extremities' of Pontormo and Rosso Fiorentino, to the 'anguish and spiritual crisis' brought on by the 'Sack of Rome, the Siege of Florence, and the Reformation'. ${ }^{40}$ But it is worth stressing that interpreters can analogize between a vast range of things on the artwork side as much as the contextual one: basic represented features and forms, of course, but also complex forms of pictorial structure, and even complex forms of pictorial effect. The risky flight and crash of Icarus depicted by Bruegel, suggests Meyer Schapiro in a simple instance, echoes the risks of financial speculation in the mid-sixteenth-century Low Countries (Fig. 3.9). ${ }^{41}$ But Hans Seydlmayr suggests, with a characteristic focus on 
structural features, that the figurative elements of Bruegel's paintings, if looked at closely, 'begin to disintegrate' into a pattern of colour patches that 'lie unconnected and unordered'. '[W] hat has become representable' in the disorder and related 'estrangement' of these works, he writes, 'consciously cultivated by Bruegel', is 'the very structure of a mad world'. ${ }^{42}$ Building in even more complex forms of effect, Alois Riegl suggests that Dutch group portraiture's open and beholder-soliciting compositions elicit a 'performative attentiveness' from the spectator that implies 'the partial dissolution of the self-contained ego necessary for sympathy and community without coercion' (Fig. 3.10). This openness of work and effect gives pictorial form to the democratic and relatively humanistic religious conditions of the Dutch republic of the time. ${ }^{43}$

Whatever aspect of the artwork it is that the interpretation appeals to, because the analogies found through the experience of the artwork are satisfying to the interpreter, such interpretation easily disavows its highly partial, contingent and speculative character. Writing on Bruegel, Schapiro appealed to composition and narrative in connection with social history, Sedelmayr to formal structure in connection with recent arthistorical commentary and the thought of Benedetto Croce (not to mention his general absorption in Nazi ideology), but both insisted they had seen the picture in its true light. Even Ruskin, making some of the most creative analogies in the history of art, such as that between the shifting style of Venetian architecture and the declining morals of its ruling inhabitants, was insistent that he relied not on external documentary matter but on the 'irrefragable' nature of the 'internal evidence' of works of art. ${ }^{44}$ At this level contextualization is cheap. Artworks and their features are malleable things that with some rhetorical skill can easily be allegorized in these new terms. ${ }^{45}$ But as we've seen already in 'mindreading narration', and will see again in Chapter 6's section on 'resurfacing', interpreters often find it hard to resist moving from presently satisfying analogy to definite claim about the past.

There is a further step possible. According to a long-standing view, 'explanation' in historical and social scientific method involves that which goes beyond any necessary connection to the perspectives of the persons involved: in the terms above, beyond those of the original makers and users of an artwork (beyond even, that is, the most limited sense claimed in depth reconstruction).$^{46}$ When working at this level of analysis, the most expansive game of contexts, there is very little about the work of art itself that can limit the use of a context: it doesn't matter if the context was consciously available to makers or users, let alone whether it was 


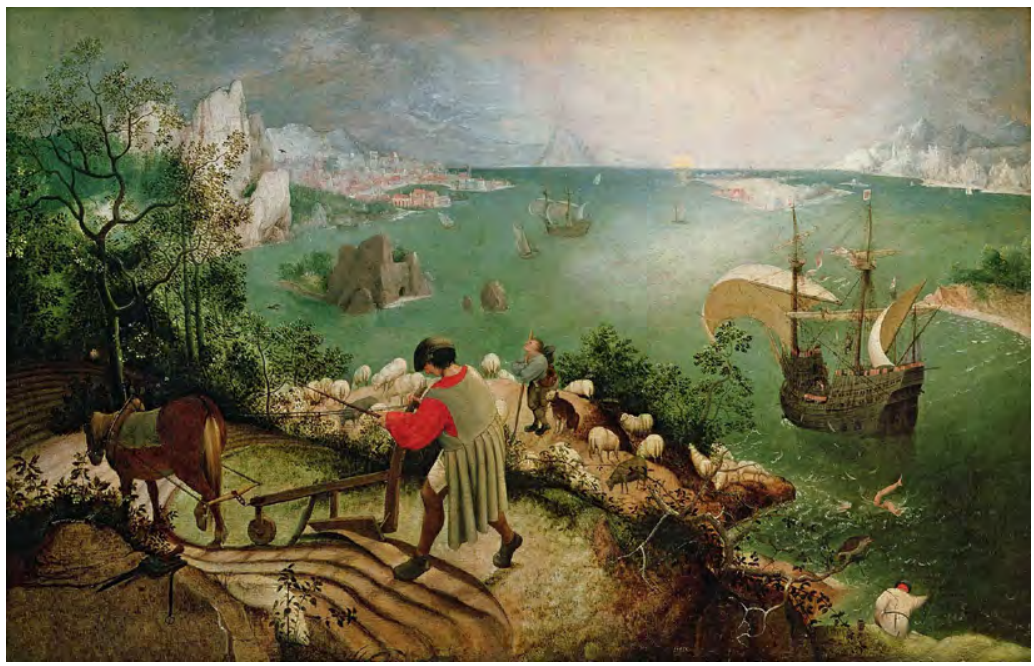

Fig. 3.9. Pieter Bruegel (attributed), Landscape with the Fall of Icarus, c. 1560 . Oil on canvas, $73.5 \times 112 \mathrm{~cm}$. Royal Museums of Fine Arts of Belgium, Brussels.

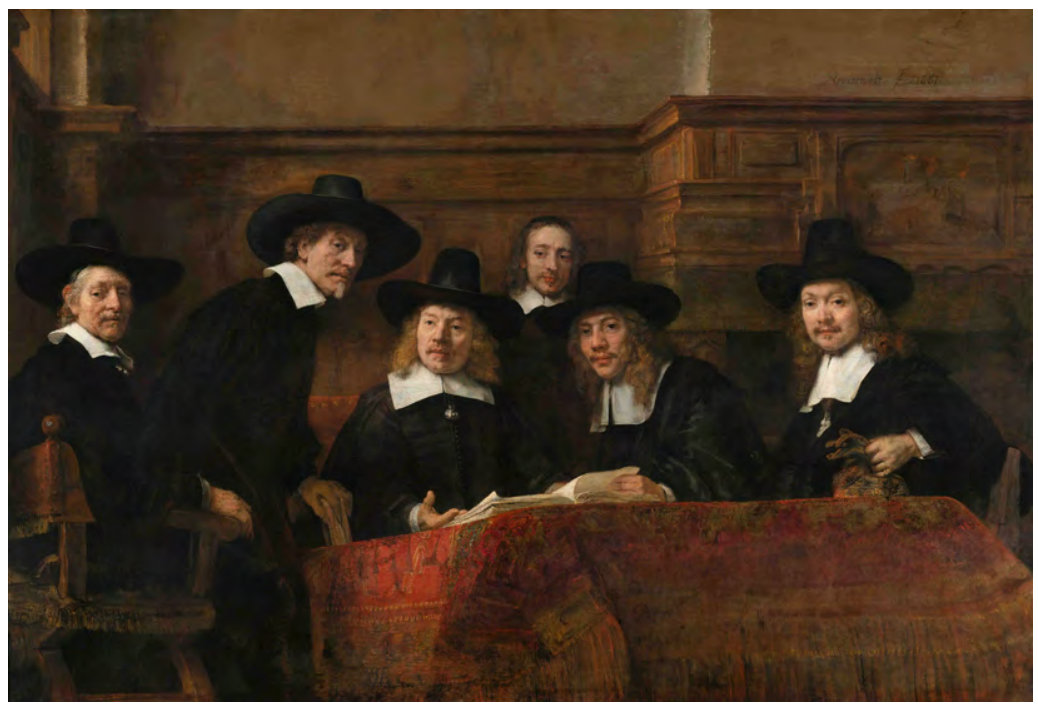

Fig. 3.10. Rembrandt van Rijn, Syndics of the Draper's Guild, 1662. Oil on canvas, $191.5 \times 279 \mathrm{~cm}$. Rijksmuseum, Amsterdam. 
acknowledged by them. And it also doesn't matter if the context is one that might have 'shown up' in the experience of the work in the past - that is, had a significant role in determining the experience of the work at any point in its history. To operate at this level places strict demands on the grounds of the interpretation because in order for the interpretation to hold historically, the context must be historically or theoretically correct. If historical, it must have definite causal connection to the work's significant features, and if theoretical, it must be true at least for that period if not universally. If the interpretation is not going to hold historically or theoretically, conversely, then the interpreter must have a real sense of why it is interesting or useful to show that, given present-day interpretative resources, it is possible to allegorize one or another artwork in the particular manner set out. This may be the reason why recent Western art history has tended to limit itself to an extraordinarily narrow set of areas from which to gather explanatory theoretical resources, knowing that psychoanalysis or semiotics, for instance, are more likely to be accepted than others such as experimental psychology or sociobiology. The problem of the value of quasi-historical allegory, meanwhile, is largely avoided by art historians who wish to maintain the discipline's uneasy quest - discussed again in Chapters 5 and 6 - to maximize the artwork (whether in terms of value, utility, interest or complexity) while at the same time claiming historical truth. These are problems the history of art has never quite faced down, even though the deepest claims for the importance of history of art as a discipline surely require them to be reckoned with.

\section{Notes}

1 La Font de Saint-Yenne, Oeuvre critique, 49-59.

2 Haskell, History and Its Images, 147-50.

3 Here as elsewhere I draw on the work of Bernadette Fort, including her stunning article 'An Academician in the Underground'.

4 Fort, 'Voice of the Public', 373, 376.

5 Stalnaker, Context, 14.

6 Kemp, 'The Work of Art and Its Beholder', 184-5.

7 Anon, 'Editorial: The Duveen Sculpture Galleries'.

8 D'Alleva, Methods and Theories of Art History, 46; Crow, 'Codes of Silence', 2.

9 Donagh, 'Georgia O'Keeffe in Context'; Johnson, 'Art in Context'; Hofmann, 'Picasso's "Guernica" in Its Historical Context'.

10 Bal and Bryson, 'Semiotics and Art History', 176.

11 Latour, Pandora's Hope, 170-3.

12 The degrees of scepticism all the way down to the call for abandonment are brought out clearly in Stejskal, 'Aesthetic Archaeology'.

13 Shapiro, 'The Absent Image: Ekphrasis and the "Infinite Relation" of Translation'.

14 Foucault, The Order of Things, 9. 
15 Davidson, 'What Metaphors Mean', 47.

16 Bordwell, Making Meaning.

17 A particularly thorough recent analysis, also picking up on Davidson's hints in order to elaborate on the metaphorical structure of art writing, is given in Grant, The Critical Imagination.

18 Rose, 'Close Looking and Conviction', 167-72.

19 Hauser, The Social History of Art, 29-30 (Vol. 2), echoing the analysis in Antal, Florentine Painting and Its Social Background.

20 As in Read, Henry Moore: A study of his life and work; Sartre, 'The Search for the Absolute'.

21 As in Riegl, The Group Portraiture of Holland; Fry, Flemish Art: A critical survey; 'American Type Painting', in Greenberg, Clement Greenberg, 208-22 (Vol. 3).

22 Barthes, 'Le discours de l'histoire', 67.

23 Sturkenboom, 'The Paintings of the Freer Divan of Sultan Ahmad b. Shaykh Uvays and a New Taste for Decorative Design'.

24 Boime, 'Blacks in Shark-Infested Waters', 22-36.

25 Pop, A Forest of Symbols, 69-73.

26 Spencer, Beyond the Happening, 113-16.

27 Though of course with many precursors. The iconographic interest in explaining particular motifs is one, as is the idea in hermeneutics that a text or work of art might have a particular feature around which all other elements unite or unfold.

28 Crow, 'The Practice of Art History in America', 86. James Elkins wrote at the time that 'Most scholarship, I think, still takes iconography as its principal or default model', Elkins, 'Art History as a Global Discipline'. In both cases what seems to underlie the scholarship being referred to is the more general phenomenon of saw-toothed contextualization.

29 Antal, Florentine Painting and Its Social Background.

30 Baxandall, Patterns of Intention; Whitney Davis, 'Art History, Re-Enactment, and the Idiographic Stance', 71.

31 Quotations in this and the following paragraphs are from Baxandall, Patterns of Intention, 15-40, 74-81.

32 ' $[\mathrm{O}] \mathrm{ften}$ much more a minor literary genre ... affected by generic constraints and suggestions of a quite literary tradition and mode', Baxandall, 81.

33 Penny, 'Momentary Substances'.

34 Art historians, it should be said, have often been reluctant to engage perceptual psychology from any moment later than the mid-twentieth century in attempting to answer this question, tending to assume that perception is entirely permeable to knowledge rather than thinking through the specifics of how and to what extent this can be the case. Some further comments and brief nods towards possible future directions can be found in Rose and Nanay, 'On Perception'.

35 English, How to See a Work of Art in Total Darkness, 2-11. As he also writes, 'The routine submittal, over time, of black artists' work to prefabricated questions and uses can be looked upon as a repressive regime targeting the work's right to difference.' (9).

36 The dynamic of control and potential loss of control provided by contexts is widely recognized across art history, literary studies, and philosophy of art, as in Bryson, 'Art in Context'; Colin Davis, Critical Excess, 175-6; Matheson and Caplan, 'Fine Individuation'.

37 Francis Haskell points to the 1840s, with the popular reception of Hegel and the writings of Ruskin and Michelet, as the key moment in a process that stretches back to before Winckelmann; Haskell, History and Its Images.

38 Hegel, 'Vorlesungen über die Philosophie der Geschichte', in Sämtliche Werke, 508 (Vol. 11).

39 Gombrich, Ideals and Idols, 24-59, especially 30-2.

40 Summers, 'Form and Gender', 243-4.

41 Shapiro developed the analysis in lectures over a number of decades, as discussed in O'Donnell, Meyer Schapiro's Critical Debates, Chap. 2.

42 'Bruegel's Macchia', in Wood, The Vienna School Reader, 325, 335.

43 Riegl, The Group Portraiture of Holland, as analysed in (and with quotations from) Iversen and Melville, Writing Art History.

44 Ruskin, The Works of John Ruskin, 22-3, 4 (Vol. 9), as broadly discussed in Haskell, History and Its Images, 309-30.

45 Whitney Davis, 'Finding Symbols in History'; Elkins, On Pictures and the Words That Fail Them; Elsner, 'Art History as Ekphrasis'; Rose, 'Close Looking and Conviction'. 
46 Roth, 'Explanation'; and more broadly Roth, The Philosophical Structure of Historical Explanation. As Roth also notes, however, the distinction has been repeatedly attacked since the heyday of logical positivism. This is not the place to explore the suggestion, but ultimately it may be that most art history functions by 'narrative explanation' in the way that Roth and others have argued of mainstream history. This would also help explain Baxandall's opting for the term 'explanation' as opposed to interpretation or understanding, effectively attempting to bridge the gap through an equation of art-historical interpretation and understanding with narrative or 'idiographic' explanation. 


\section{4 \\ Reception}

To talk of reception is to be reminded that artworks are not fixed by their maker and initial moment of creation. Artworks may have a greatly mixed reception even in their 'original' context. And artworks have long histories of use in new contexts, right through to our own context when looking at the work in the present day. The task of charting the complex, multilayered meanings accrued by an artwork over time - what we often call its 'reception history' - is ostensibly core to the writing of art's histories. How, then, have reception histories transformed the way artworks are interpreted in the history of art?

Less than we might expect, this chapter suggests, although I will discuss in closing some meaningful exceptions. Writers have long noted rival interpretations past and present while setting out their own, and some do offer accounts of the reception of works by a defined set of users in a particular period. For the most part, however, reception histories are used quite differently from how we tend to think of them. They are typically employed in the service of further art-historical interpretation in a more traditional sense: the reconstruction of how artworks were seen and used at the time they were made. Scholars use later contexts of reception, but claim an originary historicist reconstruction as the result. As with many things, this use of reception to better interpret what artists once did goes back at least to Vasari's Lives, in which we are repeatedly told of the use made of one artist's work by another so as to mutually illuminate both. Just as in some of the best recent art histories that have foregrounded reception, these are reception histories of work as it was taken up by artists at a later moment, a story of reception that is woven into a story of original creation of new works by artists. ${ }^{1}$

Folding an artwork's later reception back into its originary meaning might be termed 'reception as origin'. This use of reception as origin is rarely noted explicitly in discussions of art history, but is in fact by far the 
most common use of reception in interpretation in the history of art. In the terms of actual hermeneutics-based 'reception theory', as it developed in later-twentieth-century Germany, it has been noted that art history has been closer to the views of Wolfgang Iser than those of Hans Robert Jauss: not (on the model of Hans-Georg Gadamer taken up by Jauss) assuming understanding to be a 'continuing historical process' that evolves over time as a negotiation between artwork and shifting forms of reception, but instead closely examining artworks for the cues that allow the historian to reveal the true form of reception embodied in the 'implied beholder' of the work. ${ }^{2}$ And as is made clear in its theorization by Iser and others who have developed similarly phenomenological approaches in the present, this latter kind of use of reception in thinking about how artworks, seen properly, also originally would have been, is less counterintuitive than it might seem. ${ }^{3}$ In Chapters 2 and 3 we have already seen that the artist can never be trusted to tell us about their own work in a definite or final sense. But not only are we still interested in how the artist might have engaged with their work, but a better route to this than asking the artist may be broader investigation of what was possible within the cultural practice they worked in: what might have shown up in works of art of that kind for makers and users at the time? The philosopher Robert Pippin sums up the basic point by suggesting that yes, we are interested in what some might call 'intention', but only in the sense that this is publicly available. We go at this precisely not by going to the artist, let alone seeking out their mental state. Intention is found by looking to the evidence of the artwork itself, imaginatively placed within its reconstructed 'historical world'. ${ }^{4}$ This in a similar way raises the possibility that the use of the artwork beyond its moment of creation, its display and reception by multiple audiences after that instant, might after all be used to tell us about the original work, including the work as it was taken to be for or by the artist. In this chapter I set out three overlapping modes of emphasis this can be given: 'recorded reception as origin', in which an actual recorded reception of the work is used to indicate how it originally would have been engaged with; 'visual practices as origin', in which evidence of past visual practices are used to imaginatively reconstruct the way that the artwork would originally have been engaged with; and 'depth reception as origin', in which recorded reception is acknowledged but treated with suspicion, only ever a partial clue to forms of engagement with the artwork that no one in the past would have been able to articulate. Finally I turn to cases where interpretation does truly attempt to embrace reception without tying it to claims about origins - forms of interpretation that are at once some of the most promising and the most challenging among art histories today. 


\section{Recorded reception as origin}

One powerful way to present and justify an interpretation is to show that it has already been partly set out, perhaps around the time of creation, but perhaps instead many years later. Usually this strategy might seem to violate the points already made in Chapters 2 and 3 that no verbal account of an artwork by the artist or anyone else can precisely record the strange experience of engaging with a work of art. But in using recorded reception in a historical interpretation, such accounts may at least be seen to draw attention to an extremely significant but easily missed or hitherto unnoticed feature. Sometimes the record is obviously 'historical', as when Emily Beeny notes the range of contemporary responses to Manet's Olympia that likened the picture to a 'cadaver' at the 'Morgue', and asks about the impact of the recent opening of a grand and popular new public morgue. ${ }^{5}$ Just as often the record is simply that of a particularly favoured and allegedly insightful person whose brief but essentially correct comment can guide interpretation. Linda Nochlin opens her analysis of Seurat's 1884-6 A Sunday on La Grande Jatte with Ernst Bloch's lengthy 1910s description of the sunny scene's 'joyless leisure' and 'endless boredom', setting up her essay as an explanation of his basic insight into the 'anti-utopian signification' of the work. ${ }^{6}$

No one has been more closely associated with the use of direct records of the artwork than Erwin Panofsky, who has since become a by-word for the search for a particular textual record that might secure our understanding of a work of art. Most obviously this occurs in iconological analysis when an erudite scholar or patron offers a written account of the work that can be used as the foundation for our own historical interpretation. In writing on the 1140s reconstruction of the Choir at St-Denis, Panofsky attributed the work that has often been said to inaugurate Gothic style and 'set the course of Western architecture for more than a century' quite specifically to the Abbot who had left a fortunately lengthy written record of his life and achievements (Fig. 4.1). ${ }^{7}$ Reading Suger's meditations on the beauty of the church's various details and its objects in relation to texts by the Pseudo-Dionysus and John the Scot, Panofsky saw a consistent obsession with light. Suger, he revealed, was in fact under the spell of a 'Neo-Platonic Light Metaphysics' that animated everything about his programme of works at St Denis. The precise details of who did what in terms of the building's design and construction remain to be uncovered, Panofsky noted, but we can be sure that 'very little at least was done without his active participation'. The 


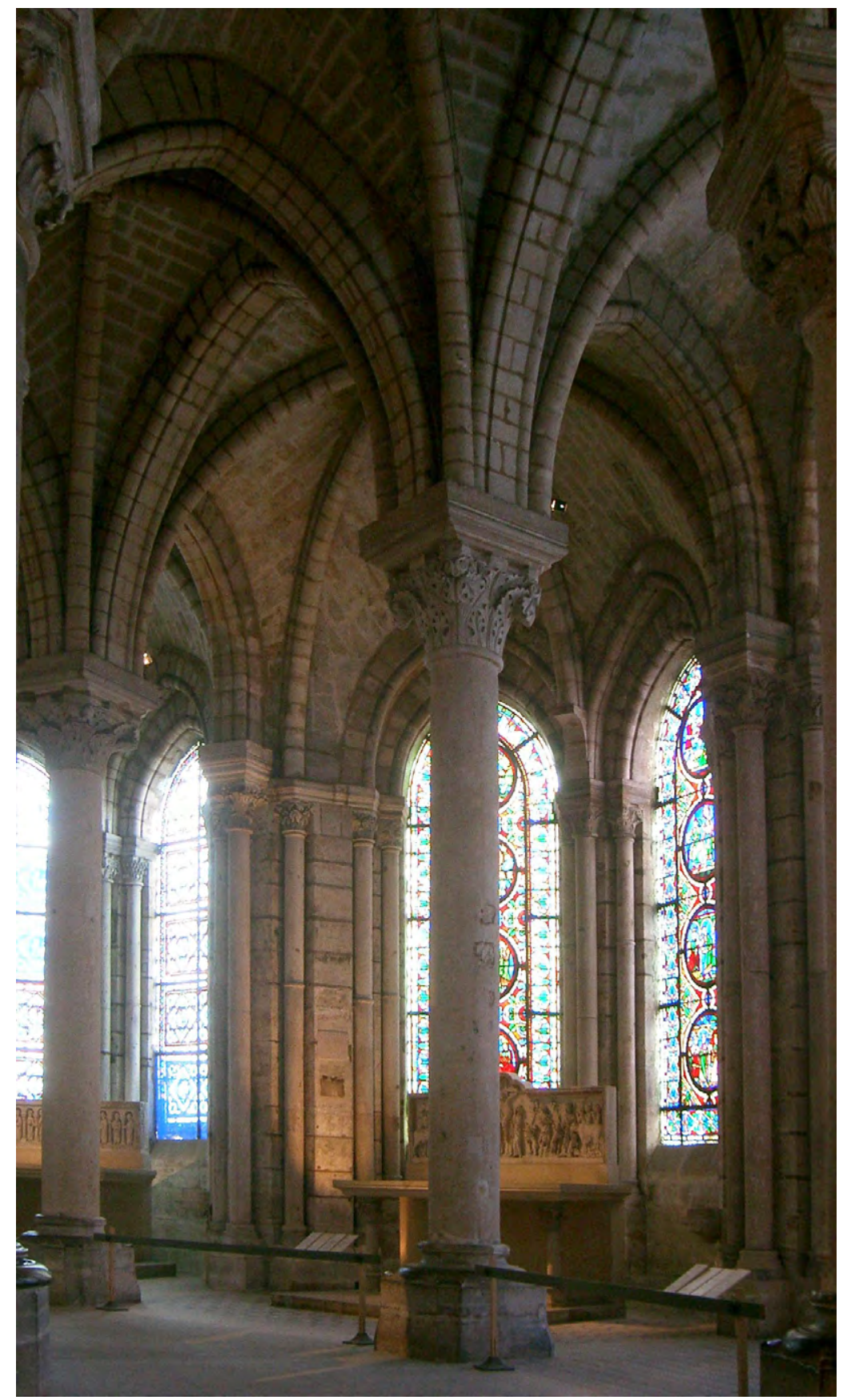

Fig. 4.1. View of the Ambulatory at the Basilica of St-Denis, Paris, c. 1140-4. Photograph: Wiki Commons. CC BY 3.0. 
rebuilt St Denis and its various windows and ornaments could thus all be interpreted through the overarching framework provided by Suger's writings, of a desire to allow light to spill throughout and transport the viewer through the senses to a realm beyond.

Panofsky's use of textual records is often more complex than this, however, and makes clearer how it is that even the most seemingly distant forms of recorded reception can nonetheless be used as a clue about origin. In one of the most masterful instances, his text on Poussin's second Et in Arcadia Ego (1637-8, Fig. 4.2), Panofsky began by contrasting a supposedly old-fashioned reading of the title phrase with one he took to 'now' be the standard. ${ }^{8}$ In 1769 King George III had, Joshua Reynolds recounted, clearly stated that the statement carved into the tombstone were words spoken by Death itself as a reminder that even in Arcadia it was present: 'Oh, there is a tombstone in the background: Ay, ay, death is even in arcady'. For Panofsky this is entirely contrary to 'our modern reading of the message', which is that the words belong to the entombed Arcadian shepherd or shepherdess, as if saying from the grave that 'I, too, was born, or lived, in Arcady'. But what relevance could this 'modern' reading have to a work of art from the 1630s, painted decades before any recorded use of the phrase in this way?

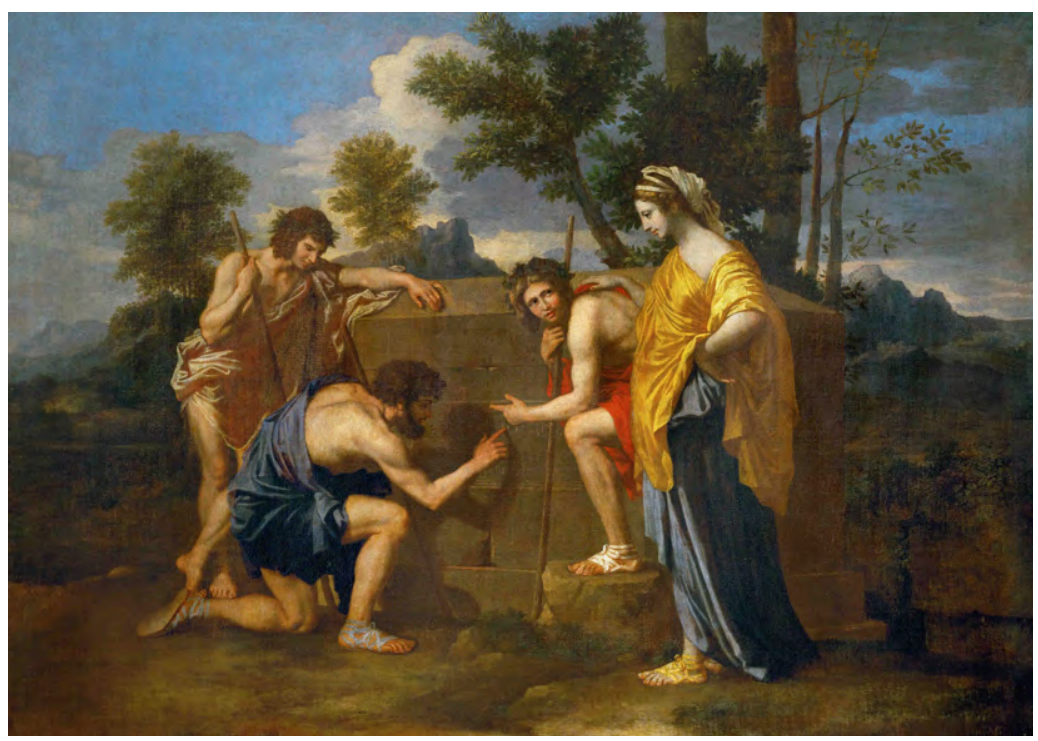

Fig. 4.2. Nicolas Poussin, Et in Arcadio Ego, 1637-8. Oil on canvas, 85 $\times 121 \mathrm{~cm}$, Musée du Louvre. 
Panofsky's twist, characteristically drawn out through pages of erudite observation about the history of the phrase, was that the 'modern' reading was in fact traceable back to this painting. In Poussin's earlier treatment of the same subject (Fig. 4.3), painted a decade earlier, he had supposedly followed an example set by Guercino that the subject warranted a memento-mori-like treatment. Here the sudden discovery of the skull-topped tomb suggests a moralistic warning against frivolity and earthly pleasures that must come to an end. In his second painting, Panofsky went on, Poussin removed the skull and surprise in favour of figures 'immersed in a mellow meditation on a beautiful past'. Now we find it 'infinitely more natural to ascribe the words, not to the tomb but to the person buried therein'. In place of the 'thinly veiled moralism' of the first painting, we now have 'undisguised elegiac sentiment'. Panofsky implied without actual evidence that Poussin had set out to illustrate the poet Sannazaro's 'Arcadia' of 1502. But what seemed to secure Panofsky's reading, including the unprecedented meaning of 'Et in Arcadia Ego' that it would have to involve, was the later mistranslation of that phrase by Poussin's second posthumous biographer in 1685 that gave it this new meaning, as also used by Diderot, Goethe, Schiller, and many other eminent writers in subsequent years. ${ }^{9}$ I myself first came to this painting

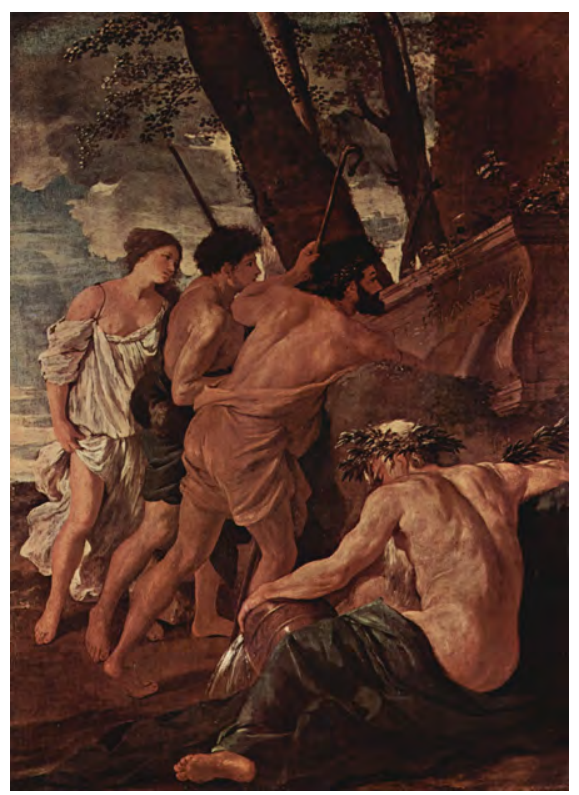

Fig. 4.3. Nicolas Poussin, Et in Arcadia Ego, 1627-8. Oil on canvas, $101 \times 82 \mathrm{~cm}$. Devonshire Collection, Chatsworth. 
when more familiar with Evelyn Waugh than Schiller, educated in what Panofsky called 'the insular English tradition' that preserved the original meaning of the phrase. For this reason, until reading his interpretation it never occurred to me to understand the title as anything other than speaking for Death itself. In this, Panofsky's text is very nearly a revelatory study in reception as afterlife, a mode I return to at the end of this chapter. But Panofsky's text was not just a claim about how different traditions might interpret the text differently, but a claim about how Poussin originally understood his painting, even though based on a mistranslation from after his death. Like so many art historians, he could not let reception be just that.

\section{Visual practices as origin}

Critics of Panofsky have pointed out that Panofsky's equation of reception with original meaning was elitist, intellectualizing, and often plain shaky: Panofsky had to make regular unproven assumptions that because a record of an iconographic scheme existed this was how the artist themselves would have been working and understanding their work. Gone was any chance of artistic deviation from the scheme, and gone was the possibility of differing receptions of the work by audiences other than the humanist intellectuals to which Panofsky was disposed. The problems were made especially clear in some of the most interesting correctives and counters to Panofsky's writing, as when Peter Kidson pointed out how tenuous it was to claim that Abbot Suger had any knowledge of PseudoDionysian light metaphysics, let alone involvement in the actual design of St Denis, his writings not clues to production but an eccentric and insignificant personal take; or more broadly when Michael Camille pointed out how odd it was to search for an original textual 'source' when there would be many different kinds of viewer, such as lay audiences and even some monks, with no ability to read or write. ${ }^{10}$

Rather than privileging textual records of past reception, another strategy has been to turn to records of visual practices that could provide evidence for the perceptual and cognitive habits and skills with which original makers and viewers would approach works of art. In this, Baxandall's 1972 Painting and Experience in Fifteenth Century Italy has been the key model, as well as being taken by many as the origin of the method-inspiring phrase 'visual culture'. ${ }^{11}$ Now written evidence of recorded reception of artworks was replaced by evidence of past visual practices, with those practices to be recovered by a variety of often 
creative means that went far beyond written records of how artworks had been seen. Rather than look to the history of artmaking and its recorded reception, that is, Baxandall looked to the wider 'period eye' or 'cognitive style' of people of the time: 'the interpreting skills [they] happen[ed] to possess, the categories, the model patterns and the habits of inference and analogy. ${ }^{12}$ Readers of Painting and Experience were asked to imagine themselves as the kind of fifteenth-century Florentine who would have bought and used these works, with their set of skills exemplified not by the intellectual elites but in the 'Quattrocento man' who 'handled affairs, went to church, led a social life'. Botticelli's graceful figure groups thus appealed to the deep experiential knowledge of dancing that such a viewer would have had, just as Piero's works, constructed from basic geometric units, depended for effects on the eye of the businessman trained in rapid mathematical and visual gauging of the volumes of barrels, sacks and bales (Fig. 4.4). A decade later Svetlana Alpers' The Art of Describing demonstrated the power of the method in dealing with a very different time, place, and artistic situation. Again direct written records of individuals' encounters with artworks were shunned in favour of evidence of the attitudes towards the visual: optical devices, maps, and treatises on sight and art. But Alpers set her account against the culture of the Italian Renaissance that had been Baxandall's main concern. Where for Alpers Italy had a 'textual' culture that offered 'easy verbal access', seventeenth-century Dutch culture was a truly visual rather than textual culture. Dutch art would all, as such, have been understood in its time in the purely visual terms that her analysis of seventeenth-century Dutch vision suggested. 'To the Dutch way of thinking, pictures, maps, history, and natural history had common means and ends'. ${ }^{13}$ A work like David Bailly's Self-Portrait was a skilfully crafted assemblage of objects relating to the painter's life and work, not the painterly collection of hidden symbols that so much other recent art history (mistakenly following the Italian model) might have suggested (Fig. 4.5).

Reception history based on visual practices faces similar problems of narrowness and evidence to Panofsky's. Baxandall's history for one was soon pointed out to be just as singular as those offered by early art historians. True, the 'public' was no longer a couple of lofty elites, but there is no diversity of, for instance, class or gender among an idealized audience for the works, which remains largely homogeneous. ${ }^{14}$ Baxandall's reliance on visual practices also resulted in an attitude towards evidence that was just as - or even more - tenuous than Panofsky's. Where Panofsky moved from definite instances of past reception of the particular artwork to generalizations about the original 


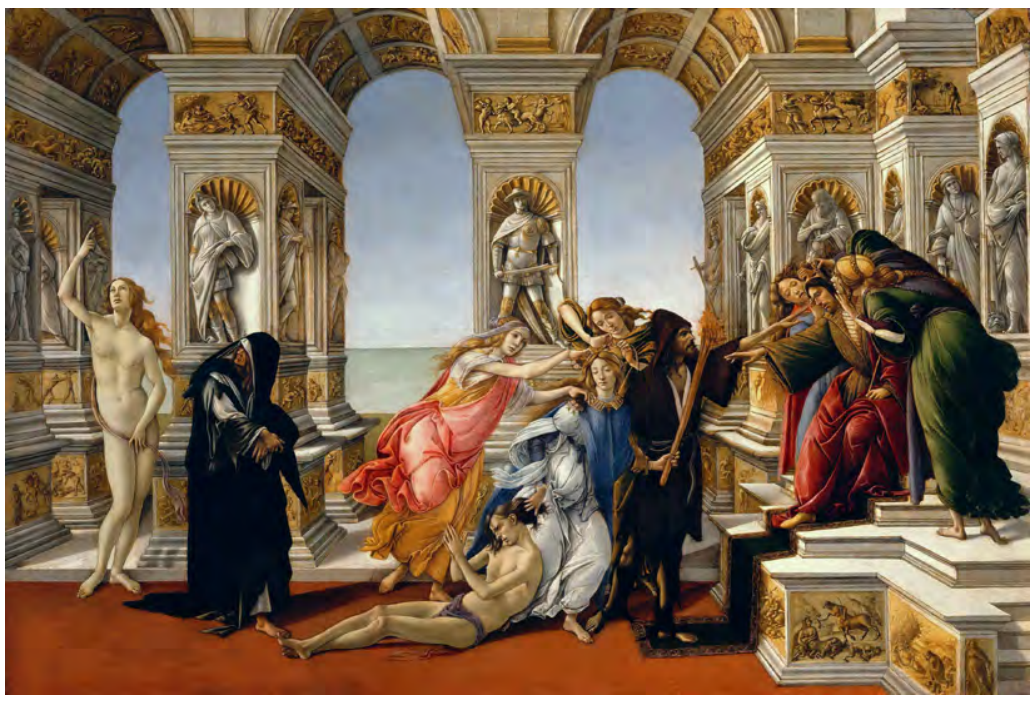

Fig. 4.4. Sandro Botticelli, Calumny of Apelles, 1494-5. Tempera on panel, $62 \times 91 \mathrm{~cm}$. Uffizi, Florence.

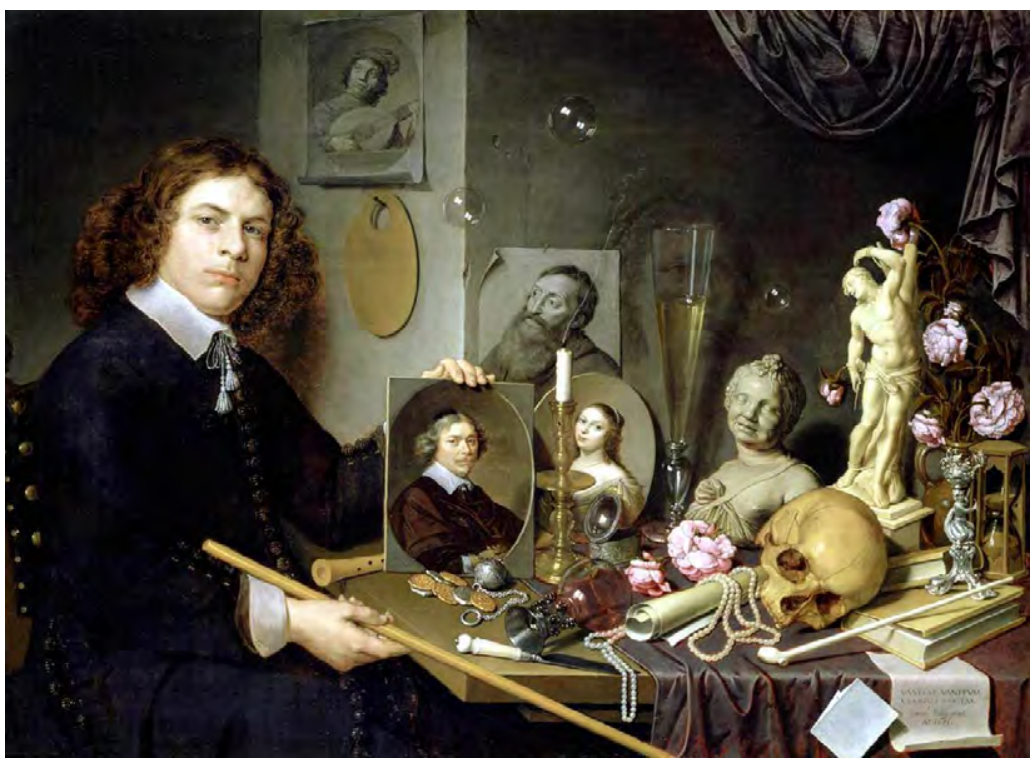

Fig. 4.5. David Bailly, Self-Portrait with Vanitas Symbols, or Still Life SelfPortrait, 1651 . Oil on canvas, $65 \times 97.5 \mathrm{~cm}$. Leiden, Museum de Lakenhal. 
reception of that artwork, Baxandall moved from definite instances of past practices of perceiving or thinking about the world to generalizations about the original reception of artworks. Questions about the actual reach of these practices, as well as their applicability to the reception of visual art, naturally apply. The interpretation that extrapolates from a mathematics textbook to a general fifteenth-century Florentine way of seeing barrels and bales to the way works of art were viewed at the time is, needless to say, far from secure.

Though often linked to direct attacks on Panofsky and iconology, the work of the many 'new' social historians and historians of visual culture from the 1970s through to the present day who took up this mode should be seen as an evolution from, rather than total overthrow of, his approach to reception. One key point about visual-practice-based reception history is that, just like Panofsky, it has tended to be strictly originalist. No one was clearer about this than Baxandall himself, whose later writings more explicitly acknowledged the centrality of the artist, correcting those who had misunderstood. Even in 1972 Baxandall's argument was not that we should shift our attention from artists to viewers, but that imaginative investigation into viewers would help us understand what the artist themselves had done. Artists and the ideal viewing public could and should not be separated analytically, for the artist not only shared the 'visual experience and habit' of their society in a direct sense, but took the visual skills of their audience into account while working, so that, in Baxandall's words, 'his public's visual capacity must be his medium. ${ }^{15}$ In the hands of his followers, meanwhile, the 'period eye' was taken to indicate a similar broad equivalence of seeing between the artist and the viewers of their time to that which traditional art historians (from Winckelmann to Wölfflin and Panofsky) always had. Reception might be emphasized, but once again it was a key to, because in fact equivalent to, the origin of the work.

\section{Depth reception as origin}

Taking recorded reception literally on the one hand, and ignoring recorded reception to search for 'visual practices' on the other, are of course extreme options, largely abstractions that few interpretations embody in a pure sense. In between the two might be an approach that reads as much recorded reception as possible but treats it as just one piece of evidence among many, potentially useful though never able to have the final word. This too has its extreme version, which I set out here in relation to two 
writers who have pushed it to its limits. This is the mode of 'depth reception as origin': of reading recorded reception of the work, but also treating it with suspicion, attempting to look through its obvious meanings in order to find the deeper truth of the original work that it reveals.

Writing against some of the more doctrinaire social history of art of the later-twentieth century, both T. J. Clark and Michael Fried have been especially disdainful of attempts to suggest that one text might provide a definite answer to the meaning of a pictorial detail, as well as of assumptions that a pictorial detail might be directly and entirely explained in terms of a single aspect of viewing practices of the time. This was 'low wattage social history of art' in Fried's words, 'social iconography' in Clark's, and 'short circuited social interpretation' in those of Thomas Crow. ${ }^{16}$ In the depth interpretative mode that both employed in writing on Manet's Olympia, the art historian must instead attempt to read as much as possible of what remains of commentary on the artist or artwork in question while also not trusting that commentary, questioning and often working against the grain of this material, and refusing the idea that pictorial details could be safely pinned to any single text or historical aspect. Reception is key here, for the artwork must be understood in relation to how it was seen and written about by commentators of the time. But no single account can be trusted to give the final word on the work of art, only once creatively read together can they show us what or how the work originally was.

Writing on Manet, for instance, Fried's close reading of critical commentary on the artist's works over the course of his lifetime charted various ways in which Manet's paintings fell outside contemporary modes of pictorial intelligibility. ${ }^{17}$ For some critics, he wrote, intelligibility depended on a transparent naturalism, which Manet's work refused. For other critics, the oddities of subject matter meant that Manet's allimportant intentions could not be read from his works, and thus once again his paintings could not be understood (Fig. 4.6). In another contemporaneous reading favoured by Fried, Manet sought overall effect, not individual detail. The public were once again unable to make sense of the works produced according to this privileging of overall effect. In attending to more than seventy responses to Manet's Olympia alone, meanwhile, Clark found a similar disarray, with the painting eluding all the normal frames of reference. ${ }^{18}$ The 'expert' art critics 'saw no sources and found no terms'. Only a very small handful of critics mentioned prostitution, and even fewer ('a grand total of six attributions') class. Just one critic had seen the painting as at once class-based representation and provocation, though even they could not fully make sense of the work. 


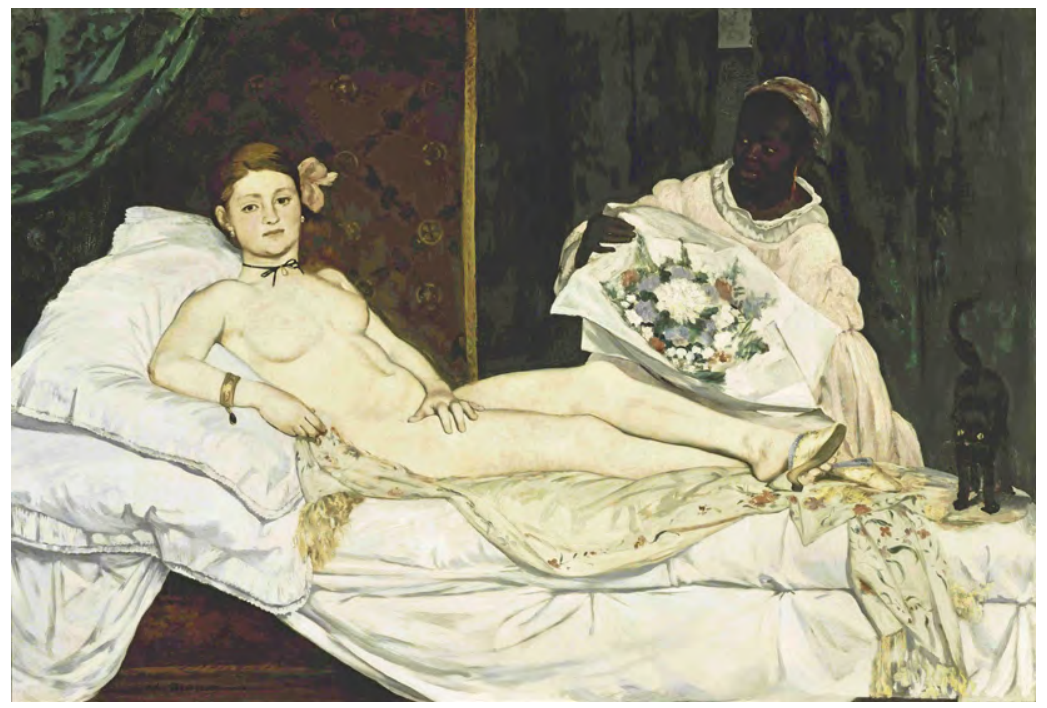

Fig. 4.6. Édouard Manet, Olympia, 1863, oil on canvas, $130 \times 191 \mathrm{~cm}$. Musée d'Orsay.

In the hands of both writers, disarray in reception was also a clue about origin, as the ambiguities of critical response turned into a definite and even an intended feature of the works. In Fried's analysis, Manet's work was seen by some as impossible to make sense of, but by others as intended to have the look that it did. Fried read these texts critically in order to create a conjunction, the upshot glossed as 'Manet's deliberate courting of unintelligibility'. ${ }^{19}$ In Clark's analysis, Manet's work was written of by a handful of the critics in terms of class, but by the vast majority of them without any mention of class. Clark, too, created a conjunction: the lack of reference to class by the majority was a historically significant failure to see what some could.

Having established the critics' failure to see the work as it truly was, Fried and Clark were able to make sense of their reading of the work as belonging to Manet in a full and original sense after all. Disarray among the critics was no longer mere difference of opinion, but the inevitable response to a work produced as part of a deliberate programme that the art historian could now recover, even though in Fried's words it was 'unavailab[le] to intellectual analysis' for critics at the time. ${ }^{20}$ For Fried, Manet's unintelligibility resulted from his strategic response to the breakdown of the dominant pictorial tradition of the previous hundred years: a strategy in which Manet attempted to make every element of the picture 'face' the viewer, and embraced the opacity of figures and subjects 
lacking in psychological interiority and narrative intelligibility. For Clark it was more than an accident on Manet's part that, though 'none of the critics ... would have agreed with me', the 'ultimate cause of the critics" difficulty with Olympia in 1865 was 'the degree to which she did not take part in the game of prostitution, and the extent to which she indicated the place of that game in class'. ${ }^{21}$ As Clark wrote later in the book: 'Inconsistencies so carefully contrived must have been felt to be somehow appropriate to the social forms the painter had chosen to show'. ${ }^{22}$ Olympia was a case of 'Manet's strategy' of embracing ambiguity and indeterminacy in order to disrupt the established representational codes according to which social life was organized: 'show[ing] us the artifice of this familiar repertoire of modern life, and call[ing] into question the forms in which the city contrives its own appearance'. ${ }^{23}$

\section{Reception as afterlife}

What would historical interpretation look like that truly accepts that artworks do, despite in one sense being bound to their origins, also transform over time? Paul Valéry has expressed as well as anyone the thought that 'A work lasts to the extent that it is capable of appearing quite different from what its author made it. It lasts in order to be transformed, and to the extent that it contained the potential for countless transformations and interpretations. ${ }^{24}$ There is a 'peculiar contingency' to the work of art, writes Amy Knight Powell, bringing the view into the art-historical present, 'whose meaning is dependent upon its context but never definitely determined by any one context - least of all its original context'. ${ }^{25}$ Might something like this provide a programme for arthistorical interpretation, accepting the transformation of artworks across time, and setting out to honestly engage these transformations rather than projecting them backwards as an account of origins after all?

True attention to reception as afterlife in the history of art is much rarer than the rhetoric of some might suggest. Works of art are of course used and reused by different people over time right through to the present. Art history and museum display both prioritize 'the historical context of [the artwork's] moment of creation', writes Avinoam Shalem, yet 'each work of art has numerous histories, and its life crosses several temporal zones'. ${ }^{26}$ The problem is, because this is so obviously true, it can also seem trivial. Few really care about how every single person in the world has differently engaged with every single artwork. A justification is needed each and every time for why this particular form 
or set of forms of reception are of interest. The most widespread traditional justification, as we've seen, has been that it shows how an artist's work originally was. Other traditional justifications are that reception histories can underpin subdisciplines such as historiography, or the histories of taste, collecting, and display. At the other end of the spectrum lie the romantic possibilities for art histories that have fully found a way to come to terms with the fact that an artwork not only moves across time but is itself already 'a bundle of components of different ages', an art history that 'lets us swim again in the flow of time, in the network of incoming and outgoing interactions, while discussing works of art, because they have neither a fixed originary moment nor a vanishing point. ${ }^{27}$ Very occasionally art history manages to successfully walk this tightrope between history and ahistoricity, brilliantly merging multiple temporalities in a way that is still - just enough - recognizable as art history. ${ }^{28}$ But what of more widespread and achievable forms of reception-as-afterlife employed in mainstream art history?

In recent years attention to reception as an end in itself has found an outlet in notions of the geographical movements and social lives of artworks. Sometimes claimed to have developed out of late-twentieth-century work in anthropology and archaeology more than art history, histories of this kind emphasize the specific temporal and geographical multiplicity of certain artworks. Most obvious perhaps is the case of the mobility of objects that move across times and places and in doing so are transformed for those who use them, whether as focused as the elaborate Lal Dera tent used by the Maharaja of Jodhpur in early- to mid-eighteenth-century north India, or as broad as the centuries-long story of the flow of Chinese porcelain from Jingdezhen to Manila to Colonial Mexico. ${ }^{29}$ Sometimes artworks are themselves made up of materials and skills in multiple places and traditions, creating an intrinsically hybrid object that needs to be picked apart as such. An eighteenth-century St Michael the Archangel is (most likely) carved by a Chinese immigrant in Manila, from African ivory, using Flemish art as a model, in order to cater to the market in Latin America for Asian luxury goods (Fig. 4.7).$^{30}$ Sometimes the artworks under discussion have themselves been physically changed or recreated over time, so that the metaphorical 'recreation' that takes place in new contexts of reception is made literal, allowing an art history of the afterlife of the artwork that is also a history of definite new originals. Roman portrait marbles are, over time, recarved for new subjects, Renaissance prints are cut and reassembled to suit personal decorative and devotional practices, and early modern Spanish portraits are repainted with religious characteristics in ways that undo apparently clear portrait/icon distinctions. ${ }^{31}$ 


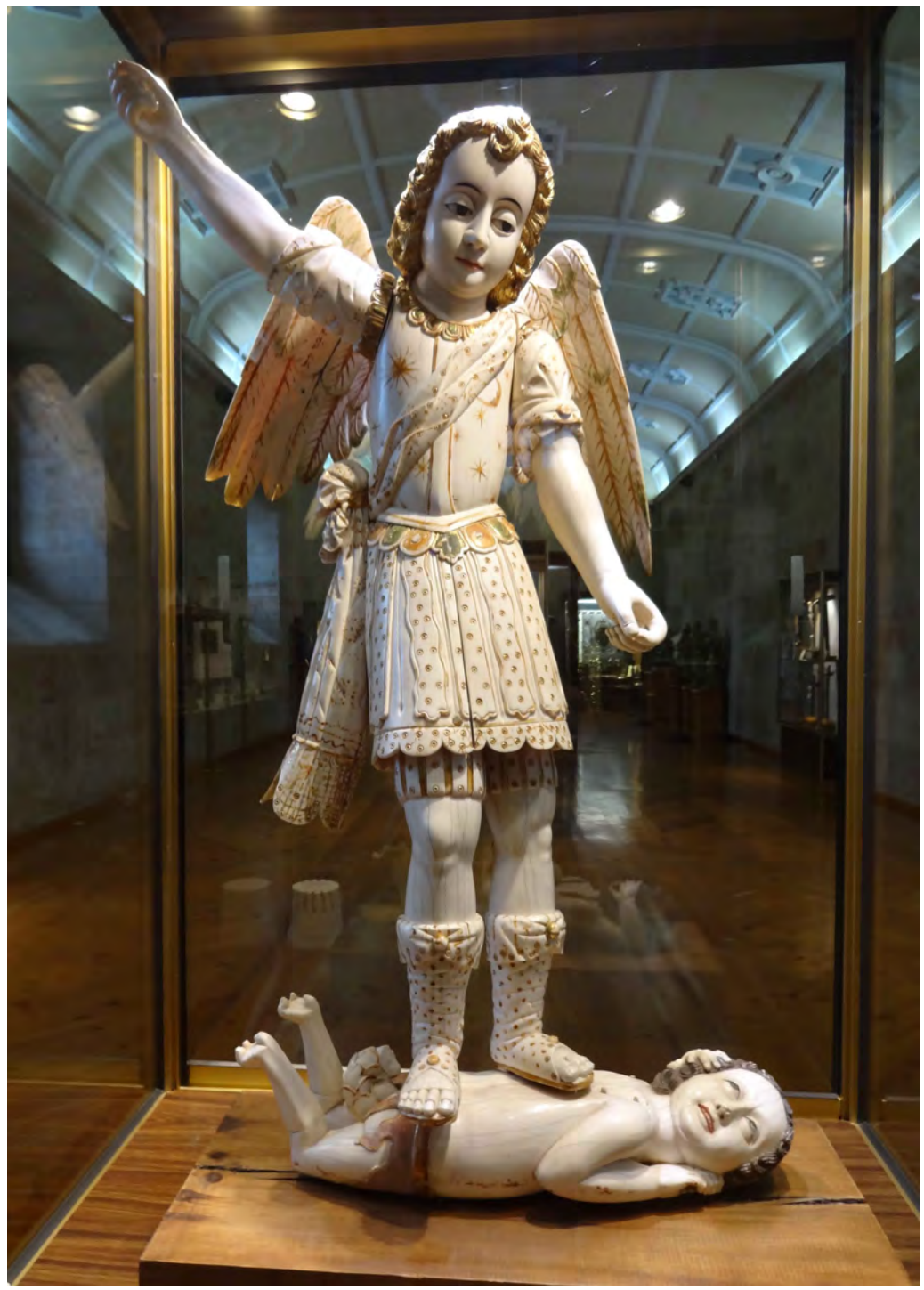

Fig. 4.7. Hispano-Philippine, St Michael the Archangel, seventeenth century. Ivory with polychromy and gilding. San Esteban, Salamanca. Photograph: Stephanie Porras.

In a time of widespread attention to transnationalism and the global turn, the justifications for all of these histories and interpretations are selfevident. They show 'global' connections, cultural encounters, and the power of artworks to mediate and propel such encounters, just as such encounters prove fundamental to histories of art making and use in turn. 
As this work comes of age, however, scholars are increasingly realizing that it needs to actually show (as all the articles mentioned here do) the real forms of difference or change that result from these encounters that is, show how these histories tell us genuinely new things that involve more about artworks or cultures than the filtering of the objects through already known theories and histories that threatens to result. This is to avoid 'theoretical straightjackets into which experiences of global relationships can be accommodated without further investigation of the processes and agents involved', and in relation to art objects more specifically to go beyond 'the identification of trade routes, material and iconographic sources for such transcultural objects' to 'the study of how these movements led to the creation of novel artistic forms and practices'. ${ }^{32}$ Otherwise triviality results after all: in a globalizing and colonial world, it's hardly intrinsically interesting, let alone surprising, to point out that things are 'connected' or 'entangled' in some way or another.

One even more radical possible direction in which Valéry's thought might lead, it should be said in closing, is a strategic anachronism, a deliberate embrace of the interpretative possibilities that result when artworks are taken out of their original time. Different methodological and historical backgrounds might be claimed here, from twentieth-century experiments in museum display, to the post-structuralist use of semiotics, to the very particular late-twentieth-century reinvention of Aby Warburg by Georges Didi-Huberman. ${ }^{33}$ Over the last fifty years Mieke Bal is probably the figure who has most creatively and thoroughly explored and developed strategic anachronism. ${ }^{34}$ Yet Bal's development has led her away from the history of art towards the contemporary, with her work now widely admired and still, like other maverick scholar-artists who push the bounds of art writing beyond long-established art historical norms, not a possible model for younger art-historical interpreters without reputational and financial security to emulate while still hoping to publish their work and find institutional employment. ${ }^{35}$ There have been other prominent recent attempts to pursue anachronism and its implications. Following his work with Christopher Wood on the different forms of temporality found in Renaissance art, Alexander Nagel has experimented with more direct anachronism that bounces works of medieval and modern art together, a move also developed in the work of Amy Knight Powell. ${ }^{36}$ This is a wonderful mode for experimentation in art writing that pushes things to the limits, just as it is for curators to revivify objects that have begun to seem all too familiar. But it is so far not one that the institutions of the discipline have been able to fully accept, still anxious as many are that we will no longer be able to give the name 'art history' to what results. 


\section{Notes}

1 As notably in Prettejohn's The Modernity of Ancient Sculpture and Modern Painters, Old Masters.

2 DaCosta Kaufman, 'Reception Theory', commenting on: Iser, The Act of Reading; Jauss, Toward an Aesthetic of Reception; and the art historical explication in works such as Bockemühl, Die Wirklichkeit des Bildes and Kemp, Der Betrachter ist im Bild. The latter position was clearly articulated for English-language audiences in Kemp, 'The Work of Art and Its Beholder'.

3 As brilliantly demonstrated in Schreyach, Pollock's Modernism.

4 Pippin, 'Fried on Intention', 50-2, 58-61.

5 Beeny, 'Christ and the Angels', 51-5.

6 Nochlin, 'Seurat's Grande Jatte', 133.

7 Quotations from Suger, Abbot Suger on the Abbey Church of St.-Denis and Its Art Treasures, 1-37. Quotations from Panofsky, 'Et in Arcadia Ego: Poussin and the elegiac tradition'.

9 André Felibien suggested that 'this inscription emphasizes the fact that the person buried in this tomb has lived in Arcady' (Panofsky's translation and emphasis), in Panofsky, 'Et in Arcadia Ego', 363. It is also worth noting that the argument from visual evidence is equally tricky. Even accepting Panofsky's highly tendentious description of the different moods of the works, for instance, the reasoning from mood to meaning of the phrase would have to rely on the extraordinary assumption that a memento mori that reminds of Death itself is always a stark moral warning, while the encounter with the actual tomb of another real person is always an occasion for elegiac reflection on the past.

10 Kidson, 'Panofsky, Suger and St Denis'; Camille, 'Mouths and Meanings'. A less directly reception-focused and more positive and playful elaboration on Panofsky's essay on Poussin that nonetheless also undoes it can be found in Marin, Détruire la peinture, 81-114.

11 Hentschel, Visual Cultures in Science and Technology.

12 Quotations from Baxandall, Painting and Experience in Fifteenth Century Italy, 29-40.

13 Alpers, The Art of Describing, xxii, 162.

14 Baxandall stressed that the audience for art was 'a small proportion of the population: mercantile and professional men, acting as members of confraternities or as individuals, princes and their courtiers, the senior members of religious houses' (38-9), and referred to the figure he had put forward as not 'an ideal type', but one who 'has the elements of the matter in him - religion, politeness, affairs' (109). Nonetheless, the point is brought out clearly in Randolph, 'Gendering the Period Eye', an analysis developed in his Touching Objects.

15 Baxandall, Painting and Experience in Fifteenth Century Italy, 40.

16 Fried, Manet's Modernism, 178; Clark, 'Art History in an Age of Image-Machines', 5; Crow, 'Codes of Silence', 9.

17 Fried, Manet's Modernism.

18 Clark, 'Preliminaries to a Possible Treatment of Olympia in 1865' and The Painting of Modern Life, Chap. 2.

19 Fried, Manet's Modernism, 357.

20 Fried, 215.

21 Clark, The Painting of Modern Life, 88, 146.

22 Clark, 251.

23 Clark, 'Preliminaries to a Possible Treatment of Olympia in 1865', 40-1.

24 Valéry, Tel Quel, 168, as quoted in Gombrich, Topics of Our Time, 57-8.

25 Powell, Depositions, 12.

26 Shalem, 'Histories of Belonging and George Kubler's Prime Object', 5.

27 Kubler, 'Style and Representation in Historical Time', 849-50; Shalem, 'Histories of Belonging and George Kubler's Prime Object', 10.

28 Wood, Forgery, Replica, Fiction; Whitney Davis, 'Queer Family Romance in Collecting Visual Culture'; Bahrani, The Infinite Image. It might be said that such work attempts to finally move beyond what Christopher Wood has identified as the empiricist, relativist, and historicist pitfalls of modern art history. In doing so however it must now confront head on the problem - also explored at length by Wood - of an academic discipline devoted to the history of a phenomenon (art) that is 'unavailable to reason and not fully involved with history, an unknown external to man even if produced by man'. Wood, A History of Art History, 407 and passim. 
29 Chowdhury, 'An Imperial Mughal Tent and Mobile Sovereignty in Eighteenth-Century Jodhpur'; Priyadarshini, Chinese Porcelain in Colonial Mexico.

30 Porras, 'Locating Hispano-Philippine Ivories'.

31 Prusac, From Face to Face; Schmidt, Altered and Adorned; Jasienski, 'Converting Portraits'.

32 Juneja, 'Circulation and Beyond: The trajectories of vision in early modern Eurasia', 60; Porras, 'Locating Hispano-Philippine Ivories', 266 n 52 (commenting on Juneja).

33 Didi-Huberman, Confronting Images; Didi-Huberman, The Surviving Image. As with contemporary German art historical uses it could also be argued that a proper following of this line of thought would in fact lead to the more precise modes of transhistoricalism seen above, for instance in Bredekamp et al., Bilderfahrzeuge.

34 Most directly and prominently in Bal, Quoting Caravaggio.

35 As in her recent trilogy on contemporary art, as well as works such as Bal, Exhibition-Ism.

36 Nagel, Medieval Modern; Powell, Depositions. 


\section{5 \\ Complexity}

'Find out as much as you can and then look as long and closely as possible' may be the most obvious unwritten rule for interpretation in the history of art. In this and the following chapter I examine another unwritten rule that has increasingly come to govern art historical interpretation over the last hundred and fifty years: 'Make your favoured artworks as complex as possible'. Complexity here serves as a historically respectable version of 'rich' or 'interesting': to make an artwork more complex is to show how it may have all manner of unexpected ties to the historical moment in which it was produced, and all manner of significant connections to audiences and interests since. We are in the realm of what philosophers of art call 'value-maximizing' interpretation: the artwork made as useful or valuable as it can be according to a particular interpreter or frame of reference. ${ }^{1}$ We are also at the point where art-historical interpretation's strange balancing act between recovering history and maximizing value is at its most visible. This chapter explores three interpretative moves that help keep the balancing act going: 'additive interpretation' in which even apparently competing interpretations are combined; 'blackboxing' in which the results of shaky or contested interpretations harden into unquestioned assumptions or 'facts'; and 'the principle of art historical charity' which allows interpreters to privilege their own experience of the work as a secure route to historical understanding.

A cynical account of what is occurring when interpretation aims to maximize complexity might suggest a confusion over what, in recent philosophy of history, have been called 'epistemic virtues' and 'intellectual goods': the virtues that regulate historical work and the ideals to which it aspires. Traditional histories make something like 'understanding' their primary good (along with related virtues such as fairness and diligence), an attempt to come to terms with the past that in the terms of this book accords with art-historical 'reconstruction'. ${ }^{2}$ Art criticism on the other 
hand often seems to foreground 'interest' as the primary good, producing 'useful' rather than historically 'reconstructed' artworks as a result. Art history's long confusion over its true purpose (or ultimate intellectual good), it might be said, blurs these boundaries. Reconstructed artworks are sometimes passed off as the most interesting way those artworks can be. Artworks made as interesting as possible to a particular interpreter or audience are sometimes passed off as reconstructions of how those artworks once were. In this, art history follows a widespread flirtation in the humanities with overinterpretation, demanding a treatment of its objects that is 'ruthless' (Alain Badiou), 'reckless' (Slavoj Žižek), or 'audacious' (Emmanuel Levinas). ${ }^{3}$

More charitably, though, it's likely that this basic blurring is fundamental to art history's status as a discipline that actually connects with the world beyond the academy. Whatever ideals might be proposed, in practice different criteria for 'good' interpretations of art are found in the many art-interpreting communities that include not only academia and its many sub-factions, but all kinds of sub-groups of artists, critics, curators, and general public interested in art and its history. ${ }^{4}$ Occasionally variants on a 'Fordist system' have been proposed that would strictly delimit the activity of art historians and leave interpretation to others altogether. ${ }^{5}$ But art historians have reasonably enough refused to accept such a sad version of what they might do. It is for this reason that investigation of the porous boundaries between reconstructed and useful artworks is so important. Simply opting for one side or the other will not only satisfy few, but is barely possible in practice. The moves charted in this and the following chapter not only can produce brilliant and exciting interpretations, but are also in some cases and to some extent inevitable given the norms of the communal and conversational nature of saying things about art. Some also - as we will see in the case of 'resurfacing' above all - threaten in a moment of interpretative exuberance to undermine so much of what art historians claim to hold dear.

\section{Additive interpretation}

Perhaps the fastest route to complexity in interpretation is to combine. Combination is a standard part of even the most basic forms of interpretation, as individual features of artworks are brought together to make the complex wholes that are the things we see before us. But interpretation commonly makes a further and more dramatic form of combination. In this - 'additive interpretation' - different interpretations 
of features and artworks are added together in turn. When faced with more than one interpretation of a feature or artwork, in other words, why choose when instead you could just combine? 'Neither argument is wrong' writes one fan of such interpretation, inadvertently summing up the key to the procedure, 'but they cannot both be right - or can they?' ${ }^{6}$

Put simply, if one viewer finds a painting beautiful, and another finds it deeply ugly, perhaps the painting is best interpreted by accepting it as in different ways beautiful and ugly, or even stressing its very ambiguity between beauty and ugliness (as if, to push a possible interpretation of such a painting further, in a fascinating manner putting in jeopardy traditional notions of an intrinsically and decidably 'beautiful' or 'ugly' work). ${ }^{7}$ In a classic case favoured by philosophers of art, Henry James's Turn of the Screw, we have the tale of a governess who continually seems to see the figures of two deceased former countryhouse workers around the grounds. ${ }^{8}$ We have James's words, which suggest this is a ghost story, a tale of a governess who is witness to real instances of the supernatural. But we also have readers who have suggested that it might be a story about a mentally unstable governess who begins to imagine supernatural goings-on. With additive interpretation applied, the book can now be understood as deliberately forcing the reader to engage with both possibilities, playing on that uncertainty and its evocation of a porous threshold between spiritual and material realms. In writing the work, the historically minded additive interpreter may go on to claim, James was perfectly well aware (whatever he 'said' on one occasion or another) of this ambiguity, and of course that instability is crucial to the original work and its contemporaneous effects.

One reason for the great productive power of additive interpretation is that the 'competing' interpretations it synthesizes can come from so many kinds of sources, be they recorded accounts, scholarly discussions, artworks that respond to other works, or even just the interpreter's own momentary uncertainty. This last option is the simplest way of all in which additive interpretation can operate. As grist for the interpretative mill, the interpreter might make use of their own interpretations of features of the work that they then combine into a complex whole. Hubert Damisch does this stunningly in talking of Piero della Francesca's Madonna del Parto, picking out as crucial the Madonna's hand gesture and the opening of the tent above, and bringing his various interpretations of these features together to play on themes of motherhood and filiation, the veiling and revealing of bodies and dreams, and the psychoanalytic implications of the 'imaginary relation that can arise between the image of the mother in painting and an adult subject' (Fig. 5.1). ${ }^{9}$ Damisch's 
interpretation extends over the course of an entire book, but the addition of different interpretations of the same features can also take place in a single moment. In an especially beautiful case Damisch takes a feature as definitely undecidable between two possibilities, allowing him to then use additive interpretation to pose the two possibilities as together crucial to making sense of the work:

The fact that we cannot decide, with any degree of certainty, whether the two angels are lifting the flaps of the tent or are instead closing them suffices to introduce the question: an effect of their gesture's undecideability being that the figure exhibits itself within an interval forever frozen in indefinite suspense, and within the embrasure of something that is in fact neither a window nor a door but rather the entry of a dais-like tent under which the Virgin-tabernacle simultaneously advances and withdraws, at the same time indicating or designating the fold of her robe, as if the better to signify that ultimately it is through here that it passes and must pass. ${ }^{10}$

Great as the possibilities are for the interpreter to generate their own views to add, there is no actual need for the interpreter to create for themselves, as the history of writing on art also generates possibilities for them. In the previous chapter we have seen how many different audience accounts of viewing a work can be taken and, rather than choosing between, combined. Reading these together, Manet becomes not a painter of scenes that are unrecognizable to the experts, or a painter of workingclass prostitution, but a painter who matches his depictions of unstable social forms with a similarly indeterminate mode of representation. (Indeed, any work that has ever had more than one differing recorded response to it might be put forward as 'objectively' undecidable or indeterminate. I return to this in the following chapter.) After-the-fact art-historical interpretations are equally useful for additive interpretation. One 'referentialist' interpretation, contextualizing in relation to the First Balkan War, suggests that the newspapers used in Picasso's cubist collages should be read in full for their sociopolitical content. ${ }^{11}$ Another 'semiological' interpretation, contextualizing in relation to the linguistics of Ferdinand de Saussure, argues that reading the text of the newspapers would miss the point of an artistic device that in fact carries out a semiological examination of the very nature of representation. ${ }^{12}$ Perhaps it is after all the ambiguous status of the text between the possibilities of reading and not reading that is key, 'the feeling of doubt about the 


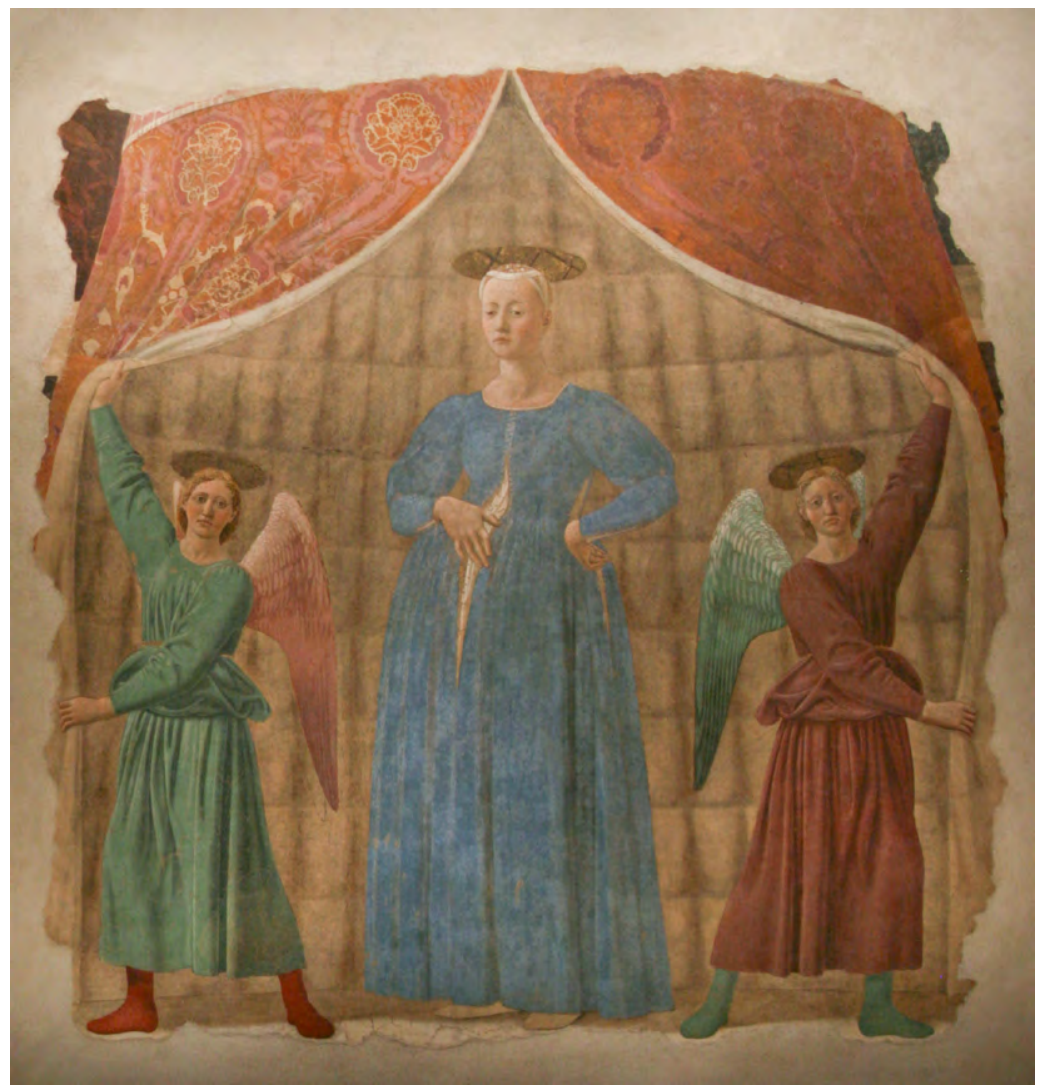

Fig. 5.1. Piero della Francesca, Madonna del Parto, c. 1460. Fresco (now detached), $260 \times 203 \mathrm{~cm}$. Musei Civici Madonna del Parto, Monterchi. Photograph: Stefano Guerrini. CC BY-SA 3.0.

newspapers' meaningfulness ... itself one of the most profound aesthetic experiences staged by the papiers collés'? ${ }^{13}$

Judging by contemporary art history's preference for acknowledging, accepting, and partially combining even seemingly conflicting interpretations, it seems possible that the very structure of modern academic life pushes writers towards this. Publication systems run by small groups or factions are known for building interpretations out of the work of one another, amplifying friends and collaborators at the expense of other brilliant research and writing. (Notoriously, the textbook Art since 1900 attempted over almost a thousand pages to survey more than a hundred years of artistic production, managing the feat with 30-40 per cent of its citations coming from a single journal and its associated writers, that journal being the one edited by the four authors. ${ }^{14}$ ) But other 
systems tend to promote addition in other ways. Supposedly less factional anonymous or 'blind' peer review - where authors have their works assessed by anonymous scholar-experts in the field - encourages addition as a tactical safeguard against the possibility that an anonymous reviewer who supports a rival interpretation will torpedo the publication of a work. ${ }^{15}$ Of course, addition of latter-day interpretations is not just a product of modern academic publication systems. In a sense it is as old as the dialogical character of writing on art, found in publications of the debates of the French Académie as well as early scholarly practices of disputing alternative opinions, in either case allowing for the possibility that agreement and conjunction might result rather than the simple triumph of one view over another. All that is important to stress, for now, is that additive interpretation could potentially take place whenever a 'community of friends', in Miguel Tamen's happy phrase, gather around an object they care enough about to interpret, and decide to work together in thinking about what and how it might be. ${ }^{16}$

\section{Blackboxing}

Hand in hand with additive interpretation comes 'blackboxing'. It's all very well to pile interpretations on top of one another, but if each interpretation remains open to question the result would quickly start to seem like the flimsiest house of cards. What is needed is for each contested and provisional interpretation, made up of multiple often-flimsy pieces of its own, to solidify into a hard and unified 'fact' on which to build.

The term 'blackboxing' originates with Bruno Latour, who uses it to describe 'the way scientific and technical work is made invisible by its own success', that is, how the contested and very human results of laboratory experiments and arguments come to be accepted as 'scientific fact' so secure that it is as if nature has spoken for itself. ${ }^{17}$ In Latour's hands blackboxing is incidental, a process that no one intends but simply results from the way that institutions are organized and information flows. Blackboxing of this kind does happen in art history, as controversial points harden over time into norms that go unquestioned for years. (The case can be as simple as the 'portrait' of Michelangelo in Raphael's School of Athens, an attribution that turns out to be a fictitious 'modern invention first proposed in 1941' (Fig. 5.2); or the 'self-portrait' of Michelangelo in the flayed skin of St Bartholomew in his Last Judgement, likewise 'another startling twentieth-century fabrication'. ${ }^{18}$ ) But in art interpretation blackboxing can also be a rhetorical strategy: a controversial point is 


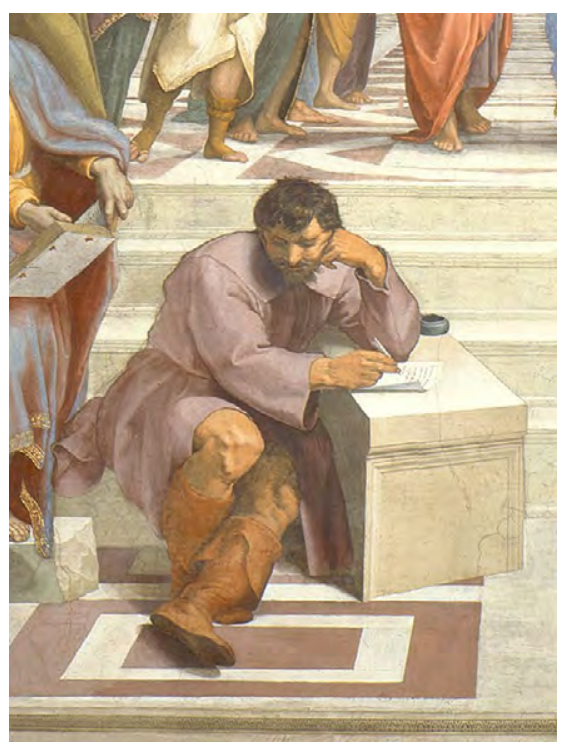

Fig. 5.2. Alleged portrait of Michelangelo, an attribution also said to be 'a modern invention first proposed in 1941'. Detail from Raphael, The School of Athens, 1509-11. Fresco, $500 \times 770 \mathrm{~cm}$. Apostolic Palace, Vatican City.

spoken about $a s$ if it is uncontested, the interpreter making a fact for themselves as they go along. A tell-tale sign of such strategic blackboxing is when scholars are said to have 'demonstrated' or 'shown', the more modest 'argument' or 'suggestion' of those original interpretations momentarily disappearing from view.

So blackboxing is a sub-character in the story, a driver of complexity because of the role it plays in additive interpretation. Recall the example of Picasso's cubism in the section above. No need to unpack the premises and parts of such different interpretations when adding, just as we don't need to debate whether Picasso was actually involved in the investigation of pictorial representation as an arbitrary system of signs. This interpretation of cubism remains a particularly telling case. Taken as a factually secure building block by a reasonably large group of North American art historians, others take the interpretation to have been so comprehensively refuted that it is barely worthy of acknowledgement, or if so then only in terms dripping with sarcasm as in the suggestion that 'that nice man Saussure in Geneva had got it right'. ${ }^{19}$ For those who do accept the reading of cubism it can unsurprisingly be used to build upon to think about connected works. In drawings produced in Nigeria in the early 1960s Uche Okeke brought in motifs from Igbo Uli art as elements 
from which to construct depicted features. ${ }^{20}$ In Two Owls and the Moon we can see that not only are the eyes of owls made up of agwọlagwọ spiral motifs, for instance, but so too is the moon above (Fig 5.3). Chika OkekeAgulu suggests that here we see the same tactic revealed by the semiological reading of Picasso's cubism: the 'ultimate lesson' of these drawings that the pictorial motifs 'do not carry meaning in themselves', but are given their particular signifying function (here as an eye or moon) by their 'context' within the artwork (that is, 'on the other lines, motifs, or spaces to which [the motif] relates'). ${ }^{21}$ Composing in this relational mode, Okeke-Agulu writes, Okeke manages to suspend the distinctions between figure/ground and positive/negative space so characteristic of premodernist drawing. The artist's achievement was thus not to have exploited the referential or meaningful parameters of Uli motifs, but that he 'successfully and rigorously examines and exploits the formal potential of an indigenous art form'. ${ }^{22}$ Others who take the interpretation of cubism as fact have also found impressively creative ways to draw on its implications where connections are less obvious. 'If Picasso and Saussure share a semiotic episteme', writes one such historian, 'so too might Ernst and Freud, or Duchamp and Jacques Lacan, share a psychological episteme'. ${ }^{23}$ The fact of Picasso's semiological cubism thus becomes the evidence needed to authorize a historical reading of Max Ernst and Marcel Duchamp in terms derived from psychoanalysis of a similar moment.

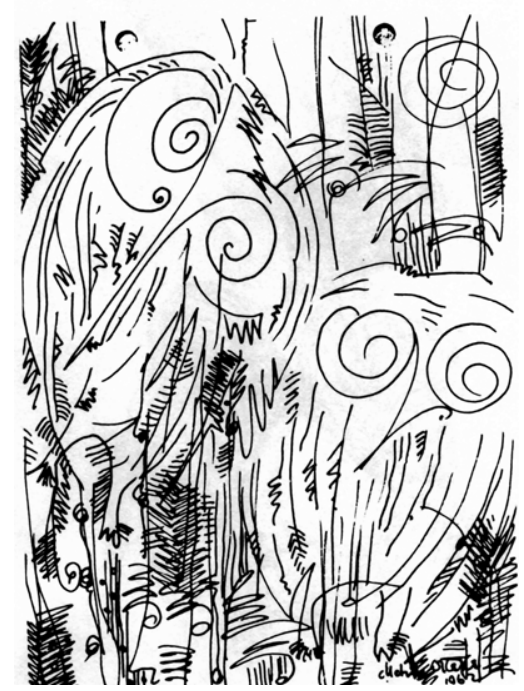

Fig. 5.3. Uche Okeke, Owls, from the Oja Suite, 1962. Ink on paper, $19 \times$ $14 \mathrm{~cm}$. Newark Museum of Art, New Jersey. (C) Uche Okeke / Asele Institute. 
The true power of blackboxing lies beyond even the normalizing and addition of particular controversial interpretations that we see here. Complexity really begins to build when multiple blackboxed elements are combined and recombined within single interpretations and across multiple ones. In the previous chapter we saw that in The Art of Describing Svetlana Alpers blackboxed centuries of speculation about the Italian Renaissance to suggest that it was a 'textual' culture producing 'Albertian' narrative art, which she then opposed to the seventeenth-century Dutch 'visual' culture that produced purely 'descriptive' art. Closing her book with a discussion of Rembrandt, Alpers then blackboxed her own interpretation before inverting and adding the two, revealing that in the seventeenth-century Netherlands Rembrandt uniquely worked in opposition to both Italian and Dutch modes, textual and visual, a painter of neither textually determinate scenes nor of only what the eye could see, but instead one who 'deserts the surface of things in this world to plumb human depths'. ${ }^{24}$

Elsewhere Alpers drew on a similar procedure with an entirely different artwork. First Alpers claimed that Las Meninas was 'unthinkable within the established rubric of art history' because of art historians' 'separation of questions of meaning from questions of representation' (Fig. 5.4). ${ }^{25}$ (The 'interpretative procedures of the discipline itself' blackboxed.) Alpers pointed instead to Michel Foucault's analysis of the absence of a viewer needed to complete the world of the painting, which in the background mirror contains its own viewing by the king and queen who sit for the portrait in progress. (Foucault's interpretation blackboxed. ${ }^{26}$ But Alpers suggests that Foucault is only half right, for the painting both contains its own viewing and suggests the opposite need for an actual viewer that stands before the work and sees the scene: 'Velázquez's ambition' is 'to embrace two conflicting modes of representation'. (The blackboxed interpretation added to its contrary.) Alpers now introduces 'two modes of representation that are central in Western art', the 'Albertian' mode in which a viewer looks out at objects and the 'northern or descriptive' mode in which representation exists independently of any individual viewer. (Alpers's blackboxed 'Italian' and self-blackboxed 'Dutch' modes introduced.) Finally the two modes that the painting holds in suspension are shown to be exactly Alpers's pair, secured as part of Velázquez's original thinking through a moment of mindreading narration:

It confounds a stable reading, not because of the absence of the viewer-subject, but because the painting holds in suspension two 


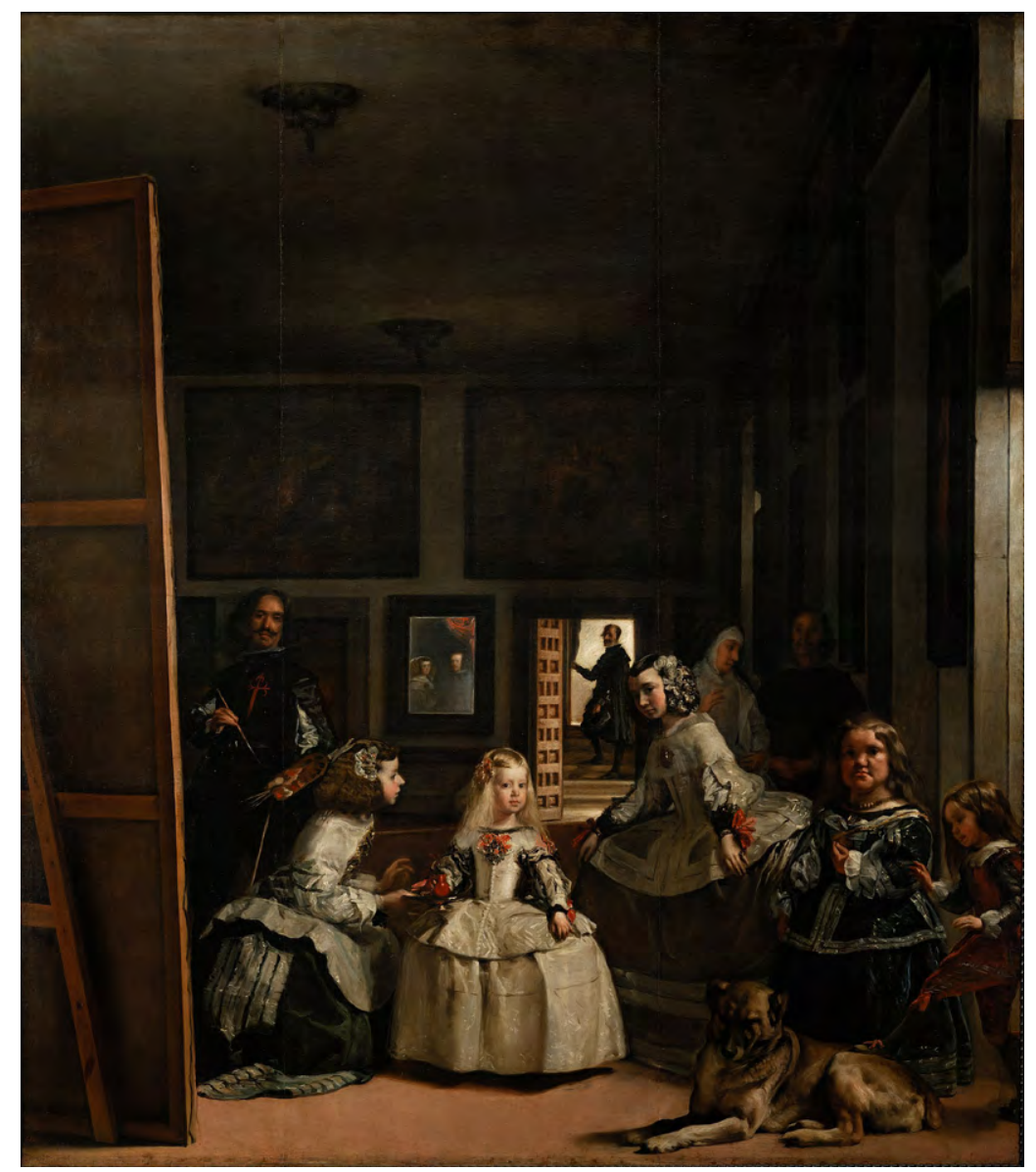

Fig. 5.4. Diego Velázquez, Las Meninas, 1656. Oil on canvas, $318 \times 276$ cm. Museo del Prado, Madrid.

contradictory (and to Velázquez's sense of things, inseparable) modes of picturing the relationship of viewer, and picture, to world. One assumes the priority of a viewer before the picture who is the measure of the world and the other assumes that the world is prior to any human presence and is thus essentially immeasurable.

In an apparently simple article of only twelve pages, it turns out, an artwork reaches dizzying levels of complexity, guided and matched by equally complex interpretative procedures. 


\section{The principle of art historical charity}

Additive interpretation and its ally blackboxing are all very well. But why would art historians embrace such risky moves in the name of complexity? Might not Occam's Razor prevail, and a paring down in favour of the more direct (though less exciting) answer occur instead? To understand this, we turn finally to the 'principle of art historical charity'.

On 8 September 1849 John Ruskin stood in the Louvre in front of Veronese's Wedding Feast at Cana and had a revelation as important for the history of art writing since as it was for his own development as a critic.

I felt as if I had been plunged into a sea of wine of thought, and must drink to drowning. But the first distinct impression which fixed itself on one was that of the entire superiority of Painting to Literature as a test, expression, and record of human intellect, and of the enormously greater quantity of Intellect which might be forced into a picture, - and read there - compared with what might be expressed in words ... I felt assured that more of Man, more of awful and inconceivable intellect, went into the making of that picture than of a thousand poems ... I felt that painting had never yet been understood as it is, an Interpretation of Humanity. ${ }^{27}$

In these words Ruskin put as eloquently as anyone has the notion that artworks have sedimented within them, and communicate through the glorious experiences they prompt, real and definite (though not necessarily clear or propositional) thought. According to this vision works of art are more than just prompts to extremely rich and complex responses of any kind. The richness and complexity of works of art now seems to be built into particular works as a very particular set of responses, a set that will in turn be recoverable by the right observer of the work. In binding together the glory of works of art and the particularity of the responses they bring about, Ruskin here united the apparently conflicting valuemaximizing and historicist ideals of art-historical interpretation. Responses to works of art that are extraordinarily elaborate in interlaced artistic detail, historical knowledge, and rhetorical flourish might now be justified not only as appropriate ways of doing justice to the possible interest of works of art, but also as doing justice to the original significance those works had for their makers. Once the interpreter feels suitably informed that they are able to judge the work on the basis of its 'internal evidence' - Ruskin's term again - gone is the fear that the interpreter is 
merely fixating on a stray, irrelevant, or accidental feature of the work. If it contributes to a richer experience in the present, then it is part of the true, original, 'human intellect ... forced into' the work.

This, in essence, is the principle of art-historical charity. Trust that the maker knew what they were doing, that the artwork is a success, and that you yourself are able to see it. More technically, try to make the artwork as interesting as it can possibly be, then assume this interest is the result of deliberateness and success on the part of the maker and their artwork. The principle is all-important in the generation of complexity in art-historical interpretation, for it sanctions the reading of the personally experienced not only as artistically significant, but as historical too.

In practice the basic move that makes use of the principle of arthistorical charity is to pick up on a feature of the work and treat it as more than mere accident or irrelevance. This is the 'esteem for the insignificant' that Walter Benjamin found in the work of Alois Riegl, that exemplary art historian who demonstrated a 'willingness to push research forward to the point where even the "insignificant" - no, precisely the insignificant

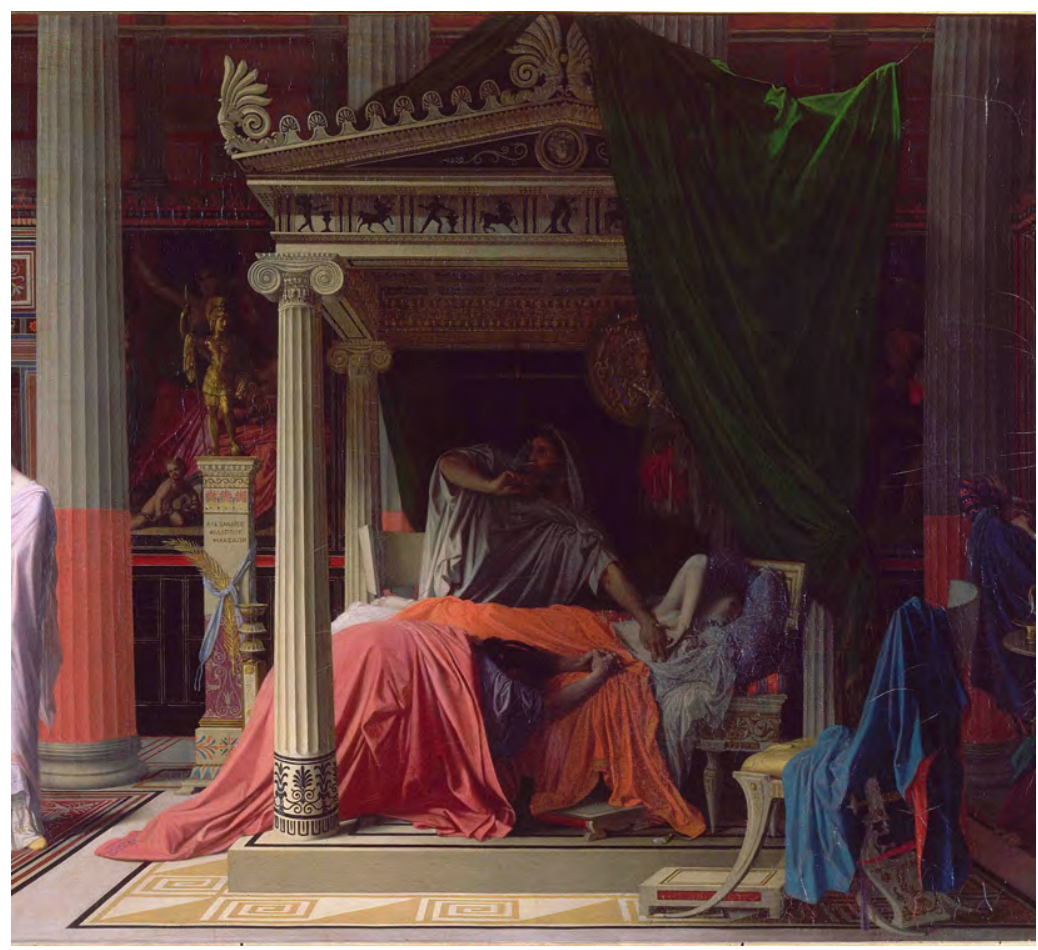

Fig. 5.5. J. A. D. Ingres, Antiochus and Stratonice (detail), 1840. Oil on canvas, $77 \times 61 \mathrm{~cm}$, Musée Condé, Chantilly. 


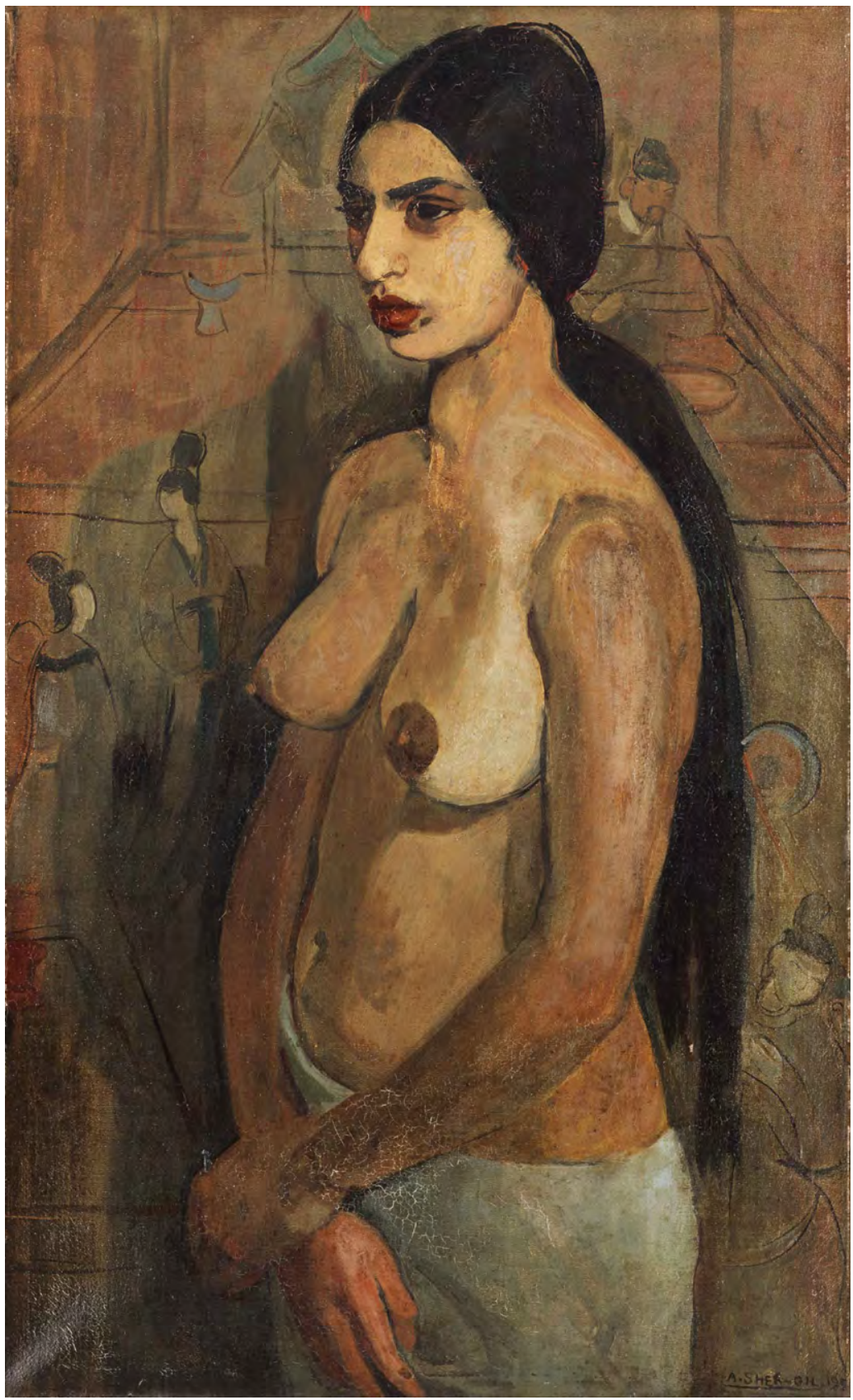

Fig. 5.6. Amrita Sher-Gil, Self-Portrait as a Tahitian, 1934. Oil on canvas, $90 \times 56 \mathrm{~cm}$. (C) Estate of Amrita Sher-Gil / Courtesy of Vivan and Navina Sundaram. 
- becomes significant'. ${ }^{28}$ (In this regard it is worth remembering that although the deliberate accident is often accepted in works of art, art history is reluctant to accept that there could be such a thing as a truly accidental accident in a work of art.) The tactic is common in rethinking apparently familiar works of art, as a feature is picked out and either newly endowed with significance, or given a new and more elaborate significance said to be central to the way the artwork should be made sense of. We see this for instance when Richard Wollheim points out the 'spatial anomalies' of the bed in Ingres' Antiochus and Stratonice that is at once in front of and beside the flanking columns, Whitney Davis picks up on the shape of reflected form of a naked diver in Thomas Eakins's The Swimming Hole, and Saloni Mathur brings into the foreground the loosely sketched Japanese screen in front of which Amrita Sher-Gil's Self-Portrait as Tahitian is posed (Figs. 5.5, 5.6). ${ }^{29}$ The move can equally double back on itself from one interpretation to another, as when Mieke Bal picks up on the 'subsemiotic' elements of Rembrandt's works that, though previously ignored, might be read as meaningful, and James Elkins counters by pointing to the many other blots and streaks in the same works that seem to emphasize the work's continued resistance to being 'read' in the way that Bal desires. ${ }^{30}$

In case the principle of art-historical charity seems like no more than an eccentricity of art writers, it is worth pointing out that it has close parallels in the philosophy of interpretation and the philosophy of history (with the intertwined principles of 'charity' and of 'inference to the best explanation'). Charity has been described as a basic premise of our everyday interpretation of speech and text, where the ability to make sense of one another would simply fall apart if we did not assume some kind of communicative intent, and attempt to 'maximize the truth or rationality in the subject's sayings'. ${ }^{31}$ In the philosophy of history the assumption that individuals act in deliberate and rational ways has likewise been put forward as crucial to any form of historical reconstruction. ${ }^{32}$ In order to make sense of the motives and beliefs of individuals in the past the historian must infer from the scattered available evidence. Such historical reasoning, just as in the historical interpretation of works of art, is a kind of 'inference to the best explanation' or 'abduction': the interpreter reasons about which hypothesis best explains the only partial and inconclusive evidence available to them. ${ }^{33}$ In this abductive sense, the reasoning involved in interpreting a work of art historically is just like that of a detective who looks at the many clues before them and decides how it is that the murder victim died and who it was that killed them. ${ }^{34}$ In this abductive sense, too, without assuming 
some level of rationality, a connection between beliefs, meanings, and motives, the interpreter is left with no constraints whatsoever on how they interpret those in the past. ${ }^{35}$ Art-historical interpretation without any assumption of rationality in aims and outcome is nicely modelled by the moment at the end of our departmental research lectures where my colleague Julian Luxford likes to ask 'but what if they were just, like, totally clueless, a really bad artist', and, realizing that if that were the case we wouldn't be able to say much at all by way of definite interpretation, everyone quietly moves on.

Ubiquitous as its usage is, it should also be said, the emphasis that the principle of art-historical charity places on the makers of works may make it seem implausible to some as a near-universal principle. Some have explicitly taken up Ruskin's language as in talk of 'pictorial intelligence' or 'daunting pictorial thought'. ${ }^{36}$ Others have found psychoanalysis helpful as a way to explain the stray but telling detail as belonging to the artist in a strictly unconscious sense, with, for instance, Griselda Pollock following Mieke Bal in talking of the 'the hysterical reading for the transformative detail'. ${ }^{37}$ But many other interpreters in the history of art have often been coy about who or what is doing the thinking, sometimes metaphorizing elegantly in their writing to attribute the operations of thought not to the artist but to the artwork itself. The device of writing about the work as if it itself is a knowing and thinking entity became not only a common one across the humanities in the twentieth century, but a central methodological plank of a number of the most famous and maverick academic interpreters. Attempting to rethink the device as not just rhetorical but a kind of research programme in itself, scholars of art, science and technology interested in the back and forth between the actions of humans and non-human things have even more recently liked to speak of objects that not only have 'agency' or 'lives', but actually 'think', 'talk', or are 'clever'. In all of these cases, though, it is important not to lose sight of the strictly metaphorical nature in which such agency is attributed: it remains a kind of 'secondary agency' that objects derive from human social use, as Alfred Gell's canonical study of artistic agency has it. ${ }^{38}$ The point was not lost even on the most extreme academic 'overinterpreters' themselves, who set up the work as a knowing or thinking entity, but also noted that this is not a real claim about the work but a heuristic device: a 'self-enabling mystification' or useful 'fiction', standing in for the possibility that the artwork was known like that for someone. ${ }^{39}$ We have already seen in 'mindreading narration' how the artwork can after all be said to be not just like that for someone, but like that for the artist. To see this in one last form, I now turn to depth interpretation, including its own seductive strategy of 'resurfacing'. 


\section{Notes}

1 As explicated and defended in Davies, Philosophical Perspectives on Art and Goldman, Philosophy and the Novel.

2 Paul, 'Weak Historicism', 387; Paul, 'Performing History', 4. Here I read Paul in a descriptive rather than prescriptive sense, though Paul himself notes that 'understanding' is a traditional goal, as outlined in D'Oro, 'Historiographic Understanding'.

3 Quoted in Colin Davis, Critical Excess, 164-5.

4 This idea is prefigured in Paul, 'Weak Historicism'. David Carrier, especially as interpreted by Jonathan Gilmore, is especially revealing in pointing out how, in the standards of truth it applies to interpretation, academic art history operates as one such community; Carrier, Principles of Art History Writing; Gilmore, 'David Carrier's Art History'.

5 Wilenski, The Study of Art.

6 Foster et al., Art since 1900 (2011), 534.

7 This possibility is hinted at (though not made explicit) in, for instance, Nehamas, Only a Promise of Happiness, 22-30.

8 Though I diverge from his reading, I draw here on Livingston, 'Intentionalism in Aesthetics'.

9 Damisch, A Childhood Memory by Piero Della Francesca, 79.

10 Damisch, 62.

11 Leighten, 'Cubist Anachronisms'.

12 Krauss, 'The Motivation of the Sign'.

13 Stark, 'Anonymity and Doubt', 110-15.

14 Troy et al., 'Interventions Review: Art since 1900', 377.

15 Rose, 'Peer Review in Art History'.

16 Tamen, Friends of Interpretable Objects. In this sense much philosophy of art has been deeply misleading in focusing on aesthetic discourse as having the aim of (or leading to) convergence, as opposed to a more general sense of coordination - a point made in Riggle, 'Convergence, Community, and Force in Aesthetic Discourse'.

17 Latour, Pandora's Hope, 183-5, 304. To be clear, I suggest 'blackboxing' as no more than one possible useful label for the process. David Lewis wrote in 1979 that 'Presuppositions can be made or destroyed in the course of a conversation', and philosophy of language has since generated an enormous literature around what Lewis called 'rules of accommodation for conversational score'; Lewis, 'Scorekeeping in a Language Game'. From a very different perspective, Frank Ankersmit's account of how 'aspects' turn into 'things' is another promising route for a more expansive account of the process; Ankersmit, Meaning Truth and Reference in Historical Representation.

18 Loh, 'Renaissance Faciality', 350-3, 354.

19 Clark, Picasso and Truth, 155.

20 Okeke-Agulu, Postcolonial Modernism, 184-96.

21 Okeke-Agulu, 193-4.

22 Okeke-Agulu, 196.

23 Foster, Prosthetic Gods, xiii.

24 Alpers, The Art of Describing, 225.

25 All quotations in this paragraph are from Alpers, 'Interpretation without Representation, or, the Viewing of Las Meninas'. Foucault's interpretation was given in Foucault, The Order of Things.

26 In Alpers's words it is 'the most serious and sustained piece of writing on this work in our time'.

27 Ruskin, Diaries, 437 (Vol. 2) (8 September 1849).

28 Benjamin and Levin, 'Rigorous Study of Art', 86-7. Benjamin attributed the phrase to the Brothers Grimm, though it seems to have originated in a letter from Sulpliz Boisserée to Goethe (86-7, n 11).

29 Wollheim, Painting as an Art, 274; Whitney Davis, 'Erotic Revision in Thomas Eakins's Narratives of Male Nudity'; Mathur, 'A Retake of Sher-Gil's Self-Portrait as Tahitian'.

30 Bal, Reading 'Rembrandt'; Bal, 'Semiotic Elements in Academic Practices'; Elkins, 'What Do We Want Pictures to Be?'.

31 Blackburn, The Oxford Dictionary of Philosophy, 62; Davidson, 'Radical Interpretation'.

32 Dray, 'The Historical Explanation of Actions Reconsidered'; Dray, History as Re-Enactment. 
33 These terms are variously touched on in relation to the interpretation of art, in Wollheim, Richard Wollheim on the Art of Painting; Gell, Art and Agency; Thomasson, 'Ontological Innovation in Art', 127. Also brilliantly telling is Blau, 'History of Political Thought as Detective-Work'.

34 Sherlock Holmes technically reasoned via abduction in its modern sense. 'Modern' sense because in the original sense developed by C. S. Peirce abduction involved the generation of hypotheses rather than choosing between them.

35 Day, The Philosophy of History, 148-9.

36 Alpers, Tiepolo and the Pictorial Intelligence; Clark, 'Veronese's "Allegories of Love".

37 Pollock, Differencing the Canon, 285, drawing on Bal, Reading 'Rembrandt'.

38 Gell, Art and Agency.

39 Colin Davis, Critical Excess, 185. 


\section{6 Depths}

Depth interpretation moves beyond the 'surfaces' of the work that seem most obviously available to experience now, or to have been experienced in the past. Instead it involves the search for what is and was hidden, implicit or repressed. Sometimes what is hidden turns out only to be hidden to us in the present, but available to see and experience for all those in the past who knew how to approach the work a particular way. Sometimes what is hidden was also hidden to those in the past, so that the present analysis reveals in words the work as it really was or is for the very first time. In either case, depth interpretation involves a characteristic double claim: that its analyses show what is truly there to be seen and experienced in the work of art, even though it may be hidden from the historical record that anyone in the past had actually seen and experienced it as such.

This chapter primarily explores depth interpretation through three of its key moves: 'the present absence', in which an absence, gap or contradiction is discovered by the interpreter and shown to be central to the work; 'association as argument', in which the interpreter relies on their present-day associations in order to uncover the seeing and thinking proper to the original historical artwork; and 'resurfacing', in which 'depth' interpretations that yielded things hidden to artists and historical observers alike move to the 'surface', and are said after all to have shown precisely what the original artists and viewers would have seen and thought. Much of what is said in this section is true of large swathes of art history, but to dramatize the points I pick out in particular some of those art historians who have pushed depth interpretation to its often extraordinary limits: the group of modernist art historians working on the edges of art criticism who embraced the influence of post-structuralism in the 1970s and 1980s, for instance, as well as some of the most creative French art historians often in dialogue with those same figures (Louis 
Marin, Hubert Damisch, Georges Didi-Huberman). Done well, depth interpretation can contribute to some of the most exciting art-historical interpretation. Mishandled, as it so often is, it threatens to spiral entirely out of control. No one has put more eloquently than Didi-Huberman the desire to 'surrender ourselves to the contingencies of a phenomenology of the gaze, perpetually subject to projection and transference', 'the sole safety-rail being our poor historical knowledge. ${ }^{1}$ Should we worry that what results is often no more than, as Eddy de Jongh scornfully remarks, 'a conducted tour of a wonderland in the company of a guide whose mental gymnastics are a marvel to behold'? ${ }^{2}$ Or should we follow DidiHuberman in a more joyful embrace of 'The beautiful risks of fiction'? ${ }^{3}$

\section{The suspicion of surfaces}

Even in ordinary interpretation, as we've seen, there are good reasons not to trust the words of the artist and their audiences. It is often productive, likewise, to view overly simple explanations of artworks with suspicion. Depth interpretation takes this distrust further, not only actively refusing the words of participants, or preferring complexity, but as a rule refusing any account that offers a straightforward explanation. Sometimes a rationalistic story really is possible that clearly explains the phenomena in question. ${ }^{4}$ Sometimes we really can reconstruct an artist's likely aims, or the most relevant surrounding context. Depth interpretation must reject this in favour of the hidden and counterintuitive. It privileges the possibility of making 'visible what had not previously been apparent', as the master depth-interpreter Leo Steinberg once put it. ${ }^{5}$

Seen in light of his own statements and those of his first major critical supporter Émile Zola, for instance, Édouard Manet's intentions seem clear enough: to portray contemporary Parisian life as he personally saw things or in his own style, wringing beauty from the surroundings that contemporary painters refused to acknowledge. The many oddities of Manet's work - glaring lights, the flatness of figures, unfinished passages, illogical perspectival constructions - were explained in the artist's own exhibition statement of 1867: 'The effect of sincerity is to give to works a character that makes them resemble a protest, when the only concern of the painter has been to render his impression'. For generations of art critics and historians, following this line, there are no 'errors' in Manet's works in a real sense - true accidental accidents - but simply an emphasis on features that mattered most to the painter, including surface pattern and texture instead of traditional verisimilitude. ${ }^{6}$ This Manet is the true 
founder of the tradition of modernist painters who realized that if they abandoned the pretence of academically understood 'realistic' representation they might find new ways to paint that more effectively responded to their actual experience of the world. In the words of Henri Matisse that stand for one logical outcome of the artistic development, 'I do not literally paint the table, but the emotion it produces upon me'? More simply, painting 'good pictures' (Clement Greenberg) was the only aim recognized by modern artists worth the name. ${ }^{8}$

Or perhaps, if we wish to go deeper, not. What if the lack of shading of Olympia, described by Courbet as 'flat like a playing card', was a more specifically meaningful ploy?? ${ }^{9}$ What if the figure to Olympia's right was more than just a maid presenting flowers from an enamoured client (Fig. 6.1)? In a reading of the painting by the independent art historian Simon Abrahams, the maid is not really a maid but a transformation of the figure of Velázquez in Las Meninas. With Las Meninas the painting 'Manet most admired', it turns out that the maid-Velázquez figure is in fact a disguised self-portrait of Manet at work, holding a painterly and colourful bouquet that transforms into his painter's palette. (Abrahams notes that Manet's friend Baudelaire had after all described Delacroix's palette as 'an expertly matched bouquet of flowers.') ${ }^{10}$ With the maid as

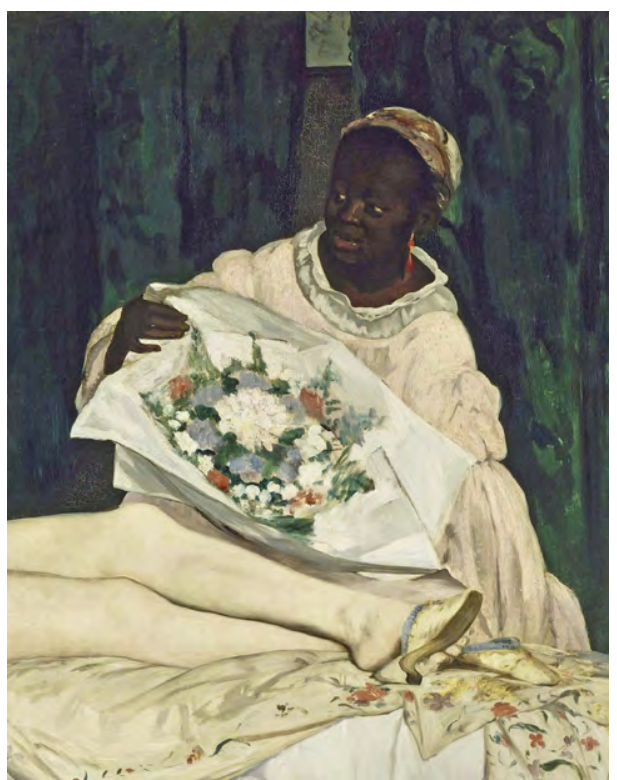

Fig. 6.1. Laure (detail of Édouard Manet, Olympia, 1863), oil on canvas, $130 \times 191 \mathrm{~cm}$. Musée d’Orsay. 
'artist', Abrahams writes, 'Olympia becomes her painting'. The scene, we are invited to realize, is an imaginative depiction of Manet's mind 'in the process of conceiving this very picture', an artist-maid painting Olympia who is 'flat' because she is only a painting within the larger scene. Those artists who later made the painter more present in their own reworkings of the scene, such as Gauguin, Cézanne, and Picasso, all understood this deeper truth.

Abrahams' reading is ultimately, in a move explored at the end of this chapter, a case of depth interpretation that becomes surface interpretation after all, a 'resurfacing' in which the hidden meanings recovered by the art historian are revealed to be Manet's own meanings all along. In 'unlock[ing]' the 'hidden theme[s]' of his works, we read, 'Manet would be cheering you on'. ${ }^{11}$ Here we are beyond the bounds of what 'ordinary' university art history accepts, witnessing the kind of 'eccentric' or 'outlier' art history noted by David Carrier and James Elkins that is produced outside of the legitimating institutions of academic publication and peer acknowledgement. ${ }^{12}$ It is nonetheless, as we will see, surprisingly close to much institutionally legitimated academic art history in depthinterpretative mode.

\section{The present absence}

Often, depth interpretation entails identifying a hidden detail that has so far gone unnoticed and which is then revealed as being key to the work. To this quite general interpretative move - discussed earlier as 'the principle of art-historical charity' - depth interpretation often adds a particular twist. Now even the absence of such a detail can be taken to be instructive, with this absence itself read as a definite feature of the work that becomes central to interpretation. To be clear, sometimes reading for absences and contradictions can be a very specific form of reconstruction, as in writings by Richard Meyer, Jonathan Katz, and others who have brought to light things deliberately obscured by artists - for example the elision of subject matter drawn from queer life which was at the time of making disdained or outright illegal. ${ }^{13}$ Depth interpretation treats its absences and contradictions differently, at least initially implying that agents would not have been aware of these, and yet that they are key to the work nonetheless.

The preference for aspects that are hidden or secret even to their makers but that nonetheless reveal the truth of the work, again, has a long history in the history of art. In his 1860 The Civilization of the Renaissance 
Jacob Burckhardt spoke of how the transmission to posterity of 'the most secret beliefs and ideals' through art was 'all the more trustworthy because it is unintended'. Later in the century Giovanni Morelli suggested that it was the unconsciously produced detail of the artwork that inadvertently revealed the truth of its authorship, and by the early- to mid-twentieth century a range of scholars were discussing Albrecht Dürer's Apocalypse in terms not only of its prophetic anticipation of the Reformation but as what Max Dvořák called a 'polemical pamphlet' aimed at the Catholic Church even though no one had noticed it right through until its twentieth-century art-historical unveiling. ${ }^{14}$ The key moment for the programmatic deployment of the present absence in the history of art, however, came with the early 1970s call for a social history of art that would go beyond the 'empirical' to look for breakdowns in the normal way of things. This was a form of art history that would not take the mass of commentary on art at face value, for 'the points where art criticism is incomprehensible are keys to its comprehension', and would likewise examine artworks and their place in pictorial tradition for 'what prevents representation as much as what allows it', for 'blindness as much as vision'. ${ }^{15}$ This call translated into art-historical terms a growing interpretative trend across film and literary studies: Pierre Macherey's Theory of Literary Production had in 1966 most clearly set out the basic structure, a programme for interpretation according to which a text's 'constituent lacks' were key to the way that it questioned or undermined its apparently obvious meanings. ${ }^{16}$ The move, like the underlying structuralist dictum that works are at their most interesting in the moments when they meaningfully resist easily graspable meaning, has remained standard ever since (even if also an ongoing target of calls for interpretation to move on from the current hegemony of 'critique' and 'historicist-contextualism'). ${ }^{17}$

The simplest use of the present absence is when the writer identifies something that is literally absent from the work, and points out how this absence is in fact a presence of a sort, a kind of definite lack that is crucial to understanding how the work functions. In Linda Nochlin's words we as viewers may be 'haunted by certain absences in the painting', absences that 'are so conspicuous that, once we become aware of them, they begin to function as presences, in fact, as signs of a certain kind of conceptual deprivation'. ${ }^{18}$ In Nochlin's early 1980s text on the Orientalism of JeanLéon-Gérôme's Snake Charmer, then, we cannot properly come to terms with the work (Fig. 6.2) without seeing the absences of 'history' or 'temporal change' and 'Western colonial or touristic presence' in the apparently objective scene it presents. Another social historian of art, Ann Bermingham, in the early 1990s likewise writes of Constable's Hay Wain 


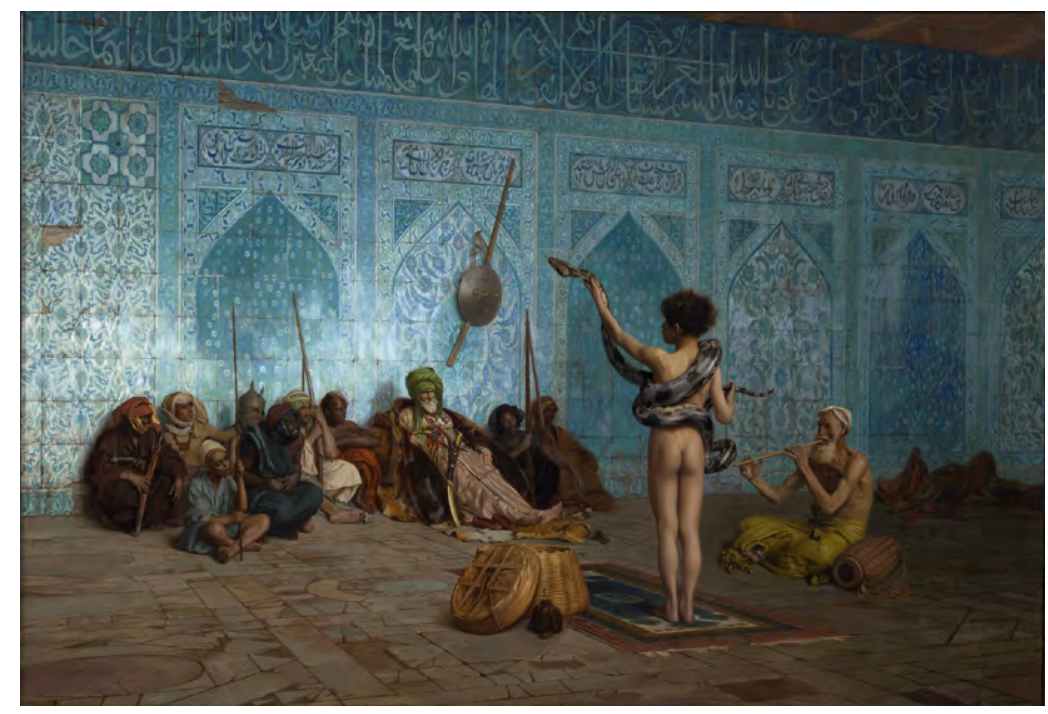

Fig. 6.2. Jean-Léon Gérôme, The Snake Charmer, c. 1879. Oil on canvas, $82.2 \times 121 \mathrm{~cm}$. Sterling and Francine Clark Art Institute, Williamstown.

in terms of the constitutive absence of the nearby mill that Constable must have chosen not to paint, the artwork serving to naturalize a landscape that has in fact been entirely reshaped in the interests of the powerful. ${ }^{19}$ The absence of signs of industry and modern life, capitalism and class, have, as Bermingham's text suggests, become a particular favourite trope of the social history of art that re-examines the many works of early modern and modern art that would appear to show none of these things.

Still central to art historical analysis of landscape, the present absence is currently more likely to be deployed in relation to pressing questions of race, empire, and ecology. Unlike the privatized farmed landscape of the Hay Wain, Gainsborough's Cornard Wood shows a rare area of eighteenth-century British countryside allowed to remain as wooded common land (Fig. 6.3). While a social historian of an earlier moment might point to the absence of agricultural development on the way to a culminating point about the absence of the kind of private ownership that concerned Bermingham, now an interpreter moves from the absence of private ownership to culminating with the absence of modern agricultural development: the painting ultimately presents us with 'a thriving pre-Anthropocene ecosystem, soon to be erased'. ${ }^{20}$ As in the previous chapter we are often left unsure about whose understanding of the artwork the interpretation reveals. The 'elegant' 1830s and 40s lithographs of Joseph Bartholomew Kidd are not innocent renderings of 
beautified views of Jamaica, but in their very absence of enslavement and colonial violence are works that "detoxify" the sugar islands through artful renderings of the plantation landscape'. ${ }^{21}$ Is this a discovery of what is most interesting for us to see in the works now, or a reconstruction of how the works were originally seen or used? The strict depthinterpretative answer is, of course, both and neither, for in setting out the former we have reached a deeper form of the latter, which goes beyond any necessarily conscious or articulable experiences that past makers and users may have had at the time.

Absence may also come in the subtler form of a definite absence of definiteness: an ambiguity, undecidability, or indeterminacy that is nonetheless determinate enough for the critic to pick out as a fundamental feature of the work. (Again literary studies provided the model, as in Paul de Man's comment, after having decided that a Shakespeare line opens on to an 'indefinite number' of possible experiences, that 'the "meaning" of the metaphor is that it does not "mean" in any definite manner'. ${ }^{22}$ )

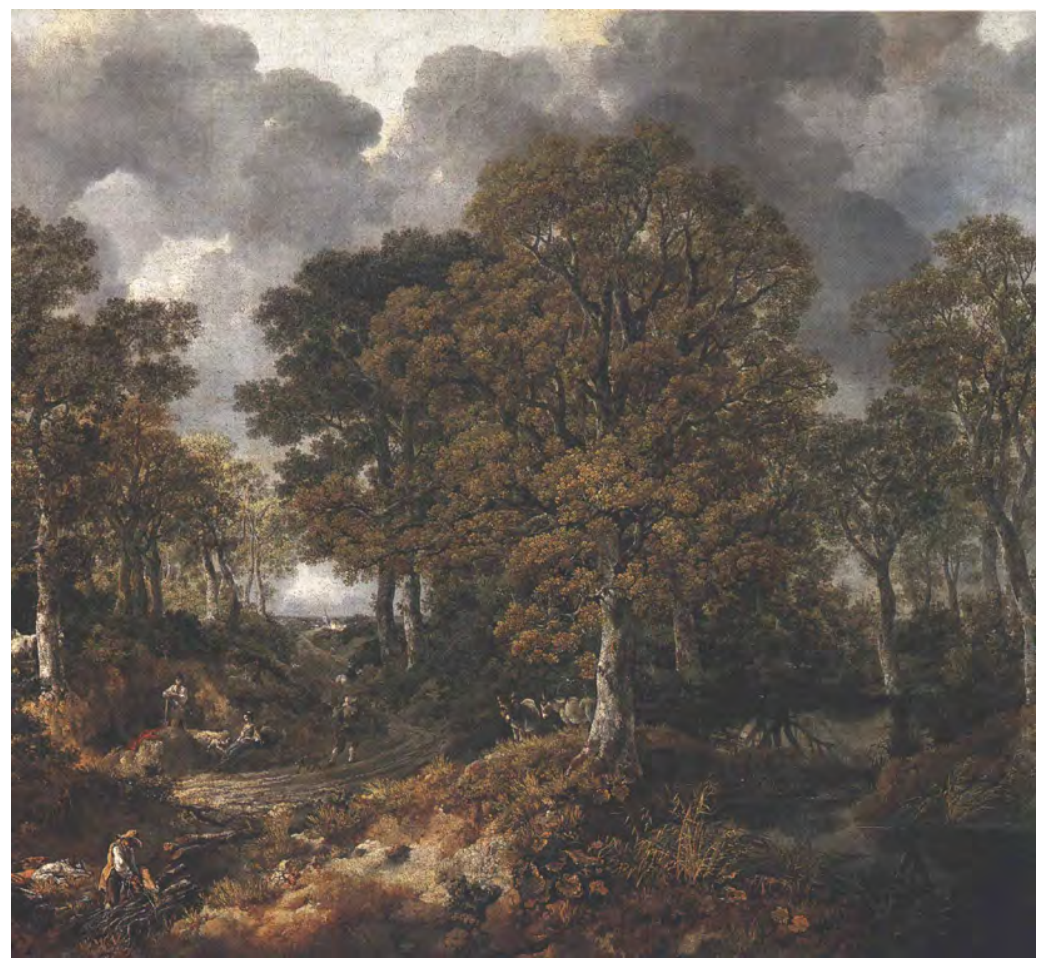

Fig. 6.3. Thomas Gainsborough, Cornard Wood, near Sudbury, Suffolk, 1748. Oil on canvas, $122 \times 155 \mathrm{~cm}$. National Gallery, London. 
In this, interpreters of visual art are aided by the fact that there are some structural features of almost all artworks that can be drawn on to this end. Artworks may represent particular people, scenes, or narratives, for example. Nonetheless there is no way to say for sure that any particular thing is definitely shown unless we know exactly what the artist intended to represent and accept that the artist's intention can determine what the work represents. Instead of arguing about what is represented, art historians can instead embrace the ambiguity head on, arguing that the work is 'structurally' undecidable, and that this structural undecidability is key to its interpretation. Rather than attempt to find clear verbal meanings for the Watteau paintings that generations of interpreters have found 'puzzling' or 'evasive', Norman Bryson argues that Watteau's works seem to both suggest a determined narrative content and disrupt all such attempts to read a fixed meaning into them (Fig. 6.4). It is this fundamental 'semantic vacuum' in the works that gives rise to a flood of writing that fruitlessly labours to fill the gap. ${ }^{23}$

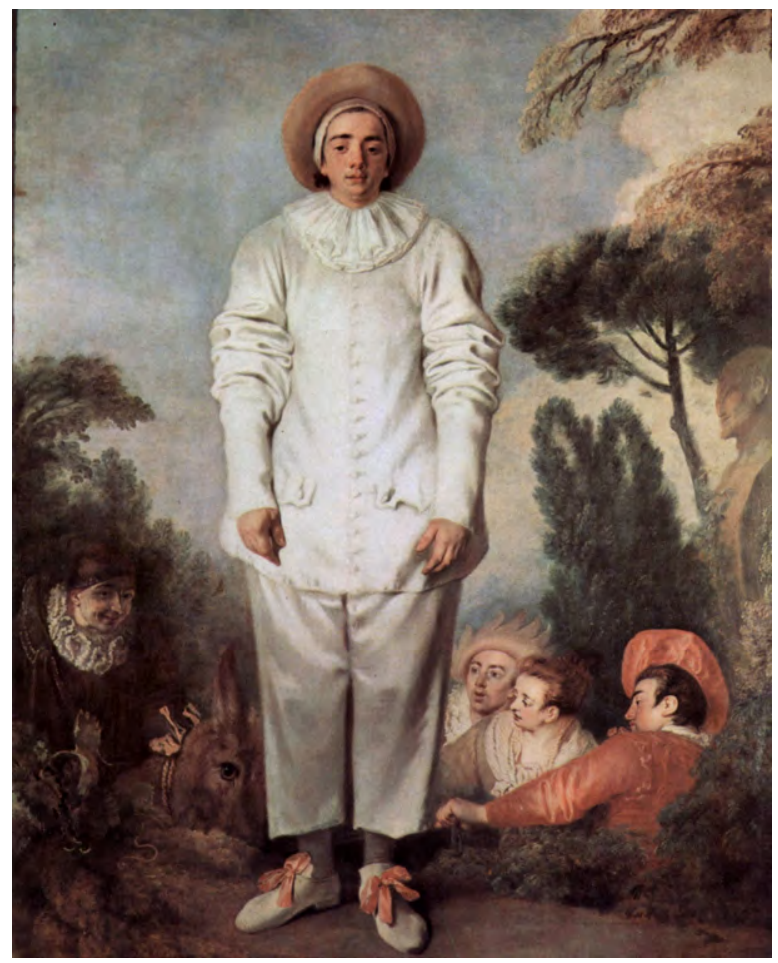

Fig. 6.4. Jean-Antoine Watteau, Pierrot, c. 1718-19. Oil on canvas, $184.5 \times 149.5 \mathrm{~cm}$. Musée du Louvre, Paris. 
In order to support a contention of structural undecidability, interpreters may also contrast multiple critical responses, arguing that the conflict of interpretations is best understood as a result of the objective undecidability of the work at that particular moment. The move is persuasive insofar as it appears evidentially grounded. But just like the feature that is undecidable between being definitely represented and not represented, it ultimately exploits a structural feature common to an enormous number of artworks: that people sometimes say different things about the same artwork. As we've seen in Chapter 4 in relation to Manet's Olympia, any artwork that has had more than one recorded response to it may be presented as objectively undecidable in this way.

Once the absence, gap, or contradiction is constructed as a definite feature, it can be used to demonstrate the hidden social or political functioning of the artwork. A standard tactic here is to link the definite absence or undecidability to a context that is itself characterized by absence or undecidability. The 'luminous obfuscation' of white light on white pigment in a Fra Angelico fresco is linked to the 'ever singular, ever dazzling event' of medieval theological knowledge that eludes closure and is grasped only by revelation. ${ }^{24}$ The 'semantic vacuum' of Watteau's work is linked to the indeterminate 'reverie' of the writing that responds to it. 'Inconsistencies' in Manet's art are linked to the instability of the 'social forms the painter had chosen to show'. The areas cut from the painted surface in a Jackson Pollock painting are linked to Jacques Lacan's account of the anamorphic 'cut' across the field of vision that reveals the subject's lack of mastery of themselves. ${ }^{25}$

In the political slant favoured by social historians and many contemporary art critics, absences might now 'expose', 'contradict' or 'critique' social and artistic assumptions and norms that the interpreter is set against. The most widespread use of this kind of present and disruptive absence in the interpretation of art has long been in the 'critical' art history of modern and contemporary art, where the constitutive absence can be used to cast the interpreter's preoccupation with particular artworks as a deeply socially engaged pursuit. If the artwork is one the critic favours then the revelatory and critical operation it is interpreted as carrying out is likely to be intrinsic to the work, perhaps part of the unconscious action of the artist themselves, or built into the effects of the work in an inevitable manner. If the work is one the critic dislikes, it can be shown to blindly and passively embody ideologies or other structural forces in a way that it took the critic themselves to reveal and condemn. In either case constitutive absences are used to disrupt the bad object in question ('rationalism', 'the subject-object division', 'commodity culture', 
'Greenbergian modernism'), interrogating and undermining what until this moment of artistic production seemed to have been firmly established certainties. Entire critical oeuvres have come to be structured this way. '[T]he book is saturated with judgements', writes one acerbic commentator on a volume containing two decade's worth of essays by one prominent art historian, 'based on the exclusive criteria of whether artists foreground, make apparent, thematize, show or reveal the "underlying conditions" of production (good artists) or whether they hide, conceal, disavow, mythicize, organicize, auraticize, or displace them (bad artists)'. ${ }^{26}$ Exciting as particular instances of depth interpretation's revelation of 'resistance and disjunction' wherever it looks has occasionally been, it is little wonder that used with such indiscriminate disregard for the actual artworks and people it subsumes under its schemes, art criticism of this kind has for many come to seem 'as routine as it is implausible', sometimes reaching 'tautological or vacuous extremes'. ${ }^{27}$

\section{Association as argument}

So depth interpretation tends towards the counterintuitive, searching for the hidden or repressed rather than the straightforward or obvious. In order to bring out such hidden features in practice, depth interpretation often favours playful and associative moves that would not be deemed legitimate or plausible in standard historical reconstruction. A longstanding interpretative habit, the method is allowed as a norm within many institutional settings. There is, after all (and as Chapters 2 and 3 have suggested), good reason to think that it is different sets of 'likenesses' that determine how differently artworks might be taken from one culture and setting to another. Recovering the analogizing activity of original makers and users is in this sense as basic and unarguable a goal for a truly historical form of interpretation as there could be. ${ }^{28}$ Association as argument, however, combines this search for analogy with an extension of the principle of art-critical charity. Now the interpreter not only privileges their own vivid experience of artwork as a route to historical understanding of that work, but more specifically they take their presentday associations to lead to, or simply be equivalent to, the analogizing activity relevant to the original, historical artwork. With association a primary strategy through which to both make the work as interesting as possible in the present and discover the 'original' or 'true' work, interpretation can now be pushed to the limit. 
Association is nowhere simpler than when the pun is put to use. ${ }^{29}$ Freud is here the key early-twentieth-century exponent and model, as in the 'false-step' of a woman dragging her leg, or the 'auto-eroticism' of kissing an uncle in a car. In film criticism as in art history, represented and material features have occasionally been treated this way: cars show 'moving on', hallways the 'passage' of life, descending characters the morally 'fallen', and mirrors that art is a 'mirror of reality'. As these simple examples might suggest, association gets going as an interpretative move when used to transformatively redescribe a feature of the artwork. Such redescription is especially powerful in the history of art given the need to translate artworks into verbal versions for readers. The subtle rhetorical power lies in the fact that while artworks might technically be primary sources for the historian, in writing down what they take to be the features of the artwork the interpreter creates a secondary source that seems to preserve the primary status. 'Objective' as description might seem, there is no getting away from association in the verbal description of visual artworks: even formalist acknowledgements of a 'triangle' and 'left-toright movement' seen in artworks are really statements that the composition appears like a triangle or a left-to-right movement to the viewer; even the statement of a represented detail such as a woman or bouquet is a statement that the feature looks like a woman or bouquet. ${ }^{30}$ But depth interpretation can be far more creative than in these everyday examples with its use of visual-verbal likeness, stretching the bounds of 'is like' far to allow the associative transformation of all manner of features into the thing that best fits the interpretation.

The freely creative power of metaphor in this case is plainest in the writings of belletristic critics working outside the norms of professional art history, such as Walter Pater's description of Luca della Robbia's 'pieces of pale blue and white earthenware' as 'like fragments of the milky sky itself, fallen into the cool streets, and breaking into the darkened churches'. ${ }^{31}$ But highly creative associative redescription has long been common in professional art history, as in Heinrich Wölfflin writing in 1905 on the 'boiling' character of Dürer's woodcuts, or Henri Focillon in 1934 on the Romanesque capital as a 'protean monster [that] rises up and unrolls its demented existence'. ${ }^{32}$ And given sufficient institutional and reputational heft, even more recent art historians can make use of extraordinary forms of association in making sense of works of art. In writing on Thomas Eakins, for instance, Michael Fried works with a thematics of 'violence and disfigurement' that comes to animate all kinds of pictorial and textual features others have found relatively ordinary: figures and faces that are not calm and upright are 'disturbing' or have a 'hint of monstrosity'; hands 
that hold objects or tense up are 'clawlike' and 'violent' contortions that pose a 'threat' to vision; the red sleeve of a figure 'by virtue of its coloristic explosiveness repels the viewer from the painting with the force of a blast'. ${ }^{33}$ In interpretative performances often noted for their bravura, Alex Nemerov radically associates in order to transform one after another pictorial feature far beyond their most obvious likenesses. In a painting by N. C. Wyeth that 'appears to be nothing more than a skilfully literal rendering of an episode from [Robert Louis] Stevenson's novel' Kidnapped, as Rachael DeLue points out, a rain-soaked ship's deck becomes the waxen face of a young boy's corpse, the sails become a mother's apron and then the open pages of a book, rolling waves become the flagstone steps of a path, a brig lost at sea becomes the inviting warmth of home or womb, a shipwrecked boy becomes a boy reading in bed at home, and whitecaps become bedsheets and dreams (Fig. 6.5). ${ }^{34}$

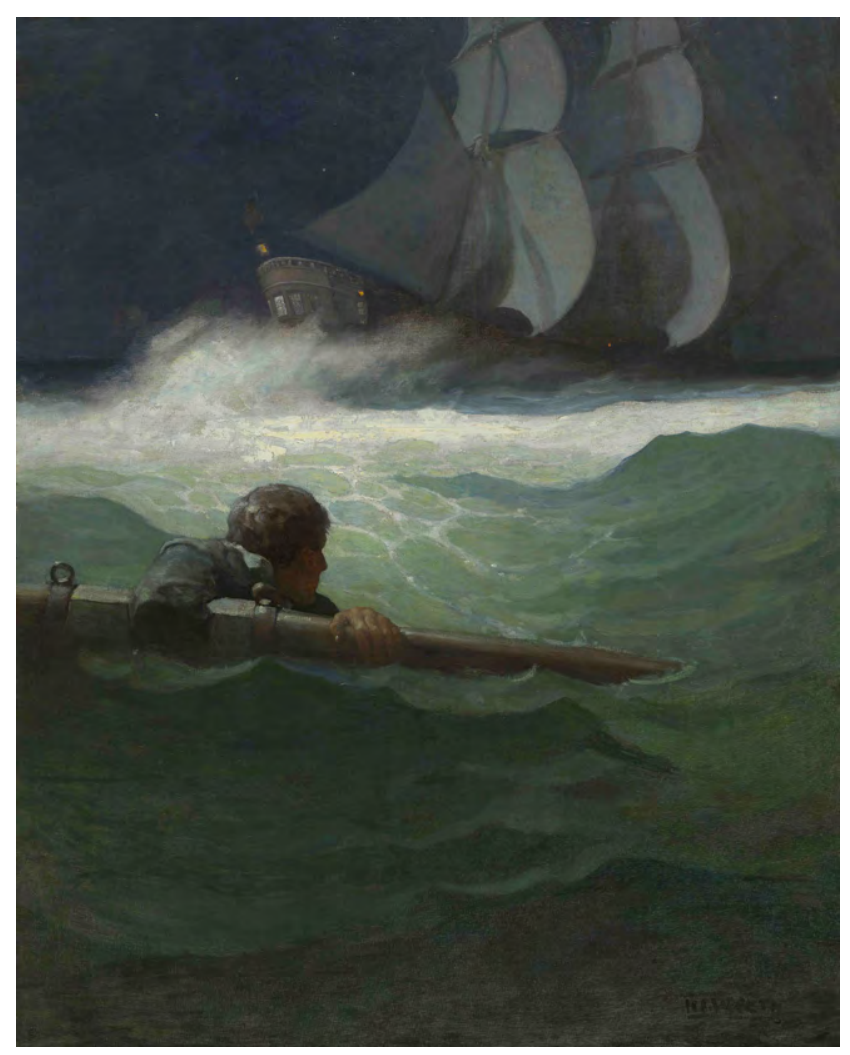

Fig. 6.5. N. C. Wyeth, The Wreck of the 'Covenant', 1913. Oil on canvas, $102.6 \times 81.9 \mathrm{~cm}$. Brandywine River Museum of Art. (C) Brandywine River Museum of Art / Bequest of Mrs. Russell G. Colt, 1986 / Bridgeman Images. 
Once transformed through associations derived from a governing context or contexts, the features can be linked back to the contexts in order to further interpret the work. As DeLue goes on, in a summary of Nemerov's art history worth quoting at length because it shows so much of what has been discussed in this book so far,

Nemerov draws a connection by way of a claim of resemblance between the back turned Robert Dinsmore in an illustration for 'Covered Embers' (1905) and the similarly posed David, whose head turns away from us, his gaze trained on the sinking ship. The latter, by virtue of his linking with the former, who represents the failure of reading, comes to be, in Nemerov's estimation, an exemplar of the power of books. This manner of reading is characteristic of Nemerov's work on other artists and images: the cavity in Frederic Remington's Fight for the Water Hole (1903) resembles a clock and, thus, evokes time and the passing of a historical era; the foodstuffs in Raphaelle Peale's still-life paintings resemble body parts and anatomical illustrations, through which they articulate a drama of identity, the sublime struggle in which a subject constitutes himself (or fails to do so) by identifying with the matter of his world. ${ }^{35}$

DeLue's words here pick out the transformation of particular features that become crucial to an interpretation. But associatively transformed features can also be combined in further 'additive interpretation'. Working with the same thematic of 'disfigurement' seen above, Fried describes writing paper as face-like due to comparable 'size and proportions', and the 'special blankness of the as yet unwritten page' as like the colouristic 'disfiguration' of the 'ashen' face of a dead soldier. Writing paper is now not only a blank face, but an already disfigured face. Bringing the two together we see that writing on that paper is now a further 'disfiguration of the face'. 'The enterprise of writing itself', this interpretative addition finally demonstrates, is revealed 'as an "unnatural" process that undoes but also complements an equally or already "unnatural" state of affairs'. ${ }^{36}$

The blackboxing and addition of such initially playful and provocative associative readings builds even further complexity into academic depth interpretation. In one particularly well-known passage on Courbet's The Stone Breakers, Fried suggests that Courbet had so fully merged himself bodily with the painting that the basket of stones of the left-hand figure and the hammer of the right are in fact the artist's palette and brush, the curves of the figures braced against the rock and bent to break stones a calligraphic tracing of the painters initials 'G.C. ${ }^{37}$ James 
Elkins for one has suggested that this is a moment of deliberate rhetorical excess, but Fried's reading of Courbet has subsequently been blackboxed by art historians who variously take Fried's demonstration as support for their own interpretation of Courbet, as a foundation on which to rethink later realism as a whole, or as a model with which to understand the 'realism' of the almost century-later Indonesian painter S. Sudjojono. ${ }^{38}$ Another art historian, Joanna Woodall, has paralleled the argument with the suggestion that the repeated motif of rounded cooking pots stirred with stick-like ladles in Dutch still life paintings are themselves painterly imaginings of the artist at work with palette and brush. ${ }^{39}$ This has certainly sounded like a return to the painter-maid in Manet's Olympia for one reader. Simon Abrahams, the depth interpreter of Olympia with which we began, has suggested not only that Fried is one of the few art historians to properly draw attention to the meaningful errors in Manet's art, but also that Woodall's analyses comes extremely close to many of Abrahams' own. ${ }^{40}$

Stepping away from strict depth interpretation for just a moment, radical associative transformation, it should be mentioned, is present even in some of the most traditional and long-standing grand narratives of art-historical interpretation. In these cases it has often gone unnoticed when, in an equally transfigurative but far less striking move, it has found sameness across multiple features and artworks. At its most extreme a kind of 'Platonizing' can take place, as many very slightly different features and phenomena are analogized to then be described as one single thing or term. ${ }^{41}$ Laura Mulvey might come close to the record for the rapid treatment of many features this way, when - in a mere two pages of text on the castration anxiety of pop artist Alan Jones - Mulvey diagnoses over twenty things in his work as 'phallic'. ${ }^{42}$ But it is when it is expanded systematically that the technique underpins art-historical attempts to group artworks by periods or explain an unfolding narrative of artistic development: Hegel's 'classical' Greek sculptures that are all entirely 'self-contained' in their unified composition and lack of address to the beholder; Heinrich Wölfflin's Renaissance art characterized uniformly by 'line', 'plane', 'closed form', 'multiplicity', and 'absolute clarity'; Clement Greenberg's history of modernist painting as the story of a century of artists' attempts to remove all traces of 'tactile depth' in search of pictorial 'flatness' and a purely 'optical' experience; Leo Steinberg's 'post-Modernist' 'pictures of the last fifteen to twenty years' that 'insist on a radically new orientation', a horizontal or 'flat-bed picture plane' that 'makes its allusion to hard surfaces such as table tops, studio floors, charts, bulletin boards' ${ }^{43}$ 
The effectiveness in each of these cases is that the interpreter only needs to find features roughly like their chosen terms, and that these can be features likely to be present in an enormous number of works of art. All manner of features can then be redescribed according to the relevant term and elevated as the defining theme of the works in question: unified composition (Hegel's Classical art); line and form (Wölfflin's Renaissance); flatness as well as pictorial depth (Greenberg's modernism); anything that contradicts the sense of the painting as a window onto the world (Steinberg's 'post-modernist' art). In the case of the conflict between flatness and depth, for instance, a whole series of features can be said to call attention to the 'flatness' of the picture surface: firm lines; pronounced brushstrokes; patches of colour; unified composition (which emphasizes the two-dimensional surface); disunified composition (which emphasizes the artifice of picture-making); and so forth. Brilliantly, the fact that none of these features is literally flat becomes not a problem for interpretation but its very basis, as interpretations are written in which the artists seem all along to have thematized the status of the relationship at that particular moment. Cézanne discovers the pursuit of flatness almost by accident in his search for a 'sculptural' impressionism, attempting to use his paint to carve out the real tangibility of things and in the process inadvertently creating not sculptural illusion but an emphasis on the painting as a flat surface. 'Every brush-stroke that followed a fictive plane into fictive depth harked back - by reason of its abiding, unequivocal character as mark made by a brush - to the physical fact of the medium; and the shape and placing of that mark recalled the shape and position of the flat rectangle which was being covered with pigment that came from tubes'. ${ }^{44}$ In linking representation to a kind of linear grid and uniform brushwork Picasso discovers how to represent things in the world that do not recede behind the picture plane but instead float before it in a kind of 'optical' space. With the swirling and dripped mode of his late-1940s canvases Jackson Pollock realizes how to bring this insight into abstraction, rethinking the cubist grid in non-representational and weightless form so that the whole abstract image now floats before the canvas and achieves the pure 'opticality' that modernism had sought all along.

\section{Resurfacing}

Depth interpretation often disavows strict truth claims. It sees itself as playful, open, generative, favouring what it is possible to make out of works of art rather than what was necessarily historically true of them. A 
problem arises because depth interpretation just as often (and often in the same text) also claims to be more than just ludic and freely subjective. The rare programmatic thinkers might stick to their guns, and admit that the truth of their depth-interpretative account holds only in as much as all of the theories (and the combinations thereof) that underpin their work are also true. The contingency of interpretation may also be admitted by those who embrace anachronism or claim only to be doing art criticism, just making the work of art as interesting as possible. But maximizing value or 'interest' of a not intrinsically historical sense is hard to justify as the primary goal for art-historical interpretations of longknown art, and there are few who attempt to work openly on these grounds. In a move common to depth interpretation at least in the history of art, the interpretation instead 'resurfaces'. '[I]f I really believed that "all signs [are] capable of meaning anything and everything simultaneously" ... then there would be no purpose to what I do; writing this essay would be a waste of time', writes Alex Nemerov. ${ }^{45}$ The interpreter sets out their depth interpretation as a surface reading after all: a 'correct' or 'best' historical interpretation in accord with how the work was in its original moment, and even potentially with how the original maker and users of the work would have taken it to be.

It is sometimes said of the theoretical revolution in literary studies which also swept through film and art history that it undid the authority of the interpreter, discrediting the kind of 'deep reading' that involved 'the dogged pursuit of an ultimate, hidden, all-determining truth', and allowing instead a free play of meanings that could be limited by neither maker nor expert interpreter. ${ }^{46}$ In art history specifically, David Carrier had suggested in 1991 that 'post-modern' art-historical interpretation had abandoned all claims to historical truth, and a decade later Keith Moxey seemed confident that art history was moving beyond 'the idea that written histories correspond with events that may have taken place in the past'. ${ }^{47}$ Nonetheless, as the realization in literary studies that a form of 'symptomatic reading' or 'historicist-contextualism' had emerged as the norm suggests, the consequences have been neither quite so simple nor singular. ${ }^{48} \mathrm{~A}$ small group of experimental writers on the edges of the discipline have truly pursued this agenda, and many continue to argue for its importance, though despite producing powerful texts it has proven hard for the academy to assimilate them as a norm. Another route prominently taken by Richard Shiff and Michael Ann Holly, following in Shiff's case the example of earlier art critics who admitted that much about art is impossible to translate into words, has been to embrace doubt: accepting that our words only tangentially connect to the objects that we 
try to do justice to (as well as in a different way the always partially lost contexts that once surrounded them). ${ }^{49}$ A very different route, however, has been to embrace certainty. What seemed to be proposed as merely 'possible' is after all said to be 'intrinsic' to the work, or else mindreading narration presents 'the artist as a conscious agent doing things on purpose' even as claims are made about unconscious and hidden psychological and sociocultural powers. ${ }^{50}$ It is in this way, when depth interpretation 'resurfaces', that it has contributed to giving the interpreter as great, if not greater, a power than ever before.

One especially controversial case in recent years has been the interpretations of formerly avant-garde art critics who entered the academy, wherein it has seemed to some that the very writers who had once apparently endorsed post-structuralism's undoing of authorship and interpretative authority had in fact not only maintained their faith in 'the artist as an originary force of meaning and value', but constructed and embraced a hegemonic position as privileged interpreters of those origins. ${ }^{51}$ Resurfacing makes this powerful, striking, and troubling all at once. One of these interpreters writes characteristically that in the 1960s and 1970s there were:

a group of readings of the work of Jackson Pollock - that work itself a dominant emblem of the sublimatory conditions of the vertical, optically conditioned, pictorial field - by means of which Pollock's painting was defiantly reinterpreted as horizontal. This was true of Andy Warhol's Oxidization paintings, through which Warhol read Pollock's dripped pictures as the work of a urinary trace (as though made by a man standing over a supine field and peeing), thus insisting on the way Pollock's canvases are permanently marked by the horizontality of their making. ${ }^{52}$

Here the interpreter's struggle with Clement Greenberg's controversial view of modernism is generalized as the situation within which artists themselves were bound to operate. The interpreter's even more controversial counterview becomes the basic aim that Warhol had in making his work. Through a mixture of blackboxing and mindreading narration, we see a disagreement between two critics projected backwards and turned into a battle in the consciousness of two artists for the soul of modernist painting. Sexuality is here absent not just from a bold interpretation of Warhol's Oxidation Paintings, but from the artist's very mind. 'Elision' and 'erasure' are terms that have been levelled as a result. ${ }^{53}$ 
Resurfacing may seem like a rather academic issue. Sure, some might object, but these claims are not meant seriously. The status of attributing the results of depth interpretation to the artist or original viewers or as 'intrinsic' to the artwork is like the 'enabling selfmystification' we saw in Chapter 5 of those who metaphorize about 'the text' or 'object' having its own interpretation: a productive 'fantasy', in the words of Stanley Cavell, or a 'necessary working hypothesis' that 'I know ... is not the case' in those of Paul de Man. ${ }^{54}$ Or else, as we saw in Chapter 2 , the interpretation is attributed not to a real-life person but merely an imaginary character consistent with the set of works in question. After all, jokes Colin Davis in his highly revealing study and partial celebration of some of the boldest interpreters of recent years, 'in matters of cultural interpretation we do not actually risk much. Nobody dies, usually. ${ }^{55}$ All the same, as I want to briefly discuss in closing, resurfacing is problematic in both methodological and ethical terms.

What are the problems with resurfacing, and what new possibilities for art historical interpretation arise if we leave resurfacing behind? Methodologically, resurfacing risks flattening history, limiting the full play of possible and actual, present and many different pasts, that (as I touched on in Chapter 4) some of the most ambitious thinking about reception and the future of art history has proposed. It is important here, in understanding the possible breadth of historical interpretation, to stress again the freedom to uncover an artwork that no one up until that point had realized was that particular way. Nemerov's interpretations, typically, capture the work in terms 'largely invisible to [the artist] even as they determined the appearance of [their] picture', a way of engaging the artwork so hidden that 'no one among the original readers and viewers would have seen it in the terms I have presented'. ${ }^{56}$ But this is not just the bold freedom of depth interpretation. Even strict reconstruction (as we have seen in Chapter 3) can reason about what was potentially 'conceptualizable' in the past without any necessary claim that anyone actually did think or act that way. Interpretations can as such analogize between artworks and all manner of contexts that might have been available and may have made a difference to the making or to a possible contemporary observer's engagement with the work.

Rachael DeLue elucidates some of the conditions under which such interpretation can satisfy as history, pointing out that interpretations are effective when they have demonstrated that 'such an evocation or association would have been possible or imaginable in historical terms', or in the case of a particular artist that their 'personal and intellectual investments as well as the cultures ... that [their] own work intersected 
and the discussions ... to which [they were] subjected' make it possible for the paintings to 'manifest the meanings' suggested. ${ }^{57}$ Here we have the first step in a programme for radically imaginative but still historical interpretation: exploring what may have been possible at a particular time and in particular terms even while finding interest in how this search for the possible may be shaped by our own present interests and differ entirely from 'actual' engagements with the work as they have been passed down to us. Resurfacing and mindreading narration, by contrast, often have the effect of flattening histories. 'Possible' becomes 'actual' when interpretations are said to be 'intrinsic' to the work or anchored in the mind of an artist. There is no space left for difference between historical times or individuals past and present, including conflict between the historical past and the present-day interests of the interpreter. In the other direction, the truly historical interpretation that we have seen called for by Avinoam Shalem could instead openly embrace both what may have been possible and what we know to have been actual at any one moment in the past, foregrounding and using the contrast, just as it can foreground and add the same dynamic of the possible and actual across multiple times. This stretches right back to those things that fed into elements of the work and its initial reception, and right through to its presence for us now.

The case is both clearer and more problematic when we think of whether interpretation really does have some ethical and political import, any connection to the world outside the text, studio, gallery, and campus. ${ }^{58}$ If what we say about artworks is only possibly historical, or fictionalizes about the historical person said to engage with an artwork, then claims that interpretation helps us to think with people past and present need to carefully acknowledge and account for that possible or fictional status. If not, blind aestheticism risks shading into active falsification, as interpreters insist on speaking for others despite the fact that what is put into their minds and mouths comes from the present interpreter alone. As with other issues discussed in this book, things are helpfully clear in those cases when artworks and their interpretation touch on live political issues that cannot be ignored. It is telling, for instance, that while a certain contingent of the late-twentieth-century academy celebrated endless interpretative freedom, much queer theory remained committed to an ethics of truth-telling, to the claim 'to have meant what it said'. ${ }^{59}$ It is harder to be blasé about what we attribute to particular persons when their own experiences and stories have always been in danger of being suppressed or erased entirely. 
Even where we have little worry about the ethics of speaking for the artist, worries about speaking for others remain. Do we risk falsifying so much of those real-life political realities that interpretation might otherwise reveal when we ascribe things to artists whom we don't really believe to have worked or thought that way? In Carrie Mae Weems's 1997 Not Manet's Type, a series of five photographs show the artist posed as if a painter's model, the scene visible to the viewer in a circular mirror placed in the corner of the room (Fig. 6.6). Text printed in red below each photograph describes a self-interrogation of sorts as the artist imagines herself at once posed in front of and unsuitable for canonical male modernists; 'It was clear, I was not Manet's type / Picasso - who had a way with women - / only used me \& Duchamp never / even considered me'. As the past tense suggests, and as she has stated elsewhere, the artist's 'critical study' of her body stands in for what these artists 'left out', for a 'historical body that for the most part has not been the subject of these great painters': 'As much as I love them, I revere them, I'm also very, very disappointed in their engagement of the historical body of... the Black self, the Black body, of the Black imagination'. ${ }^{60}$

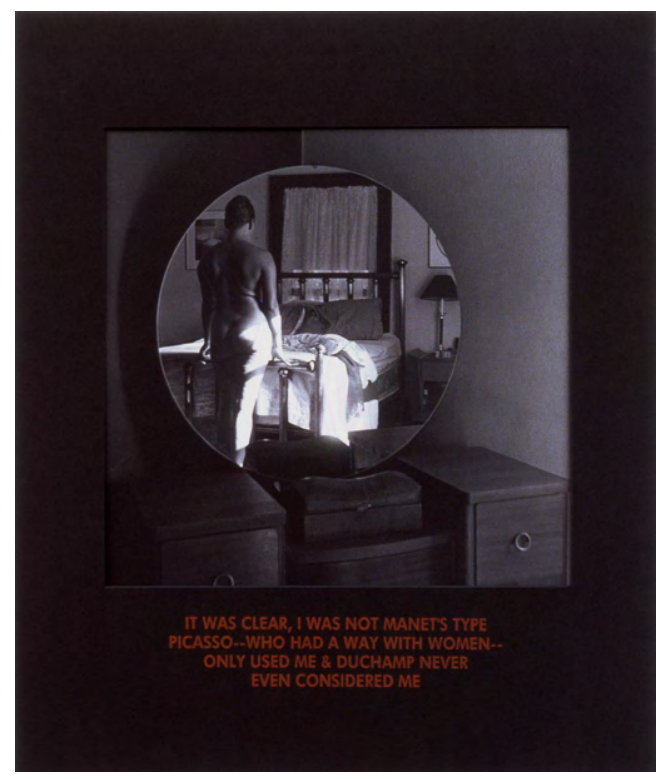

Fig. 6.6. Carrie Mae Weems, Not Manet's Type, 1997. Gelatin silver print with text on mat (second in series of five), $62.9 \times 52.7 \mathrm{~cm}$. San Francisco Museum of Modern Art. (C) Carrie Mae Weems. Courtesy of the artist and Jack Shainman Gallery, New York. 
In recent years scholarship has finally started to properly address one black woman that Manet did paint, Laure, more widely known as the figure of the maid in Manet's Olympia. ${ }^{61}$ Through this writing, interpreters use Manet's painting to allow us to think about race in nineteenth-century France in revelatory ways. Paintings of Laure do not show an exoticized foreigner, but instead a 'newly enfranchised member of the working class', figuring 'the range of the roles ... with which free black Parisian women ... gained an economic foothold and became a fixture in the daily life of Paris', and making 'visible France's former colonial reliance on slavery, as well as its recent enfranchisement of its colonies' slaves and redefinition of all black persons as paid workers'. ${ }^{62}$ In this way, in combination with the complexities of creation, representation, and viewer perception, these works shed light on the dynamics of the 'unresolved anxiety about race in Paris society just fifteen years after the 1848 emancipation of slavery'. ${ }^{63}$ No one could doubt the importance of this writing. But, in the context of Carrie Mae Weems's work, a question raises itself. The representation of Laure breaks dramatically from an exoticizing or 'Orientalizing' mode, but do we really need to attribute this interest to Manet? The norms of interpretation, as we've seen throughout this book, suggest that this is what will result. But knowing these norms could also allow us to operate differently. We could instead acknowledge the power of these recent interpretations in blending artwork, possible and actual responses at different historical moments, and present concerns, to make clear what the artwork helps us realize even though there is no 'resurfacing' possibility that the artist themselves at any level realized these things. And in doing so we could hold together these interpretations of Manet's artwork with that of Manet himself that we find in Not Manet's Type, avoiding redemption of the artist as the master of something as seemingly conscious and controlled as 'Manet's de-Orientalizing project'. ${ }^{64}$ It might seem strange to make so much of a possibility that these interpretations have for the most part carefully avoided. But if the past history of interpretation in the history of art is anything to go by, it will not be long before features like blackboxing and mindreading narration set in, and an 'ambivalent' artist is converted once again to the heroic figure who is everything we could at our most optimistic hope him to have been. ${ }^{65}$ What I have tried to do, in this book, is bring to light some of the interpretative mechanisms and habits through which such a process might unthinkingly take place. With that in mind, the hope is, a more clearsighted set of conversations about the kinds of historical interpretation that might be written, and how we understand the people who emerge from those interpretations, might begin. 


\section{Notes}

1 Didi-Huberman, Confronting Images, 16.

2 de Jongh, 'Review of The Art of Describing', 51.

3 Didi-Huberman, Confronting Images, 16.

4 An explicit experiment in this direction that attempts to explain rather than add complexity is made with Watteau in Elkins, Our Beautiful, Dry, and Distant Texts, Chap. 6.

5 Steinberg, Michelangelo's Last Paintings, 6.

6 The point, found throughout the long formalist tradition taking off from Zola, received a kind of summa in Hamilton, Manet and His Critics, and possibly the most explicit formulation in Howard, 'Early Manet and Artful Error'.

7 Interview with Clara T. MacChesney (1912), in Matisse, Matisse on Art, 66.

8 Greenberg, Clement Greenberg, 218 (Vol. 3).

9 Quotations in this paragraph from Abrahams, 'Manet's Olympia (1863) Part 1' and Abrahams, 'Manet's Olympia (1863) Part 2'.

10 Baudelaire, The Painter of Modern Life and Other Essays, 48.

11 Abrahams, 'Manet's Errors'.

12 Carrier, 'Deep Innovation and Mere Eccentricity: Six case studies of innovation in art history'; Carrier, 'Deep Innovation and Mere Eccentricity in Islamic Art History'; Elkins, Our Beautiful, Dry, and Distant Texts, 1-10. This contrasts slightly with Marc Gotlieb's use of the term 'outsider art history', as I see depth interpretation even within the academy as conforming to his analysis of the researcher's 'profound discovery' of a 'secret ... self-evident to all when at last laid bare'; Gotlieb, 'Our Monstrous Double'.

13 As for instance in Meyer, Outlaw Representation; Katz, 'John Cage's Queer Silence; Or, How to Avoid Making Matters Worse'; and given especially clear formulation in Meyer, 'Lookout: On Queer American art and history'.

14 Burckhardt quoted in Haskell, History and Its Images, 332; Morelli, Italian Masters in German Galleries; Białostocki, Dürer and His Critics, 1500-1971, 265-307.

15 Clark, Image of the People, 12, 15.

16 Macherey, A Theory of Literary Production. The book's first publication in English was in 1978. Crucial for art history was the take-up in film criticism, where the method was normalized in Cahiers du cinéma in the late 1960s and early 1970s, and in Screen from around 1971, as well as in the hands of particular star theorist-interpreters being read by art historians at that time such as Christian Metz and Jean-Louis Baudry. The relevant history of film studies is discussed in Bordwell, Making Meaning, Chap. 6.

17 Culler, Structuralist Poetics, 222-5. The calls have been made for instance in Felski, The Limits of Critique, and North, Literary Criticism.

18 Nochlin, 'The Imaginary Orient'.

19 Bermingham, 'Redesigning Nature: John Constable and the Landscape of Enclosure'.

20 Cheetham, 'Outside In'.

21 Barringer, 'Landscape Then and Now', drawing on Kriz, Slavery, Sugar, and the Culture of Refinement.

22 De Man, Blindness and Insight: Essays in the rhetoric of contemporary criticism, 235.

23 Bryson, Word and Image, Chap. 3.

24 Didi-Huberman, Confronting Images, 11, 19.

25 Fer, On Abstract Art, 95-107.

26 Cronan, 'One Way Cul-de-Sac', 392.

27 Whitney Davis, A General Theory of Visual Culture, 41.

28 A point explored in detail in Davis, A General Theory of Visual Culture, and Davis, Visuality and Virtuality.

29 Here I follow the discussion and examples of punning from Freud and film criticism in Bordwell, Making Meaning, 137-42.

30 Davis, A General Theory of Visual Culture, 150-86.

31 Pater, The Works of Walter Pater, 64 (Vol. 1).

32 Wölfflin, The Art of Albrecht Dürer, 57; Focillon, The Life of Forms in Art, 42.

33 Fried, Realism, Writing, Disfiguration, 61-3, 72.

34 Here I draw on Rachael DeLue's extraordinarily insightful analysis, DeLue, 'Response', itself commenting on Nemerov, 'The Boy in Bed'. 
35 DeLue, 'Response', 35. Nemerov himself talks of his search for visual metaphors that might consist 'of formal resonances between disparate parts of a single picture (coiled hair and spiraling rail in Jim Hawkins Leaves Home); between parts of different pictures by the same artist (The "Covenant" and Hawkins Leaves Home); between pictures by different artists of the same period and training (The "Covenant" and the works of Elizabeth Shippen Green and Jessie Willcox Smith); and between pictures at a diachronic remove (The "Covenant" and precursors such as Thomas Cole's Voyage of Life: Youth)'; Nemerov, 'The Author Replies', 61.

36 Fried, Realism, Writing, Disfiguration, 99-100.

37 Fried, Courbet's Realism, 105-8.

38 Onians, European Art, 311-12; Young, Realism in the Age of Impressionism, 4-6, 11, 138, and passim; Chua, 'Courbet after Sudjojono'.

39 Woodall, 'Laying the Table'.

40 Abrahams, 'Joanna Woodall on Cooking Artists in Dark Rooms'.

41 I take this use of the term from Carroll, Mystifying Movies.

42 Mulvey, Visual and Other Pleasures, 8-10.

43 Wölfflin, Principles of Art History: The problem of the development of style in later art; 'Modernist Painting', in Greenberg, Clement Greenberg, 85-93, Vol. 4; 'Other Criteria', in Steinberg, Other Criteria, 82-91.

44 'Cézanne', in Greenberg, Art and Culture: Critical essays, 55.

45 Nemerov, 'The Author Replies', 61.

46 Felski, 'Introduction', v-vi.

47 Carrier, Principles of Art History Writing; Moxey, The Practice of Persuasion, 9.

48 Best and Marcus, 'Surface Reading'; North, Literary Criticism.

49 Shiff, Doubt; Holly, The Melancholy Art, developing ideas from Davis, 'Winckelmann Divided'.

50 DeLue, 'Response', 41. An excellent alternative view of the implied 'realism' of such analyses has recently been given in Verstegen, 'In the Sistine Chapel with Marcia and Leo' (forthcoming).

51 Troy et al., 'Interventions Review: Art since 1900', 378.

52 Krauss, Cindy Sherman, 95-6.

53 Troy et al., 'Interventions Review: Art since 1900', 378-9.

54 Quotations from Colin Davis, Critical Excess, 185. Davis also notes that Umberto Eco's wellknown appeal to the 'intention of the work' ultimately reduces to a choice between authorial intention or value-maximizing interpretation (167-71), commenting in particular on Eco, Interpretation and Overinterpretation.

55 Colin Davis, Critical Excess, 184.

56 Nemerov, 'The Author Replies', 66.

57 DeLue, 'Response', 36.

58 The literature is too vast to cite here, though it is necessary to at least note Linda Alcoff's foundational essay, Alcoff, 'The Problem of Speaking for Others', and the book that has explored and popularized the term 'epistemic injustice' for such cases, Fricker, Epistemic Injustice. There is clearly great potential for a more extensive analysis of art and literary interpretative ethics in such terms.

59 Kurnick, 'A Few Lies', 349-50.

60 Weems, 'Interview in conjunction with the exhibition The Memory of Time'.

61 O'Grady, 'Olympia's Maid: Reclaiming black female subjectivity'; Pollock, 'A Tale of Three Women: Seeing in the dark, seeing double, at least, with Manet', in Differencing the Canon, 247-316; Murrell, 'Seeing Laure: Race and modernity from Manet's Olympia to Matisse, Bearden and beyond'; Grigsby, 'Still Thinking about Olympia's Maid'; Murrell, Posing Modernity.

62 Grigsby, 'Still Thinking about Olympia's Maid', 432; Murrell, 'Seeing Laure: Race and modernity from Manet's Olympia to Matisse, Bearden and beyond', 37.

63 Murrell, 'Seeing Laure: Race and modernity from Manet's Olympia to Matisse, Bearden and beyond', 9.

64 Murrell, 14; the idea of the painting (though not the historical person Manet) as 'de-Orientalizing' was first proposed in Pollock, Differencing the Canon, 285.

65 'Ambivalent' is Denise Murrell's term, as developed in her extremely subtle analysis in Murrell, 'Seeing Laure: Race and modernity from Manet's Olympia to Matisse, Bearden and beyond', 35-112. 


\section{References}

Abrahams, Simon. 'Manet's Olympia (1863) Part 1'. Everypainterpaintshimself, November 2010. https://www.everypainterpaintshimself.com/article/manets_olympia.

Abrahams, Simon. 'Manet's Errors'. Everypainterpaintshimself, January 2011. https://www. everypainterpaintshimself.com/blog/manets_errors.

Abrahams, Simon. 'Manet's Olympia (1863) Part 2'. Everypainterpaintshimself, March 2011. https://www.everypainterpaintshimself.com/index.php?/article/ manets_olympia_1863_._part_2/.

Abrahams, Simon. 'Joanna Woodall on Cooking Artists in Dark Rooms'. Everypainterpaintshimself, August 2015. https://www.everypainterpaintshimself.com/ blog/joanna_woodall_on_cooking_artist.

Alcoff, Linda. 'The Problem of Speaking for Others'. Cultural Critique 20 (Winter 1991-2): 5-32.

Alpers, Svetlana. The Art of Describing: Dutch art in the seventeenth century. Chicago: University of Chicago Press, 1983.

Alpers, Svetlana. 'Interpretation without Representation, or, the Viewing of Las Meninas'. Representations 1 (1983): 31-42. https://doi.org/10.2307/3043758.

Alpers, Svetlana. Tiepolo and the Pictorial Intelligence. New Haven: Yale University Press , NY, 1994. Ankersmit, F. R. Meaning, Truth, and Reference in Historical Representation. Ithaca, NY: Cornell University Press, 2012.

Anon. 'Editorial: The Duveen Sculpture Galleries'. Burlington Magazine for Connoisseurs 71/413 (1937): 61.

Antal, Frederick. Florentine Painting and Its Social Background. London: K. Paul, 1947.

Auden, W. H. The Shield of Achilles. New York: Random House, 1955.

Bahrani, Zainab. The Infinite Image: Art, time and the aesthetic dimension in antiquity. London: Reaktion Books, 2014.

Bal, Mieke. Reading 'Rembrandt': Beyond the word-image opposition. New York: Cambridge University Press, 1991.

Bal, Mieke. 'Semiotic Elements in Academic Practices'. Critical Inquiry 22/3 (1996): 573-89.

Bal, Mieke. Quoting Caravaggio: Contemporary art, preposterous history. Chicago: University of Chicago Press, 1999.

Bal, Mieke. Exhibition-Ism: Temporal togetherness. Berlin: Sternberg Press, 2020.

Bal, Mieke and Norman Bryson. 'Semiotics and Art History'. Art Bulletin 73/2 (1991): 174-208.

Barolsky, Paul. Why Mona Lisa Smiles and Other Tales by Vasari. University Park, PA: Penn State University Press, 1991.

Barolsky, Paul. Giotto's Father and the Family of Vasari's Lives. University Park, PA: Penn State University Press, 1992.

Barringer, Tim. 'Landscape Then and Now'. British Art Studies 10 (29 November 2018). https:// doi.org/10.17658/issn.2058-5462/issue-10/tbarringer.

Barthes, Roland. 'Le discours de l'histoire'. Social Science Information 6 (April 1967): 63-75.

Barthes, Roland. Image, Music, Text. New York: Hill \& Wang, 1978.

Baudelaire, Charles. The Painter of Modern Life and Other Essays. London: Phaidon Press, 1995.

Baxandall, Michael. Painting and Experience in Fifteenth Century Italy: A primer in the social history of pictorial style. Oxford: Clarendon Press, 1972.

Baxandall, Michael. 'The Language of Art History'. New Literary History 10/3 (1979): 453-65.

Baxandall, Michael. Patterns of Intention: On the historical explanation of pictures. New Haven: Yale University Press, 1985. 
Beeny, Emily A. 'Christ and the Angels'. Representations 122/1 (1 May 2013): 51-82.

Benjamin, Walter and Thomas Y. Levin. 'Rigorous Study of Art'. October 47 (1988): 84-90.

Berenson, Bernard. The Study and Criticism of Italian Art. London: G. Bell, 1901.

Bermingham, Ann. 'Redesigning Nature: John Constable and the landscape of enclosure'. In Nowhere: Space, time and modernity, edited by Roger Friedland and Deirdre Boden, 236-56. Berkeley: University of California Press, 1994.

Best, Stephen and Sharon Marcus. 'Surface Reading: An introduction'. Representations 108/1 (2009): 1-21.

Białostocki, Jan. Dürer and His Critics, 1500-1971: Chapters in the history of ideas, including a collection of texts. Baden-Baden: V. Koerner, 1986.

Blackburn, Simon. Oxford Dictionary of Philosophy. New York: Oxford University Press, 1994.

Blau, Adrian. 'History of Political Thought as Detective-Work'. History of European Ideas 41/8 (17 November 2015): 1178-94.

Bockemühl, Michael. Die Wirklichkeit des Bildes: Bildrezeption als Bildproduktion: Rothko, Newman, Rembrandt, Raphael. Stuttgart: Urachhaus, 1985.

Boime, Albert. 'Blacks in Shark-Infested Waters: Visual encodings of racism in Copley and Homer'. Smithsonian Studies in American Art 3/1 (1 January 1989): 19-47.

Bordwell, David. Making Meaning: Inference and rhetoric in the interpretation of cinema. Cambridge, MA: Harvard University Press, 1989.

Bredekamp, Horst, Andreas Beyer, Uwe Fleckner and Gerhard Wolf (eds). Bilderfahrzeuge: Aby Warburgs Vermächtnis und die Zukunft der Ikonologie. Berlin: Verlag Klaus Wagenbach, 2018.

Bryson, Norman. Word and Image: French painting of the ancien régime. New York: Cambridge University Press, 1981.

Bryson, Norman. Looking at the Overlooked: Four essays on still life painting. Cambridge, MA: Harvard University Press, 1990.

Bryson, Norman. 'Art in Context'. In The Point of Theory: Practices of cultural analysis, edited by Mieke Bal and Inge E. Boer, 66-78. Amsterdam: Amsterdam University Press, 1994.

Burckhardt, Jacob. Der Cicerone: Eine Anleitung zum Genuss der Kunstwerke Italiens. Basel: Schweighauser'sche Verlagsbuchhandlung, 1855.

Camille, Michael. 'Mouths and Meanings: Towards an anti-iconography of medieval art'. In Iconography at the Crossroads, edited by Brendan Cassidy, 43-85. Princeton: Princeton University Press, 1993.

Carreira da Silva, Filipe and Patrick Baert. Social Theory in the Twentieth Century and Beyond. 2nd ed. Cambridge: Polity, 2010.

Carrier, David. Principles of Art History Writing. University Park, PA: Penn State University Press, 1991.

Carrier, David. 'Deep Innovation and Mere Eccentricity: Six case studies of innovation in art history'. In Art History and Its Institutions: Foundations of a discipline, edited by Elizabeth Mansfield, 115-31. London: Routledge, 2002.

Carrier, David. 'Deep Innovation and Mere Eccentricity in Islamic Art History'. In Making Art History: A changing discipline and its institutions, edited by Elizabeth Mansfield 173-86. London: Routledge, 2007.

Carroll, Noël. Mystifying Movies: Fads and fallacies in contemporary film theory. New York: Columbia University Press, 1988.

Carroll, Noël. 'Interpretation and Intention: The debate between hypothetical and actual intentionalism'. Metaphilosophy 31/1-2 (2000): 75-95.

Cheetham, Mark A. 'Outside In: Reflections of British landscape in the long Anthropocene'. British Art Studies 10 (29 November 2018). https://doi.org/10.17658/issn.2058-5462/issue-10/ mcheetham.

Chowdhury, Zirwat. 'An Imperial Mughal Tent and Mobile Sovereignty in Eighteenth-Century Jodhpur'. Art History 38/4 (2015): 668-81.

Chua, Kevin. 'Courbet after Sudjojono'. Art History 41/2 (2018): 292-317.

Clark, T. J. Image of the People: Gustave Courbet and the 1848 revolution. London: Thames \& Hudson, 1973.

Clark, T. J. 'Preliminaries to a Possible Treatment of Olympia in 1865'. Screen 21 (Spring 1980): $18-41$.

Clark, T. J. The Painting of Modern Life: Paris in the art of Manet and his followers. Rev. ed. Princeton: Princeton University Press, 1999.

Clark, T. J. 'Art History in an Age of Image-Machines'. EURAMERICA 38 (March 2008): 1-30. 
Clark, T. J. Picasso and Truth: From Cubism to Guernica (A. W. Mellon Lectures in the Fine Arts). Princeton: Princeton University Press, 2013.

Clark, T. J. 'Veronese's “Allegories of Love”'. London Review of Books 36/7 (3 April 2014). https:// www.lrb.co.uk/the-paper/v36/n07/t.j.-clark/veronese-s-allegories-of-love.

Cohn, Dorrit. 'Signposts of Fictionality: A narratological perspective'. Poetics Today 11/4 (1990): $775-804$.

Cronan, Todd. 'One Way Cul-de-Sac: Benjamin Buchloh's art history'. Art History 41/2 (2018): 392-4.

Crow, Thomas. 'Codes of Silence: Historical interpretation and the art of Watteau'. Representations 12 (1985): 2-14.

Crow, Thomas. 'The Practice of Art History in America'. Daedalus 135/2 (2006): 70-90.

Culler, Jonathan D. Structuralist Poetics: Structuralism, linguistics, and the study of literature. Ithaca, NY: Cornell University Press, 1975.

DaCosta Kaufmann, Thomas. 'Reception Theory'. In The Dictionary of Art, Vol. 26, 61-4. Basingstoke: Macmillan, 1996.

D'Alleva, Anne. Methods and Theories of Art History. London: Laurence King, 2005.

Damisch, Hubert. A Childhood Memory by Piero Della Francesca, trans. John Goodman. Stanford, CA: Stanford University Press, 2007.

Danto, Arthur C. The Philosophical Disenfranchisement of Art. New York: Columbia University Press, 1986.

Davidson, Donald. 'Radical Interpretation'. Dialectica 27/3-4 (1973): 313-28.

Davidson, Donald. 'What Metaphors Mean'. Critical Inquiry 5/1 (1978): 31-47.

Davies, Stephen. Philosophical Perspectives on Art. New York: Oxford University Press, 2007.

Davis, Colin. Critical Excess: Overreading in Derrida, Deleuze, Levinas, Žižek and Cavell. Stanford, CA: Stanford University Press, 2010.

Davis, Whitney. The Canonical Tradition in Ancient Egyptian Art. New York: Cambridge University Press, 1989.

Davis, Whitney. 'Finding Symbols in History'. In Animals into Art, edited by Howard Morphy, 170-89. London: Unwin Hyman, 1989.

Davis, Whitney. Masking the Blow: The scene of representation in late prehistoric Egyptian art. Berkeley: University of California Press, 1992.

Davis, Whitney. 'Erotic Revision in Thomas Eakins's Narratives of Male Nudity'. Art History 17/3 (1994): 301-41.

Davis, Whitney. 'Winckelmann Divided'. Journal of Homosexuality 27/1-2 (15 September 1994): 141-60.

Davis, Whitney. A General Theory of Visual Culture. Princeton: Princeton University Press, 2011.

Davis, Whitney. 'Queer Family Romance in Collecting Visual Culture'. GLQ: A Journal of Lesbian and Gay Studies 17/2-3 (1 June 2011): 309-29.

Davis, Whitney. 'Art History, Re-Enactment, and the Idiographic Stance'. In Michael Baxandall: Vision and the work of words, edited by Peter Mack and Robert Williams, 69-89. Abingdon: Ashgate, 2015.

Davis, Whitney. Visuality and Virtuality: Images and pictures from prehistory to perspective. Princeton: Princeton University Press, 2017.

Day, Mark. The Philosophy of History: An introduction. New York: Continuum, 2008.

DeLue, Rachael Ziady. 'Response: Seeing and reading N. C. Wyeth and Robert Louis Stevenson'. The Art Bulletin 88/1 (2006): 33-42.

De Man, Paul. Blindness and Insight: Essays in the rhetoric of contemporary criticism. New York: Oxford University Press, 1971.

Diderot, Denis. CEuvres esthétiques. Paris: Garnier, 1968.

Diderot, Denis. Salons. 2nd ed. Oxford: Clarendon Press, 1975.

Diderot, Denis. Essais sur la peinture: Salons de 1759, 1761, 1763, edited by Gita May and Jacques Chouillet. Paris: Herman, 1984.

Diderot, Denis. OEuvres. Paris: R. Laffont, 1994.

Didi-Huberman, Georges. Confronting Images: Questioning the ends of a certain history of art. University Park, PA: Penn State University Press, 2005.

Didi-Huberman, Georges. The Surviving Image: Phantoms of time and time of phantoms: Aby Warburg's history of art. University Park, PA: Penn State University Press, 2017.

Donagh, Rita. 'Georgia O’Keeffe in Context'. Oxford Art Journal 3/1 (April 1980): 44-51.

D’Oro, Guiseppina. 'Historiographic Understanding'. In A Companion to the Philosophy of History and Historiography, edited by Aviezer Tucker, 142-51. Chichester: Wiley-Blackwell, 2009. 
Dray, William. 'The Historical Explanation of Actions Reconsidered'. In Philosophy and History, edited by Sidney Hook, 105-35. New York: New York University Press, 1963.

Dray, William. History as Re-Enactment: R. G. Collingwood's Idea of History. New York: Oxford University Press, 1995.

Eco, Umberto. Interpretation and Overinterpretation. Cambridge: Cambridge University Press, 1992.

Elkins, James. 'What Do We Want Pictures to Be? Reply to Mieke Bal'. Critical Inquiry 22/3 (April 1996): 590-602.

Elkins, James. On Pictures and the Words That Fail Them. New York: Cambridge University Press, 1998.

Elkins, James. Our Beautiful, Dry, and Distant Texts: Art history as writing. New York: Routledge, 2000.

Elkins, James. 'Art History as a Global Discipline'. In Is Art History Global?, edited by James Elkins, 3-23. London: Routledge, 2007.

Elsner, Jaś. 'Art History as Ekphrasis'. Art History 33 (January 2010): 10-27.

English, Darby. How to See a Work of Art in Total Darkness. Cambridge, MA: MIT Press, 2007.

English, Darby. 1971: A year in the life of color. Chicago: University of Chicago Press, 2016.

Félibien, André. Conferences de l'Academie royale de peinture et de sculpture: Pendant l'année 1667. Paris: Chez Frederic Leonard, 1669.

Félibien, André. Seven Conferences Held in the King of France's Cabinet of Paintings: Between Mr. Le Brun, Mr. Bourdon, Mr. De Champagne, Mr. Perrault, \&c. on Some of the Most Celebrated Pictures of Raphael, Titian ... Translated from the French of Felibien. With a Curious Preface. London: Printed for T. Cooper, 1740.

Felski, Rita. 'Introduction'. New Literary History 45/2 (2014): v-xi.

Felski, Rita. The Limits of Critique. Chicago: University of Chicago Press, 2015.

Fer, Briony. On Abstract Art. New Haven: Yale University Press, 1997.

Fine, Gary Alan. Talking Art: The culture of practice and the practice of culture in MFA education. Chicago: University of Chicago Press, 2018.

Fish, Stanley. Doing What Comes Naturally: Change, rhetoric, and the practice of theory in literary and legal studies. Durham, NC: Duke University Press, 1989.

Flax, Neil. 'Fiction Wars of Art'. Representations 7 (1984): 1-25.

Focillon, Henri. The Life of Forms in Art. New York: Zone Books, 1989.

Fort, Bernadette. 'Voice of the Public: The carnivalization of salon art in prerevolutionary pamphlets'. Eighteenth-Century Studies 22 (1989): 368-94.

Fort, Bernadette. 'An Academician in the Underground: Charles-Nicolas Cochin and art criticism in eighteenth-century France'. Studies in Eighteenth-Century Culture 23 (1994): 3-27.

Foster, Hal. Prosthetic Gods. Cambridge, MA: MIT Press, 2004.

Foster, Hal, Rosalind Krauss, Yve-Alain Bois and Benjamin Buchloch. Art since 1900: Modernism, antimodernism, postmodernism. 2 vols. London: Thames \& Hudson, 2004.

Foster, Hal, Rosalind Krauss, Yve-Alain Bois, Benjamin Buchloch and David Joselit. Art since 1900: Modernism, antimodernism, postmodernism. 2nd ed. 2 vols. London: Thames \& Hudson, 2011.

Foucault, Michel. The Order of Things: An archaeology of the human sciences. New York: Vintage Books, 1973.

Foucault, Michel. Aesthetics, Method, and Epistemology. New York: New Press, 1998.

Freud, Sigmund. 'Der Moses Des Michelangelo'. Imago 3 (1914): 15-36.

Freud, Sigmund. Collected Papers. (International Psycho-Analytical Library, 7-10). Vienna: International Psycho-Analytical Press, 1924.

Fricker, Miranda. Epistemic Injustice: Power and the ethics of knowing. Oxford: Oxford University Press, 2007.

Fried, Michael. Realism, Writing, Disfiguration: On Thomas Eakins and Stephen Crane. Chicago: University of Chicago Press, 1987.

Fried, Michael. Courbet's Realism. Chicago: University of Chicago Press, 1990.

Fried, Michael. Manet's Modernism, or, The Face of Painting in the 1860s. Chicago: University of Chicago Press, 1996.

Frow, John. On Interpretive Conflict. Chicago: University of Chicago Press, 2019.

Fry, Roger. Flemish Art: A critical survey. London: Chatto and Windus, 1927.

Gell, Alfred. Art and Agency: An anthropological theory. Oxford: Clarendon Press, 1998.

Genette, Gérard. 'Fictional Narrative, Factual Narrative'. Poetics Today 11/4 (1990): 755-74. 
Gilmore, Jonathan. 'David Carrier's Art History'. Journal of Aesthetics and Art Criticism 53/1 (1995): 39-47.

Gilmore, Jonathan. The Life of a Style: Beginnings and endings in the narrative history of art. Ithaca, NY: Cornell University Press, 2000.

Goethe, Johann Wolfgang von. Gedenkausgabe der Werke, Briefe und Gespräche. Zürich: Artemis-Verlag, 1948.

Goldman, Alan H. Philosophy and the Novel. Oxford: Oxford University Press, 2013.

Gombrich, E. H. Ideals and Idols: Essays on values in history and in art. Oxford: Phaidon, 1979.

Gombrich, E. H. Topics of Our Time: Twentieth-century issues in learning and in art. Berkeley: University of California Press, 1991.

Gotlieb, Marc. 'Our Monstrous Double: The dream of research in "outsider art history"'. In What is Research in the Visual Arts? Obsession, archive, encounter, edited by Michael Ann Holly and Marquard Smith, 85-102. Williamstown, MA: Sterling and Francine Clark Art Institute, 2008.

Gowing, Lawrence. Vermeer. New York: Harper \& Row, 1970.

Grant, James Eric. The Critical Imagination. Oxford: Oxford University Press, 2013.

Green, Nicholas. 'Dealing in Temperaments: Economic transformation of the artistic field in France during the second half of the nineteenth century'. Art History 10 (March 1987): 57-76.

Green, Nicholas. 'Stories of Self-Expression: Art history and the politics of individualism'. Art History 10 (December 1987): 527-32.

Greenberg, Clement. Art and Culture: Critical essays. Boston: Beacon Press, 1961.

Greenberg, Clement. Clement Greenberg: The collected essays and criticism. Chicago: University of Chicago Press, 1986.

Grigsby, Darcy. 'Still Thinking about Olympia's Maid'. The Art Bulletin 97 (2015): 430-51.

Grootenboer, Hanneke. 'The Pensive Image: On thought in Jan van Huysum's still life paintings'. Oxford Art Journal 34/1 (1 March 2011): 13-30.

Grootenboer, Hanneke. Review of 'Rembrandt: The Painter Thinking'. Caareviews, December 2017. http://www.caareviews.org/reviews/2901.

Guercio, Gabriele. Art as Existence: The artist's monograph and its project. Cambridge, MA: MIT Press, 2006.

Gumbrecht, Hans Ulrich. Production of Presence: What meaning cannot convey. Stanford, CA: Stanford University Press, 2004.

Hamilton, George Heard. Manet and His Critics. New Haven: Yale University Press, 1954.

Haskell, Francis. History and Its Images: Art and the interpretation of the past. New Haven: Yale University Press, 1993.

Hauser, Arnold. The Social History of Art. 2nd ed. London: Routledge and Kegan Paul, 1962.

Heffernan, A. W. Museum of Words: The poetics of ekphrasis from Homer to Ashbery. Chicago: University of Chicago Press, 1993.

Hegel, Georg Wilhelm Friedrich. Sämtliche Werke. Stuttgart: F. Frommann, 1957.

Hegel, Georg Wilhelm Friedrich. Aesthetics: Lectures on fine art. Oxford: Clarendon Press, 1975.

Heinich, Nathalie. The Glory of Van Gogh: An anthropology of admiration, trans. Paul Leduc Browne. Princeton: Princeton University Press, 1997.

Hennion, Antoine. 'Those Things That Hold Us Together: Taste and sociology'. Cultural Sociology 1/1 (1 March 2007): 97-114.

Hennion, Antoine. The Passion for Music: A sociology of mediation, trans. Margaret Rigaud. Abingdon: Ashgate, 2015.

Hennion, Antoine. 'From ANT to Pragmatism: A journey with Bruno Latour at the CSI'. New Literary History 47/2-3 (2016): 289-308.

Hennion, Antoine and Bruno Latour. 'Objet d'art, objet de science: Note sur les limites de l'anti-fétichisme'. Sociologie de l'art 6 (1993): 7-24.

Hentschel, Klaus. Visual Cultures in Science and Technology: A comparative history. New York: Oxford University Press, 2014.

Herbert, James. Brushstroke and Emergence: Courbet, Impressionism, Picasso. Chicago: University of Chicago Press, 2015.

Hofmann, Werner. 'Picasso's "Guernica” in Its Historical Context'. Artibus et Historiae 4/7 (1983): 141-69.

Holly, Michael Ann. The Melancholy Art. Princeton: Princeton University Press, 2013.

Homer. The Iliad of Homer, trans. Alexander Pope. Edinburgh: Hamilton, Balfour \& Neiie, 1761.

Houston, Kerr. An Introduction to Art Criticism: Histories, strategies, voices. Boston: Pearson, 2013. 
Howard, Seymour. 'Early Manet and Artful Error: Foundations of anti-illusion in modern painting'. Art Journal 37/1 (1977): 14-21.

Interview Magazine. 'Cindy Sherman', 23 November 2008. https://www.interviewmagazine.com/ art/cindy-sherman.

Irvin, Sherri. 'The Artist's Sanction in Contemporary Art'. Journal of Aesthetics and Art Criticism 63/4 (2005): 315-26.

Iser, Wolfgang. The Act of Reading: A theory of aesthetic response. Baltimore: Johns Hopkins University Press, 1980.

Iversen, Margaret and Stephen Melville. Writing Art History: Disciplinary departures. Chicago: University of Chicago Press, 2010.

Jasienski, Adam. 'Converting Portraits: Repainting as art making in the early modern Hispanic world'. Art Bulletin 102/1 (2 January 2020): 7-30.

Jauss, Hans Robert. Toward an Aesthetic of Reception. Minneapolis: University of Minnesota Press, 1981.

Johnson, Marion. 'Art in Context'. Journal of African History 24/3 (1983): 413-14.

Jongh, E. de. Review of The Art of Describing: Dutch art in the seventeenth century, by Svetlana Alpers. Simiolus: Netherlands Quarterly for the History of Art 14/1 (1984): 51-9.

Juneja, Monica. 'Circulation and Beyond: The trajectories of vision in early modern Eurasia'. In Circulations in the Global History of Art, edited by Béatrice Joyeux-Prunel, Catherine Dossin and Thomas DaCosta Kaufman, 59-79. London: Routledge, 2015.

Katz, Jonathan D. 'John Cage's Queer Silence: Or, how to avoid making matters worse'. GLQ: A Journal of Lesbian and Gay Studies 5/2 (1 April 1999): 231-52.

Kemp, Wolfgang (ed.). Der Betrachter ist im Bild: Kunstwissenschaft und Rezeptionsästhetik. Cologne: DuMont, 1985.

Kemp, Wolfgang. 'The Work of Art and Its Beholder'. In The Subjects of Art History: Historical objects in contemporary perspectives, edited by Mark A. Cheetham, Michael Ann Holly and Keith P. F. Moxey, 180-96. New York: Cambridge University Press, 1998.

Kidson, Peter. 'Panofsky, Suger and St Denis'. Journal of the Warburg and Courtauld Institutes 50 (1987): 1-17.

Kivy, Peter (ed.). The Blackwell Guide to Aesthetics. Malden, MA: Blackwell, 2004.

Krauss, Rosalind E. The Originality of the Avant-Garde and Other Modernist Myths. Cambridge, MA: MIT Press, 1985.

Krauss, Rosalind E. 'The Motivation of the Sign'. In Picasso and Braque: A symposium, edited by Lynn Zelevansky, 261-86. New York: Museum of Modern Art, 1992.

Krauss, Rosalind E. Cindy Sherman, 1975-1993. New York: Rizzoli, 1993.

Kriz, Kay Dian. Slavery, Sugar, and the Culture of Refinement: Picturing the British West Indies, 1700-1840. New Haven: Yale University Press, 2008.

Kurnick, David. 'A Few Lies: Queer theory and our method melodramas'. ELH 87 (Summer 2020): 349-74.

La Font de Saint-Yenne. Oeuvre critique. Paris: Ecole nationale supérieure des beaux-arts, 2001.

Lamarque, Peter. Work and Object: Explorations in the metaphysics of art. New York: Oxford University Press, 2010.

Latour, Bruno. Pandora's Hope: Essays on the reality of science studies. Cambridge, MA: Harvard University Press, 1999.

Leighten, Patricia. 'Cubist Anachronisms: Ahistoricity, cryptoformalism, and business-as-usual in New York'. Oxford Art Journal 17/2 (1994): 91-102.

Levinson, Jerrold. 'Defending Hypothetical Intentionalism'. British Journal of Aesthetics 50/2 (1 April 2010): 139-50.

Lewis, David. 'Scorekeeping in a Language Game'. Journal of Philosophical Logic 8/1 (January 1979): 339-59.

Livingston, Paisley. 'Intentionalism in Aesthetics'. New Literary History 29/4 (1998): 831-46.

Livingston, Paisley. Art and Intention: A philosophical study. New York: Oxford University Press, 2005.

Loh, Maria H. 'Renaissance Faciality'. Oxford Art Journal 32/3 (2009): 341-63.

Löschnigg, Martin. 'Narratological Categories and the (Non)-Distinction between Factual and Fictional Narratives'. In Recent Trends in Narratological Research, edited by John Pier, 31-48. Tours: Presses universitaires François-Rabelais, 2017.

Macherey, Pierre. A Theory of Literary Production, trans. Geoffrey Wall. Boston: Routledge \& Kegan Paul, 1978 [French original Pour une théorie de la production littéraire, 1966]. 
Mack, Peter and Robert Williams. Michael Baxandall: Vision and the work of words. Abingdon: Ashgate, 2015.

Marin, Louis. Détruire la peinture. Paris: Éditions Galilée, 1977.

Matheson, Carl and Ben Caplan. 'Fine Individuation'. British Journal of Aesthetics 47 (April 2007): 113-37.

Mathur, Saloni. 'A Retake of Sher-Gil's Self-Portrait as Tahitian'. Critical Inquiry 37/3 (March 2011): 515-44.

Matisse, Henri. Jazz. Munich: R. Piper, 1960.

Matisse, Henri. Matisse on Art. Berkeley: University of California Press, 1995.

Meyer, Richard. Outlaw Representation: Censorship and homosexuality in twentieth-century American art. New York: Oxford University Press, 2002.

Meyer, Richard. 'Lookout: On Queer American art and history'. In A Companion to American Art, edited by John Davis, Jennifer A. Greenhill and Jason D. LaFountain, 433-46. London: Wiley, 2015.

Montagu, Jennifer. The Expression of the Passions: The origin and influence of Charles Le Brun's 'Conference Sur l'expression Générale et Particuliere'. New Haven: Yale University Press, 1994.

Morelli, Giovanni. Italian Masters in German Galleries: A critical essay on the Italian pictures in the Galleries of Munich, Dresden, Berlin. London: G. Bell, 1883.

Moxey, Keith. The Practice of Persuasion: Paradox and power in art history. Ithaca, NY: Cornell University Press, 2001.

Mulvey, Laura. Visual and Other Pleasures. Basingstoke: Macmillan, 1988.

Murrell, Denise. 'Seeing Laure: Race and modernity from Manet's Olympia to Matisse, Bearden and beyond'. PhD Dissertation. Columbia University, New York, 2014.

Murrell, Denise. Posing Modernity: The black model from Manet and Matisse to today. New Haven: Yale University Press, 2018.

Nagel, Alexander. Medieval Modern: Art out of time. London: Thames \& Hudson, 2012.

Nanay, Bence. Between Perception and Action. Oxford: Oxford University Press, 2013.

Nehamas, Alexander. 'The Postulated Author: Critical monism as a regulative ideal'. Critical Inquiry 8/1 (1981): 133-49.

Nehamas, Alexander. Only a Promise of Happiness: The place of beauty in a world of art. Princeton: Princeton University Press, 2007.

Nelson, Steven. 'Issues of Intimacy, Distance, and Disavowal in Writing about Deana Lawson's Work'. Hyperallergic (4 June 2018). https://hyperallergic.com/444883/ issues-of-intimacy-distance-and-disavowal-in-writing-about-deana-lawsons-work/.

Nemerov, Alexander. 'The Boy in Bed: The scene of reading in N. C. Wyeth's "Wreck of the 'Covenant"'. Art Bulletin 88/1 (2006): 7-27.

Nemerov, Alexander. 'The Author Replies'. Art Bulletin 88/1 (2006): 61-8.

Nemerov, Alexander. 'Paper Stars'. Art History 38/3 (2015): 566-9. https://doi. org/10.1111/1467-8365.12161.

Nochlin, Linda. 'The Imaginary Orient'. In The Politics of Vision, by Linda Nochlin, 33-59. New York: Harper \& Row, 1989.

Nochlin, Linda. 'Seurat's Grande Jatte: An anti-utopian allegory'. Art Institute of Chicago Museum Studies 14/2 (1989): 133-242.

Noë, Alva. Action in Perception. Cambridge, MA: MIT Press, 2004.

North, Joseph. Literary Criticism: A concise political history. Cambridge, MA: Harvard University Press, 2017.

O'Donnell, C. Oliver. Meyer Schapiro's Critical Debates: Art through a modern American mind. University Park, PA: Penn State University Press, 2019.

O'Grady, Lorraine. 'Olympia's Maid: Reclaiming black female subjectivity'. In New Feminist Criticism: Art, identity, action, edited by Johanna Frueh, Cassandra L. Langer and Arlene Raven, 152-70. New York: Icon, 1994.

Okeke-Agulu, Chika. Postcolonial Modernism: Art and decolonization in twentieth-century Nigeria. Durham, NC: Duke University Press, 2015.

Onians, John. European Art: A neuroarthistory. New Haven: Yale University Press, 2016.

Orton, Fred and Griselda Pollock. Avant-Gardes and Partisans Reviewed. New York: St. Martin's Press, 1996.

Panofsky, Erwin. Meaning in the Visual Arts: Papers in and on art history. Hardmondsworth: Penguin, 1955. 
Panofsky, Erwin. 'Et in Arcadia Ego: Poussin and the elegiac tradition'. In Meaning in the Visual Arts, by Erwin Panofsky, 340-67. Harmondsworth: Penguin, 1970.

Panofsky, Erwin. 'The History of Art as a Humanistic Discipline'. In Meaning in the Visual Arts, by Erwin Panofsky, 1-25. Harmondsworth: Penguin, 1970.

Pater, Walter. The Works of Walter Pater. New York: Macmillan, 1900.

Paul, Herman. 'Performing History: How historical scholarship is shaped by epistemic virtues'. History and Theory 50/1 (2011): 1-19.

Paul, Herman. 'Weak Historicism: On hierarchies of intellectual virtues and goods'. Journal of the Philosophy of History 6/3 (1 January 2012): 369-88.

Penny, Nicholas. 'Momentary Substances'. London Review of Books 7/20 (21 November 1985). https://www.lrb.co.uk/the-paper/v07/n20/nicholas-penny/momentary-substances.

Petrovich, Dushko. 'Intimacy, Distance, and Disavowal in Art Publishing: Conversations with Dushko Petrovich'. Art Journal Open (August 2018). http://artjournal.collegeart. org $/ \mathrm{p}=10169$.

Pihlainen, Kalle. 'The Moral of the Historical Story: Textual differences in fact and fiction'. New Literary History 33/1 (2002): 39-60.

Pippin, Robert. 'Fried on Intention'. In Michael Fried and Philosophy, edited by M. Abbott, 48-63. London: Routledge, 2007.

Platt, Verity. 'The Artist as Anecdote: Creating creators in ancient texts and modern art history'. In Creative Lives in the Ancient World, edited by J. Haninck and R. Fletcher, 274-304. Cambridge: Cambridge University Press, 2016.

Pollock, Griselda. Differencing the Canon: Feminist desire and the writing of art's histories. New York: Routledge, 1999.

Pop, Andrei. A Forest of Symbols: Art, science, and truth in the long nineteenth century. New York: Zone Books, 2019.

Porras, Stephanie. 'Locating Hispano-Philippine Ivories'. Colonial Latin American Review 29/2 (2 April 2020): 256-91.

Powell, Amy. Depositions: Scenes from the late medieval church and the modern museum. New York: Zone Books, 2012.

Prettejohn, Elizabeth. The Modernity of Ancient Sculpture: Greek sculpture and modern art from Winckelmann to Picasso. New York: I.B. Tauris, 2011.

Prettejohn, Elizabeth. Modern Painters, Old Masters: The art of imitation from the Pre-Raphaelites to the First World War. New Haven: Yale University Press, 2017.

Preziosi, Donald. Rethinking Art History: Meditations on a coy science. New Haven: Yale University Press, 1989.

Priyadarshini, Meha. Chinese Porcelain in Colonial Mexico: The material worlds of an early modern trade. Cham: Palgrave Macmillan, 2018.

Prusac, Marina. From Face to Face: Recarving of Roman portraits and the late-Antique portrait arts. Boston: Brill, 2011.

Pullens, David. 'The Individual's Triumph: The eighteenth-century consolidation of authorship and art historiography'. Journal of Art Historiography 16 (June 2017): 1-26.

Randolph, Adrian W. B. 'Gendering the Period Eye: Deschi Da Parto and Renaissance visual culture'. Art History 27/4 (2004): 538-62.

Randolph, Adrian W. B. Touching Objects: Intimate experiences of Italian fifteenth-century art. New Haven: Yale University Press, 2014.

Read, Herbert. Henry Moore: A study of his life and work. London: Thames \& Hudson, 1965.

Riegl, Alois. The Group Portraiture of Holland. Los Angeles: Getty Research Institute for the History of Art and the Humanities, 1999.

Riggle, Nick. 'Convergence, Community, and Force in Aesthetic Discourse'. Ergo: An Open Access Journal of Philosophy (forthcoming).

Rollins, Mark (ed.). Danto and His Critics. 2nd ed. Malden, MA: Wiley-Blackwell, 2012.

Rose, Sam. 'Close Looking and Conviction'. Art History 40/1 (2017): 156-77.

Rose, Sam. 'The Fear of Aesthetics in Art and Literary Theory'. New Literary History 48/2 (2017): 223-44.

Rose, Sam. 'The Significance of Form'. Nonsite.org 20 (January 2017). https://nonsite.org/ the-significance-of-form/.

Rose, Sam. Art and Form: From Roger Fry to global modernism. University Park, PA: Penn State University Press, 2019.

Rose, Sam. 'Peer Review in Art History'. Burlington Magazine 161 (1 August 2019): 621-5. 
Rose, Sam and Bence Nanay. 'On Perception'. In A Companion to Arthur Danto, edited by Jonathan Gilmore and Lydia Goehr. Oxford: Blackwell (forthcoming).

Roth, Paul A. 'Explanation'. In Encyclopedia of Political Theory, edited by Mark Bevir, 478-81. London: SAGE, 2010.

Roth, Paul A. The Philosophical Structure of Historical Explanation. Evanston, IL: Northwestern University Press, 2020.

Ruskin, John. The Works of John Ruskin. New York: Longmans, Green, 1903.

Ruskin, John. Diaries. Oxford: Clarendon Press, 1956.

Sartre, Jean-Paul. 'The Search for the Absolute'. In Alberto Giacometti: Exhibition of sculptures, paintings, drawings, 2-22. New York: Pierre Matisse Gallery, 1948.

Schmidt, Suzanne Kathleen Karr. Altered and Adorned: Using Renaissance prints in daily life. New Haven: Yale University Press, 2011.

Schreyach, Michael. Pollock's Modernism. New Haven: Yale University Press, 2017.

Shalem, Avinoam. 'Histories of Belonging and George Kubler's Prime Object'. Getty Research Journal 3 (2011): 1-14.

Shapiro, Gary. 'The Absent Image: Ekphrasis and the "infinite relation" of translation'. Journal of Visual Culture 6 (2007): 13-24.

Shiff, Richard. Doubt. New York: Routledge, 2008.

Shusterman, Richard. 'Beneath Interpretation: Against hermeneutic holism'. Monist 73/2 (1 April 1990): 181-204.

Shusterman, Richard. Surface and Depth: Dialectics of criticism and culture. Ithaca, NY: Cornell University Press, 2002.

Siegel, Susanna. The Contents of Visual Experience. Oxford: Oxford University Press, 2011.

Smith, Zadie. 'Through the Portal: Locating the magnificent'. In Deana Lawson: An Aperture monograph. New York: Aperture, 2018.

Sontag, Susan. 'Against Interpretation'. In Against Interpretation and Other Essays, by Susan Sontag, 3-14. New York: Dell, 1966.

Soussloff, Catherine M. The Absolute Artist: The historiography of a concept. Minneapolis: University of Minnesota Press, 1997.

Spencer, Catherine. Beyond the Happening: Performance art and the politics of communication. Manchester: Manchester University Press, 2020.

Stalnaker, Robert. Context. New York: Oxford University Press, 2014.

Stark, Trevor. 'Anonymity and Doubt: Reading Picasso's papiers collés with Mallarmé'. Art History 41/1 (2018): 104-31.

Steinberg, Leo. Other Criteria: Confrontations with twentieth-century art. New York: Oxford University Press, 1972.

Steinberg, Leo. Michelangelo's Last Paintings: The Conversion of St. Paul and the Crucifixion of St. Peter in the Cappella Paolina, Vatican Palace. New York: Oxford University Press, 1975.

Stejskal, Jakub. 'Aesthetic Archaeology'. Critical Inquiry (forthcoming).

Sturkenboom, Ilse. 'The Paintings of the Freer Divan of Sultan Ahmad b. Shaykh Uvays and a New Taste for Decorative Design'. Iran 56/2 (3 July 2018): 184-214.

Suger. Abbot Suger on the Abbey Church of St.-Denis and Its Art Treasures. Princeton: Princeton University Press, 1946.

Summers, David. 'Form and Gender'. New Literary History 24/2 (1993): 243-71.

Tamen, Miguel. Friends of Interpretable Objects. Cambridge, MA: Harvard University Press, 2001.

Thomasson, Amie L. 'The Ontology of Art'. In Blackwell Guide to Aesthetics, edited by Peter Kivy, 78-92. Oxford: Blackwell, 2004.

Thomasson, Amie L. 'Ingarden and the Ontology of Cultural Objects'. In Existence, Culture, and Persons: The ontology of Roman Ingarden, edited by Arkadiusz Chrudzimski, 115-36. Frankfurt: Ontos, 2005.

Thomasson, Amie L. 'Ontological Innovation in Art'. Journal of Aesthetics and Art Criticism 68/2 (3 May 2010): 119-30.

Troy, Nancy J., Geoffrey Batchen, Amelia Jones, Pamela M. Lee, Romy Golan, Robert Storr, Jodi Hauptman and Dario Gamboni. 'Interventions Review: Art since 1900'. Art Bulletin 88/2 (2006): 373-89.

Valéry, Paul. Tel Quel. Paris: Gallimard, 1941.

Verstegen, Ian. A Realist Theory of Art History. New York: Routledge, 2013.

Verstegen, Ian. 'In the Sistine Chapel with Marcia and Leo' (forthcoming).

Walton, Kendall. 'Categories of Art'. Philosophical Review 79 (July 1970): 334-67. 
Warhol, Robyn. 'A Feminist Approach to Narrative'. In Narrative Theory: Core concepts and critical debates, by David Herman, James Phelan, Peter J. Rabinowitz, Brian Richardson and Robyn Warhol, 9-13. Columbus: Ohio State University Press, 2012.

Weems, Carrie Mae. 'Interview in conjunction with the exhibition The Memory of Time', National Gallery of Art, Washington, DC, September 2015. https://www.youtube.com/ watch?v=_jIwiBgSNtk.

White, Harrison C. Canvases and Careers: Institutional change in the French painting world. Chicago: University of Chicago Press, 1993.

Wilde, Oscar. Oscar Wilde: The major works, edited by Isobel Murray. Oxford: Oxford University Press, 2000.

Wilenski, R. H. The Study of Art. London: Faber \& Faber, 1934.

Winckelmann, Johann Joachim. Geschichte der Kunst des Alterthums. Dresden: Walther, 1764.

Winckelmann, Johann Joachim. Geschichte der Kunst des Alterthums. 2nd ed. Vienna: Akademischen Verlage, 1776.

Winckelmann, Johann Joachim and G. Henry Lodge. The History of Ancient Art. Boston: J.R. Osgood, 1873.

Wölfflin, Heinrich. 'Kunstgeschichtliche Grundbegriffe: Eine Revision'. Logos 22 (1933): 210-18.

Wölfflin, Heinrich. Principles of Art History: The problem of the development of style in later art. New York: Dover, 1950.

Wölfflin, Heinrich. Classic Art: An introduction to the Italian Renaissance, trans. Peter Murray and Linda Murray. 3rd ed. London: Phaidon, 1968.

Wölfflin, Heinrich. The Art of Albrecht Dürer. London: Phaidon, 1971.

Wollheim, Richard. Art and Its Objects: An introduction to aesthetics. New York: Harper \& Row, 1968.

Wollheim, Richard. Painting as an Art. (A. W. Mellon Lectures in the Fine Arts). Princeton: Princeton University Press, 1987.

Wollheim, Richard. Richard Wollheim on the Art of Painting: Art as representation and expression. New York: Cambridge University Press, 2001.

Wood, Christopher S. (ed.). The Vienna School Reader: Politics and art historical method in the 1930s. New York: Zone Books, 2000.

Wood, Christopher S. Forgery, Replica, Fiction: Temporalities of German Renaissance art. Chicago: University of Chicago Press, 2008.

Wood, Christopher S. A History of Art History. Princeton: Princeton University Press, 2019.

Woodall, Joanna. 'Laying the Table: The procedures of still life'. Art History 35/5 (2012): 976-1003.

Yeazell, Ruth Bernard. Picture Titles: How and why Western paintings acquired their names. Princeton: Princeton University Press, 2015.

Young, Marnin. Realism in the Age of Impressionism: Painting and the politics of time. New Haven: Yale University Press, 2015.

Zelevansky, Lynn (ed.). Picasso and Braque: A symposium. New York: Museum of Modern Art, 1992. 


\section{Index}

abduction 84-5

Sherlock Holmes and 87

abolitionism 37, 108

Abrahams, Simon 90-1, 101

'absences' used in interpretation 92-6

absences and contradictions, reading for 91

abstract concepts 1

Académie Royale 32

'accidental' artworks 84

'additive interpretation' 71-7

aesthetics 7

afterlife 65-6

agency, artistic 7, 23, 26, 28, 85

Albertian art 79

allegory 50

Alpers, Svetlana 60, 79

analogy 47-8, 60, 97, 105

Antal, Friedrich 36-7, 41

art, history of see art history and art historians love of 7

Art Bulletin 41

art criticism 15-16, 33, 42, 63-5, 71-2, 88, 96-7, 103-4

art history and art historians $1-7,10-16$, 19-20, 34-6, 41-7, 50, 53, 60, 63, 65, 68, 71-6, 79, 81, 84-5, 88-92, 95, 98, 101-5; see also social history of art; global art history

Art Since 1900 (textbook) 75

art writing 24, 34, 36, 74, 76

artist-academicians 1

artistic identity as distinct from historical artists persons 20-

control of meanings 1

status of 9,11

in their own words 13-14, 20

artworks

and accident 65, 82, 102

causation of 9

made by and belonging to artists $12-20$

meaning of 14

natural or accidental 15, 84

reconstructed and useful 72

responses to 71,96

seen as knowing and thinking entities 85

to suit individuals 37

in their original state $13,17-20,76-7,81$, 103

thinking see agency 'association as argument' 88, 97-102

associative description and reading 98, 100

attribution of artworks 16-17, 23, 76-7

Auden, W. H. 22

'author function' 14

Badiou, Alain 72

Bailly, David 60-1

Baker, Benjamin 42

Bal, Mieke 35, 68, 84-5

Barthes, Roland 14-15, 37, 41

Bartholomew, St 76

Baudelaire, Charles 90

Baxandall, Michael 42-3, 59-61

Beeny, Emily 55

Benjamin, Walter 82

Berenson, Bernard 20, 47

Bermingham, Ann 92-3

'blackboxing' 71, 76-82, 100, 108

Bloch, Ernst 55

Bordwell, David 36

Botticelli, Sandro 60-1

Bourdieu, Pierre 7

Bruegel, Pieter 47-9

Brunelleschi, Filippo 23-4

Bryson, Norman 26, 35, 95

Burckhardt, Jacob 23, 91-2

Camille, Michael 59

Caravaggio, Michelangelo Merisi da 26-8

Carrier, David 91, 103

Catholic Church 92

Cavell, Stanley 105

Cézanne, Paul 91, 102

Chardin, J. S. 42-3

charity, see 'principle of art-historical charity'

China 37, 66

Clark, Ed 9-10, 21, 63-5

Cochin, Charles-Nicolas 33

Colbert, Jean-Baptiste 33

'cold reads' 13

combination as part of interpretation 72-5

complexity of artworks 53, 71, 79, 82

connoisseurs 16-20

Constable, John 92-3

context and contextualization 32-50

Copley, John Singleton 37

Courbet, Gustave 90, 100-1

critique $7,8,96$

'crits' 13 
Croce, Benedetto 14, 20, 48

Crow, Thomas 41, 63

'cruel intentions' 12, 14

cubism 77-8, 102

Damisch, Hubert 73-4, 88-9

Danto, Arthur 14

Davidson, Donald 35-6

Davis, Colin 105

Davis, Whitney 84

'death of the author' 14

description 21-9, 32-41, 97-102 and interpretation 5, 7

de Jongh, Eddy 89

Delacroix, Eugene 90

deliberate artworks 12, 16-21 implicitly and explicitly 16

della Francesca, Piero 73, 75

della Robbia, Luca 98

DeLue, Rachael 99, 100, 105

de Man, Paul 94, 105

depth interpretation 63, 88-91, 97-105

depth reception $54,62-5$

depth reconstruction 45-8

Diderot, Denis 15-16, 58

Didi-Huberman, Georges 68, 88-9

Dinsmore, Robert 100

Donagh, Rita 34

du Bois, Abbé 32

Duchamp, Marcel 78, 107

Dürer, Albrecht 92, 98

Dutch culture 48, 79, 101

Dvořák, Max 92

Eakins, Thomas 84, 98

ekphrasis 15, 22

Elkins, James 91, 100-1

English, Darby 21, 45

Enlightenment tradition 6

envisioning of artworks 14

Ernst, Max 78

'esteem for the insignificant' 82

experience of artworks, 55

historian's use of personal 9, 13, 20, 48

historical 34, 42-5

visual practices as route to $59-62$

Feaver, Alice 3

film criticism 98

Fiorentino, Rossi 47

Flax, Neil 16

Focillon, Henri 98

Fordism 72

formalist writers $37,101-2$

Forth Bridge 42-3

Foucault, Michel 14, 35, 79

Fra Angelico 96

French pragmatic sociology 7

Freud, Sigmund 17-18, 78, 98

Fried, Michael 63-4, 98-101

Fry, Roger 20, 37

Gadamer, Hans-Georg 8, 54

Gainsborough, Thomas 93-4

Gauguin, Paul 91

Gell, Alfred 85
Gentile da Fabriano 41

George III, King 57

Gérôme, Jean-Léon 92

global art history $6,65-8$

Goethe, J. W. von 16, 45-6, 58

Gombrich, Ernst 46-7

Gothic style 55

Greek artists 1

Greenberg, Clement 37, 96-7, 102, 104

Guercino 58

Guillet de Saint Georges, Georges 23

Haskell, Francis 23

Hauser, Arnold 36-7

Hegel, G. W. F. 11, 45-6, 101-2

Hennion, Antoine 7

Hephaestus 22

hidden features in an artwork 88, 91, 96-7, 103

historical context 34-5

historical interpretation and historical sense 89, 103

history see art history and art historians; realist understanding of history

history painting 32

Hoffman, Werner 34

Hogarth, William 32

Holly, Michael Ann 103

Homer 21-2

Iconography and iconographers 14, 51 55, 59, 68

'social iconography' 63

'implicitly deliberate' artworks 16

indigenous art forms 78

Ingres, J. A. D. 82, 84

intellectual goods 71-2

intention 12-29, 102-8

'interesting' artworks 72, 82

internationalization 5

interpretation of art 4-7, 12-21, 26, 36-7, 41, 45-50, 60, 96-108

art-historical 81, 85

by artists of their own work 14

in an inclusive sense 7

norms of 5

using personal experience of artworks 13, 16,37

secondary nature of 5

theory and practice of 6

'value-maximizing' 71

variety of 5-6

see also additive interpretation; depth interpretation

interpretative 'logics' 6

Irvin, Sherri 11

Iser, Wolfgang 54

James, Henry 73

Jauss, Hans Robert 54

Jesus Christ 47

Jodhpur, Maharaja of 66

John the Scot 55

Johnson, Marion 34

Jones, Alan 101

Julayir, Ahmad, Sultan 37, 39

Katz, Jonathan 91 
Kemp, Wolfgang 34

Kidd, Joseph Bartholomew 93-4

Kidson, Peter 59

'labelling' of artworks 9

Lacan, Jacques 78, 96

La Font de Saint-Yenne 32-3, 36

Lairesse, Gerard de 32

Latour, Bruno 35, 76

Laure 90-1, 107-8

Lawson, Deana 2-3

Levinas, Emmanuel 72

literary studies 103

living artists 2

Locke, John (and Lockeanism) 42, 45

'low-wattage social history of art' (Fried) 63

Luxford, Julian 85

Macherey, Pierre 92

makerly narration $12,21-6$

Manet, Edouard 20, 37, 40, 53, 63-5, 74, 89-91, 96, 108

oddities in the work of 89

race in the work of 107-8

Marin, Louis 88-9

Mathur, Saloni 84

Matisse, Henri 12, 90

meaning-making 5-6

metaphor 98

Meyer, Richard 91

Michelangelo Buonarotti 17-18, 76-7

Michelet, Jules 45-6

mindreading 1-2, 12, 23-6, 85, 108

Minujín, Marta 40

modernism 88, 101, 104

Morelli, Giovanni 92

Moses 17-18

Moxey, Keith 103

Mulvey, Laura 101

Nagel, Alexander 68

Nelson, Steven 2-4

Nemerov, Alex 99, 100, 103, 105

networking by artists 12

Nochlin, Linda 55, 92

Okeke, Uche 77-8

Okeke-Agulu, Chika 78

Orientalism 108

overinterpretation 72,85

painted paper from China 37

Panofsky, Erwin 11, 55-9

critics of 59

Pater, Walter 98

Peale, Raphaelle 100

peer review 76

Peron, Juan 40

philosophy of art and of history 71, 84

Picasso, Pablo 74, 77-8, 91, 102, 107

Piper, Adrian 3

Pippin, Robert 54

Plato 5

Pliny 10, 21-2

Poe, Edgar Allan 37

Pollock, Griselda 20
Pollock, Jackson 85, 96, 102, 104

Pontormo 37

Pope, Alexander 22

porcelain, Chinese 66

postcritical 7

post-structuralism 34-5, 88, 104

Poussin, Nicolas 13, 57-8

Powell, Amy Knight 65

'pre-set contextualization' 32, 36-7, 41

'present absence' 88, 91-7

'principle of art-historical charity' 71, 81-5, 91, 97

Pseudo-Dionysus 55, 59

psychoanalysis 85

publication systems 75-6

'Quattrocento man' 60

queer theory 91, 106

Raphael 2, 76-7

Read, Herbert 37

realist understanding of history 5

reception 53-68

as afterlife $65-8$

as history $53,61,66$

as origin 53-4

recorded 54-9, 62

theory 54

reconstruction 41

redescription, 36, 41, 98

Reformation 92

Rembrandt van Rijn 11, 49, 79, 84

Remington, Frederic 100

Renaissance 79

'resurfacing' 88, 91, 102-8

Reynolds, Joshua 57

Richardson, Jonathan 32

Riegl, Alois 37, 48, 82-4

Rorty, Richard 8

Ruskin, John 23-4, 45-8, 81, 85

St-Denis Basilica, Paris 55-9

Sannazaro 58

Sartre, Jean-Paul 37

Saussure, Ferdinand de 74, 77-8

'saw-toothed contextualization' 36-7, 41

Schapiro, Meyer 47-8

Schiller, Friedrich 58-9

Schlosser, Julius von 20

Seurat, Georges 55

Seydlmayr, Hans 47-8

Shakespeare, William 94

Shalem, Avinoam 65

Sher-Gil, Amrita 83-4

Sherman, Cindy 12, 15, 19-20

shield of Achilles 22-3

Shiff, Richard 103

Simpson, Lorna 3

slavery and the slave trade 37,108

Smith, Zadie 2-3

social history of art 41, 63, 92-3

Sontag, Susan 5

spirit of the age 46

spiritual realm 73

Stalnaker, Robert 34

Steinberg, Leo 89, 101-2 
Stevenson, Robert Louis 99

students, artworks by 13

subjectivity of artists 23

Sudjojono, S. 101

Suger, Abbot 55-9

Summers, David 47

surfaces, suspicion of 89-91

Tamen, Miguel 76

textual additions to artworks 32

'theories and methods', 4, 6, 43-5

Thomasson, Amie 11

Valery, Paul 65, 68

Van Dyck, Anthony 11

Van Huysum, Jan 2

Vasari, Giorgio 1, 10, 23, 47, 53

Velázquez, Diego 79-80, 90

Vendramin, Andrea 23-5

Venice and Venetian art 23, 47-8

verbal descriptions of artworks 98

Vermeer, Johannes 26-7

visual practices as origin 59-62

Warhol, Andy 104

Watteau, Jean-Antoine 95

Waugh, Evelyn 59

Weems, Carrie Mae 3, 107-8

Wilde, Oscar 15

Winckelmann, J. J. 1-2, 45-6, 62

Wölfflin, Heinrich 11, 62, 98, 101-2

Wollheim, Richard 84

Wood, Christopher 68

Woodall, Joanna 101

writerly habits $1-2$

Wyeth, N. C. 99

Žižek, Slavoj 72

Zola, Émile 89 
'In this lucid, sensible and insightful book, Sam Rose investigates interpretive practices common to almost all professional art historians, regardless of their objects of study, their professed "methods" and their schools of historical thought. Anyone curious about the "how" of art history as an intellectual and aesthetic endeavour will find Rose to be an invaluable guide.'

Whitney Davis, University of California at Berkeley

'It's wonderful to have a book that focuses on what art historians actually do when we interpret art, as opposed to the claims we make about our methods and their histories... Interpreting Art shows how apparently well-understood paths of interpretation are actually half-articulated ideals that are as likely to run away with our texts as support them, and for that reason it should be on the desk of every doctoral student when they set out to write.'

James Elkins, School of the Art Institute of Chicago

How do people make sense of works of art? And how do they write to make others see the same way? There are many guides to looking at art, histories of art history and art criticism, and accounts of various 'theories' and 'methods', but this book offers something very unlike the normal search for difference and division: it examines the general and largely unspoken norms shared by interpreters of many kinds.

Ranging widely, though taking writing within the Western tradition of art history as its primary focus, Interpreting Art highlights the norms, premises, and patterns that tend to guide interpretation along the way. Why, for example, is the concept of artistic 'intention' at once so reviled and yet so hard to let go of? What does it really involve when an interpretation appeals to an artwork's 'reception'? How can 'context' be used by some to keep things under control and by others to make the interpretation of art seem limitless? And how is it that artworks only seem to grow in complexity over time?

Interpreting Art reveals subtle features of art writing central to the often unnoticed interpretative practices through which we understand works of art. In doing so, the book also sheds light on possible alternatives, pointing to how writers on art might choose to operate differently in the future.

Sam Rose is Senior Lecturer in Art History at the University of St Andrews.

Cover image:

Édouard Manet,

Olympia (1863)

Cover design: www.hayesdesign.co.uk

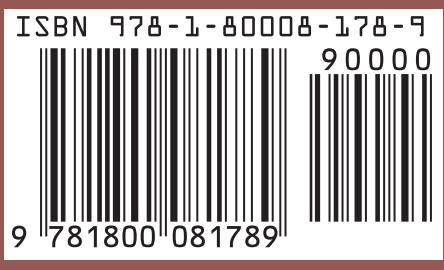

